\title{
Herrmann et al.
}

\section{Viral-mediated ubiquitination impacts interactions of host proteins with viral RNA and promotes viral RNA processing}

Christin Herrmann ${ }^{1,2}$, Joseph M. Dybas ${ }^{1,3,4}$, Jennifer C. Liddle ${ }^{1,4}$, Matthew Charman ${ }^{1,4}$, Eui Tae Kim", ${ }^{1,4}$ Benjamin A Garcia ${ }^{5,7}$, and Matthew D Weitzman ${ }^{1,4,5, *}$

${ }^{1}$ Division of Protective Immunity and Division of Cancer Pathobiology,

\section{The Children's Hospital of Philadelphia, Philadelphia, PA 19104, USA}

${ }^{2}$ Cell \& Molecular Biology Graduate Group, University of Pennsylvania, Philadelphia, PA 19104, USA

${ }^{3}$ Department of Biomedical and Health Informatics,

${ }^{4}$ Department of Pathology and Laboratory Medicine,

Perelman School of Medicine, University of Pennsylvania, Philadelphia, PA 19104, USA

\section{${ }^{5}$ Epigenetics Institute,}

Perelman School of Medicine, University of Pennsylvania, Philadelphia, PA 19104, USA

${ }^{6}$ Graduate Group in Biochemistry and Biophysics,

${ }^{7}$ Department of Biochemistry and Biophysics, 
Herrmann et al.

\section{ABSTRACT}

34 Viruses promote infection by hijacking host ubiquitin machinery to counteract or redirect 35 cellular processes. Adenovirus encodes two early proteins, E1B55K and E4orf6, that 36 together co-opt a cellular ubiquitin ligase complex to overcome host defenses and

37 promote virus production. Adenovirus mutants lacking E1B55K or E4orf6 display defects

38 in viral RNA processing and protein production, but previously identified substrates of the 39 redirected ligase do not explain these phenotypes. Here we used a quantitative 40 proteomics approach to identify substrates of E1B55K/E4orf6-mediated ubiquitination

41 that facilitate RNA processing. While all currently known cellular substrates of

42 E1B55K/E4orf6 are degraded by the proteasome, we uncovered RNA-binding proteins 43 (RBPs) as high-confidence substrates which are not decreased in overall abundance.

44 We focused on two RBPs, RALY and hnRNP-C, which we confirm are ubiquitinated 45 without degradation. Knockdown of RALY and hnRNP-C increased levels of viral RNA 46 splicing, protein abundance, and progeny production during infection with E1B55K-

47 deleted virus. Furthermore, infection with virus deleted for E1B55K resulted in increased 48 interaction of hnRNP-C with viral RNA, and attenuation of viral RNA processing. These 49 data suggest viral-mediated ubiquitination of RALY and hnRNP-C relieves a restriction 50 on viral RNA processing, revealing an unexpected role for non-degradative ubiquitination 51 in manipulation of cellular processes during virus infection. 
Herrmann et al.

\section{INTRODUCTION}

Viruses have evolved mechanisms to alter cellular pathways to promote infection and inactivate host defenses. One way this can be achieved is through viral factors that redirect host post-translational protein modification such as ubiquitination, in order to regulate protein function and turnover. Viruses interface with the host ubiquitin system by encoding their own ubiquitin ligases, redirecting cellular ubiquitin ligases, or altering ubiquitin removal by deubiquitinating enzymes ${ }^{1-3}$. Ubiquitin can be employed as a signal for diverse outcomes, including proteasome-mediated degradation, protein localization, and regulating interactions with other proteins or nucleic acids ${ }^{4-7}$. This diversity of function makes hijacking the host ubiquitin machinery an attractive approach for viruses to manipulate multiple cellular pathways.

The nuclear-replicating Adenovirus (Ad) encodes two early proteins (E1B55K and E4orf6) which integrate into an existing host ubiquitin ligase complex containing Elongin $B$ and C, Cullin5, and RBX18,9. The cellular ligase is recruited through E4orf6, and the

67 E1B55K protein is involved in substrate recognition to redirect the ligase activity ${ }^{9}$. The importance of hijacking the host ubiquitin machinery for productive virus infection has been demonstrated using Ad deletion mutants or expression of dominant negative Cullin5, which all severely limit virus production ${ }^{10-18}$. Several cellular proteins have been identified as targets for proteasomal degradation mediated by the Ad serotype 5 (Ad5)

72 E1B55K/E4orf6 complex, including MRE11, RAD50, NBS1, DNA Ligase IV, BLM, Integrin

$73 \alpha 3$, and the tumor suppressor p538,19-23. Degradation of these proteins represses DNA

74 damage signaling and apoptosis during infection ${ }^{24-26}$. However, the E1B55K/E4orf6

75 complex also stimulates export of viral late mRNAs and synthesis of viral late proteins ${ }^{11-}$

76 16. Viral mutants defective for either E1B55K or E4orf6 exhibit reduced viral late RNA,

77 late protein abundance, and progeny production but show little impact on early stages of 78 virus infection ${ }^{11-16}$. The mutant virus phenotype was mapped to a nuclear step of viral 79 late RNA processing. None of the known substrates fully explain these deficiencies, since

80 mutant viruses still show lower late protein levels in cells deficient in p53 or lacking a 81 functional DNA damage response ${ }^{10-16}$.

82 In this study, we used an unbiased global proteomics approach to identify new 83 cellular substrates of ubiquitination mediated by the Ad5 E1B55K/E4orf6 complex. We 
84 used antibody-based di-glycine remnant enrichment combined with profiling by mass

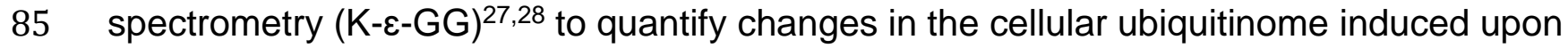
86 expression of E1B55K and E4orf6. The K-E-GG approach allows for direct identification

87 of peptides modified as a result of E1B55K/E4orf6 expression. Furthermore, we 88 examined the impact of ubiquitination on protein abundance by employing whole cell 89 proteomics (WCP). This combined approach enabled us to identify many potential targets 90 of the E1B55K/E4orf6 complex, and classify these proteins as predicted degraded or non91 degraded substrates. Our analysis suggests that the E1B55K/E4orf6 complex can 92 facilitate different types of ubiquitination, and reveals that the majority of cellular 93 substrates are ubiquitinated without significant changes in their protein abundance.

94 Among the cellular substrates predicted to be ubiquitinated without degradation, we found 95 an enrichment for cellular RNA-binding proteins (RBPs). We further validated the 96 importance of the highly ubiquitinated RBPs RALY and hnRNP-C as two host proteins 97 modified by the virus to overcome restriction of viral late transcript production. We identify 98 the first substrates that provide a mechanistic link between E1B55K/E4orf6-mediated 99 ubiquitination and the known roles of the complex in Ad5 viral RNA processing. 100 Furthermore, these studies highlight a viral approach to exploit ubiquitination without 101 degradation as a strategy to manipulate host pathways.

102

\section{RESULTS}

104 Functional Ad E1B55K/E4orf6 complex is required for viral late RNA splicing. We 105 hypothesized that ubiquitination mediated by the E1B55K/E4orf6 complex can either 106 target cellular proteins for proteasomal degradation, as seen for all currently known 107 substrates including MRE11, RAD50, and BLM ${ }^{20,23}$, or could impact function without 108 affecting protein abundance (Fig. 1a). We assessed the role of E1B55K/E4orf6-mediated 109 ubiquitination on RNA processing and late protein accumulation by inactivating the 110 complex through deletion of the E1B55K gene or chemical inhibition of Cullin5 ubiquitin 111 ligase activity ${ }^{29}$. Infection with an E1B55K mutant virus $(\triangle \mathrm{E} 1 \mathrm{~B})$ resulted in decreased

112 levels of viral late proteins (hexon, penton, fiber and protein VII) but had minimal impact 113 on viral early protein production (DBP) when compared to wild-type (WT) Ad5 infection

114 (Fig. 1b; Supplementary Fig. 1a). Cullin ubiquitin ligases require post-translational 
115 modification by the ubiquitin-like protein NEDD8 to form a functional ubiquitin ligase

116 complex ${ }^{30,31}$. We hypothesized that inhibition of the Cullin5 complex hijacked by

117 E1B55K/E4orf6 would mimic $\triangle \mathrm{E} 1 \mathrm{~B}$ virus infection. We used a small molecule inhibitor of

118 the neddylation activating enzyme (NEDDi; MLN492429) to block Cullin-mediated 119 ubiquitination during infection. Inhibition of Cullin neddylation was confirmed by

120 decreased abundance of the slower-migrating modified Cullin5 (Fig. 1b). Inhibition of the 121 ubiquitin ligase activity of the viral E1B55K/E4orf6 complex was confirmed by blocking of 122 MRE11 and BLM degradation. NEDDi treatment during WT Ad5 infection substantially 123 decreased levels of viral late proteins (hexon, penton, fiber and protein VII) but only 124 marginally decreased production of the viral early protein DBP (Fig. 1b; Supplementary 125 Fig. 1a). Furthermore, NEDDi treatment did not further alter the late protein defect 126 observed with E1B55K deletion (Fig. 1b). The increase of E1B55K levels upon NEDDi

127 treatment is likely caused by inhibition of auto-ubiquitination, which is common among 128 ubiquitin ligases ${ }^{32}$. We then assessed several steps of viral RNA processing during 129 inhibition of ubiquitination or E1B55K deletion. We observed decreased accumulation of 130 viral late mRNA for transcripts containing the major late promoter (MLP) and fiber gene 131 during NEDDi treatment of WT Ad5 infection, similar to decreases detected with E1B55K 132 deletion (Fig. 1c). These lower mRNA levels could be caused by defects in different 133 steps of RNA processing: transcription, splicing, or decay. We assessed transcription 134 and RNA turnover in WT and $\triangle \mathrm{E} 1 \mathrm{~B}$ infection using 4sU-labeling of nascent RNA 135 (Supplementary Fig. 1b). Our analysis revealed that deletion of E1B55K does not 136 negatively impact transcription or RNA decay of viral early (E1A and E4) or viral late 137 (MLP) RNA. Furthermore, we analyzed RNA decay by blocking transcription with 138 Actinomycin D and measuring viral early (E1A) and late (MLP) RNA levels over a time 139 course, comparing WT and $\triangle \mathrm{E} 1 \mathrm{~B}$ infection (Supplementary Fig. 1c). This experiment 140 confirmed that turnover of spliced viral RNA does not decrease in the absence of E1B55K. 141 We used quantitative reverse transcription PCR (RT-qPCR) to determine the ratio of 142 spliced:unspliced transcript as a measure for splicing efficiency (Supplementary Fig. 143 1d). This analysis revealed that both NEDDi treatment and E1B55K deletion decreased 144 splicing efficiency of viral late transcripts (MLP and fiber), compared to untreated WT, 145 without negatively impacting the early E1A transcript (Fig. 1d; Supplementary Fig. 1e 
146 and 1f). We also examined cytoplasmic RNA accumulation by fluorescence in situ 147 hybridization (FISH) for fiber transcripts. This experiment demonstrated that less fiber 148 RNA reaches the cytoplasm upon E1B55K deletion, which was recapitulated by NEDDi 149 inhibition (Fig. 1e; Supplementary Fig. 1g). Failure to splice transcripts correctly causes 150 retention in the nucleus and subsequent degradation of the unspliced RNA ${ }^{33,34}$. Incorrect

151 splicing could explain the observed RNA export defect and decrease in RNA levels 152 observed for late viral transcripts. These data demonstrate that chemical inhibition of 153 Cullin ligases recapitulates the effects of E1B55K deletion, highlighting that 154 E1B55K/E4orf6-mediated ubiquitination of substrates is important for RNA splicing, RNA 155 export, and protein production of viral late transcripts during Ad5 infection. None of the 156 previously identified cellular substrates of E1B55K/E4orf6-mediated ubiquitination explain 157 these phenotypes.

159 Proteomics reveals enrichment of RNA-binding proteins among cellular substrates 160 of the E1B55K/E4orf6 complex. To identify cellular substrates of the Ad5 $161 \mathrm{E} 1 \mathrm{~B} 55 \mathrm{~K} / \mathrm{E} 40 \mathrm{rf6}$ complex that could explain the RNA processing defect of the $\Delta \mathrm{E} 1 \mathrm{~B}$ virus, 162 we conducted global remnant profiling of the ubiquitinome (K- $\varepsilon-\mathrm{GG}$ ) and associated whole 163 cell proteome (WCP) over a time course of transduction of HeLa cells with viral vectors 164 encoding Ad5 E1B55K and E4orf6 ${ }^{19,35}$ (Fig. 2a; Supplementary Fig. 2). Using non165 replicating viral vectors allowed us to identify substrates specific to the activity of the viral 166 E1B55K/E4orf6 complex outside the context of Ad5 infection. We assayed the 167 degradation kinetics of known cellular substrates (BLM, MRE11, RAD50, and NBS1) by 168 immunoblotting to determine when proteins were most likely to be modified but still 169 detectable (Supplementary Fig. 2a). We subsequently performed K- $\varepsilon-G G$ analysis for 170 ubiquitin modification at 0,6, 8, and 10 hours post-transduction (hpt), and WCP at 0 and 17110 hpt for protein abundance ${ }^{27,28}$ (Fig. 2a).

$172 \quad$ Ubiquitin is covalently attached to its substrate and upon proteolytic cleavage with 173 trypsin the C-terminal glycine residues of ubiquitin remain attached to the modified lysine 174 residue $(\mathrm{K}-\varepsilon-\mathrm{GG})$. We enriched for peptides containing these di-glycine remnants using 175 an antibody 27 and identified modified peptides by mass spectrometry. We performed 176 three replicates for each timepoint and identified a similar number of peptides in 
177 untransduced cells (2,050 peptides quantified in at least two replicates) and those

178 transduced by E1B55K/E4orf6 at 6, 8, and 10 hours (2,132; 2,010; and 2,154 peptides

179 respectively) (Supplementary Fig. 2b; Supplementary Table 1). The identified K- $\varepsilon-G G$

180 peptides corresponded to 1,164 proteins overall. Changes in peptide modification were 181 then normalized to changes in total protein abundance. Expression of E1B55K/E4orf6 182 induced a significant increase in ubiquitination $(p<0.05$ and $\log 2$ fold-change $>1)$ for 39 183 peptides (Fig. 2b). Additionally, 51 peptides were ubiquitinated upon expression of 184 E1B55K/E4orf6 but were not identified as ubiquitinated in untransduced cells, and 185 therefore do not have a calculated fold-change or associated $p$-value. Peptides uniquely 186 ubiquitinated during transduction are defined as those not quantified in any mock cell 187 samples but found in 2-3 replicates from transduced cells. Since these unique peptides 188 were not identified in mock conditions, they therefore do not have quantification values. 189 The lack of quantification values precludes calculation of associated fold changes or $p$ 190 values since both of these calculations require numerical values for both compared 191 conditions. Therefore, in these cases, we used z-scores to assess abundance of 192 ubiquitination during expression of E1B55K/E4orf6, and for downstream analysis to 193 define the most highly ubiquitinated proteins. Peptides that exhibited increased or unique 194 ubiquitination upon E1B55K/E4orf6 expression included known protein substrates 195 MRE11 (4 peptides) and RAD50 (5 peptides).

196 A similar number of proteins were quantified in the WCP of untransduced cells 197 (6,213 proteins identified in at least 2 replicates) and cells transduced by E1B55K/E4orf6 198 (6,241 proteins identified in at least 2 replicates in 10 hour timepoint) (Supplementary 199 Fig. 2c; Supplementary Table 1). The WCP data show that E1B55K/E4orf6 expression 200 induced significant changes in protein abundance, with 46 proteins significantly 201 decreased at the 10 hour timepoint (log2 fold change $<=-1$ and $p<0.05$ or unique 202 identification at 0 hour timepoint). Consistent with previous studies, we observed 203 significant decreases for the known substrates MRE11, NBS1, RAD50, and LIG4 upon 204 E1B55K/E4orf6 expression (Fig. 2b).

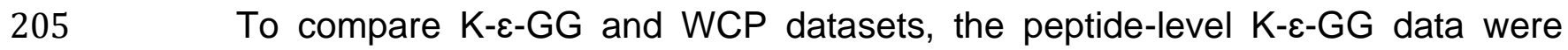
206 transformed into protein-based $\mathrm{K}-\varepsilon-\mathrm{GG}$ abundance changes by calculating the 207 abundance-weighted average of the $K-\varepsilon$-GG peptide log2 fold-changes for all modified 
208 peptides detected for the respective protein. Resulting protein-based K- $\varepsilon$-GG log2 fold209 changes were plotted against their associated WCP fold-changes (Fig. 2c). We 210 implemented a threshold for protein-based K- $\varepsilon-G G$ increase of $>2$ fold and identified 120 211 host proteins as putative substrates of the Ad5 ubiquitin ligase. Proteins that were 212 ubiquitinated and also decreased in abundance by more than 1 standard deviation (s.d.) 213 from the mean proteome change were predicted to be degraded substrates of the 214 E1B55K/E4orf6 complex (Fig. 2c and 2d, red; Supplementary Table 2). The degraded 215 substrates (25 proteins) include known targets MRE11 and RAD50. Conversely, proteins 216 that were ubiquitinated and exhibited abundance changes within 1 s.d. of the mean WCP 217 abundance change were predicted to be ubiquitinated as a result of the E1B55K/E4orf6 218 complex but not subsequently degraded (91 proteins) (Fig. 2c and 2d, blue; 219 Supplementary Table 2). These data provide the first evidence that the Ad5 220 E1B55K/E4orf6 complex facilitates non-degradative ubiquitination, and suggest that the 221 majority of potential substrates of the viral complex fall into this category.

222 Gene ontology analysis of predicted substrates for the E1B55K/E4orf6 complex 223 revealed significant enrichment of "poly(A) RNA binding" and "RNA-binding" GO 224 annotations (Fig. 2e; Supplementary Table 3). Since E1B55K deletion has been shown 225 to induce RNA processing defects, we focused on the 26 proteins included within the 226 RNA-binding GO terms (Supplementary Fig. 3a). There were 7 RBPs predicted to be 227 ubiquitinated only in the presence of E1B55K/E4orf6, of which RALY stands out as the 228 RBP with the highest abundance of ubiquitination at $10 \mathrm{hpt}$. Additionally, hnRNP-C is an 229 interaction partner of RALY which had the largest number of sites that increase in 230 ubiquitination among RBPs (Fig. 2f; Supplementary Fig. 3b). We used the Reactome ${ }^{36}$ 231 protein-protein interaction database to analyze interactions among all predicted 232 substrates of the E1B55K/E4orf6 complex, and found RALY and hnRNP-C together in an 233 interaction module with other RBPs (Fig. 2g; Supplementary Fig. 4 and Table 3). A 234 literature search revealed that 11 of the 17 proteins in this module have reported 235 association with viral infection (Fig. 2g; Supplementary Table 4). Both RALY and 236 hnRNP-C are expressed at high levels in all tissues ${ }^{37}$ and are implicated in multiple steps 237 of RNA processing, including RNA splicing and export ${ }^{38-43}$. Additionally, it has been 238 reported that hnRNP-C binds to Ad transcripts encoding late proteins ${ }^{44}$. We therefore 
Herrmann et al.

239 chose to further validate RALY and hnRNP-C as cellular substrates of the E1B55K/E4orf6 240 complex and to characterize their impact on Ad5 biology.

242 RALY and hnRNP-C are ubiquitinated but not degraded upon E1B55K/E4orf6 243 expression. RALY and hnRNP-C are $\sim 43 \%$ homologous, with the highest homology $244(63 \%)$ in the coiled-coil (CC) domain, which contains all the lysine residues that show 245 increased ubiquitination upon E1B55K/E4orf6 expression (Fig. 3a; Supplementary Fig. 246 5). The lysine residue of hnRNP-C that shows the highest increase in ubiquitination 247 (K204) is analogous to the only detected ubiquitination site in RALY (K198). Since 248 E1B55K is the substrate recognition component of the ligase assembled with the $\mathrm{Ad}$ 249 complex, we examined interaction of E1B55K with the two host RBPs during Ad5 virus 250 infection (Fig. 3b). We performed immunoprecipitation (IP) of E1B55K, RALY and 251 hnRNP-C for mock, Ad5 WT, and $\triangle \mathrm{E} 1 \mathrm{~B}$ infection conditions followed by immunoblotting 252 for viral and host proteins. IP of E1B55K isolated RALY and hnRNP-C from cells infected 253 with WT virus but not the $\triangle \mathrm{E} 1 \mathrm{~B}$ mutant (Fig. 3b). In the reciprocal experiment, E1B55K 254 was detected upon IP of either RALY or hnRNP-C during WT virus infection, confirming 255 interaction between the E1B55K/E4orf6 complex and the two host RBPs (Fig. 3b). The 256 cellular hnRNP-C and RALY proteins interact in reciprocal IPs, as reported previously ${ }^{45}$, 257 and this association was not impacted by virus infection. To confirm ubiquitination of 258 RALY and hnRNP-C induced by viral proteins, we expressed Flag-tagged RALY or 259 hnRNP-C, HA-tagged ubiquitin, and E4orf6 by transfection of HEK293 cells (this cell line 260 contains a genomic integration of Ad5 E1B55K ${ }^{46}$ ). IP for the HA epitope and 261 immunoblotting for Flag revealed an increase in high molecular weight ubiquitin262 complexes of RALY and hnRNP-C in the presence of E4orf6 (Fig. 3c; Supplementary 263 Fig. 6a). hnRNP-C2, an alternative isoform of hnRNP-C, is also ubiquitinated in the 264 presence of the E1B55K/E4orf6 complex (Supplementary Fig. 6b). The overall 265 stoichiometry for ubiquitination is low relative to the total protein abundance of RALY and 266 hnRNP-C, as is the case with many post-translational protein modifications. To 267 demonstrate that activated Cullin complexes are involved in ubiquitination of RALY and 268 hnRNP-C by the Ad5 complex, we performed experiments with NEDDi treatment. The 269 elevated ubiquitination of RALY and hnRNP-C detected by expression of E4orf6 and HA- 
Herrmann et al.

270 ubiquitin was decreased upon NEDDi treatment (Fig. 3d; Supplementary Fig. 6c).

271 Inhibition of NEDDylation appeared to reduce endogenous ubiquitination of hnRNP-C but

272 not RALY. These data suggest that a Cullin ubiquitin ligase may ubiquitinate hnRNP-C

273 but not RALY in the absence of the viral proteins, consistent with the K-ع-GG data where

274 hnRNP-C modification was increased from the mock condition but RALY was uniquely

275 modified during infection. We also verified that hnRNP-C was ubiquitinated during

276 infection with Ad5 WT but not with the $\triangle E 1 B$ mutant (Fig. 3e). The RALY antibody quality

277 precluded our ability to detect endogenous protein in this assay. Our WCP analysis

278 showed that RALY and hnRNP-C are not decreased in abundance during infection

279 (Supplementary Fig. 3a). Lack of degradation was confirmed by immunoblot analysis

280 which showed stable abundance of RALY and hnRNP-C protein levels over a time course

281 of Ad5 WT infection or transduction with E1B55K/E4orf6 vectors (Fig. 3f; Supplementary

282 Fig. 6d). RALY and hnRNP-C levels were also stable during transduction of A549 and

283 U2OS cells with E1B55K/E4orf6 vectors, as well as transfection of HEK293 cells with an

284 E4orf6 expression vector (Supplementary Fig. 6e). RALY and hnRNP-C protein levels

285 remained relatively stable during infection in the presence of cycloheximide, further

286 supporting that turnover is not increased by infection (Fig. 3g). Finally, mRNA levels for

287 RALY and hnRNP-C as measured by RT-qPCR, remain stable during a time course of

288 Ad WT infection (Supplementary Fig. 6f). We hypothesize that the E1B55K/E4orf6

289 complex facilitates ubiquitination that induces degradative and non-degradative

290 outcomes, depending on the substrate. To test this hypothesis, we investigated

291 differences in ubiquitination of MRE11, RAD50, RALY, and hnRNP-C mediated by the

292 E1B55K/E4orf6 complex. Proteasome inhibition by drugs such as MG132 leads to

293 accumulation of ubiquitinated proteins that would otherwise be degraded. Ubiquitination

294 assays were performed by transfection of HEK293 cells with and without MG132-

295 mediated proteasome inhibition (Fig. 3h). Expression of E4orf6 increased ubiquitination

296 of MRE11 which was further increased by proteasome inhibition, consistent with MRE11

297 being a known degraded substrate of the viral complex. In contrast, expression of E4orf6

298 increased ubiquitination of RALY and hnRNP-C but there was no further increase upon

299 treatment with MG132. The fact that MG132 treatment did not alter ubiquitination of RALY

300 and hnRNP-C suggests that ubiquitination of these substrates does not result in 
Herrmann et al.

301 degradation by the proteasome. Since the effect of proteasomal inhibition varies between

302 substrates of the E1B55K/E4orf6 complex, we examined the ubiquitin chains attached to

303 RALY and hnRNP-C as compared to MRE11 and RAD50. The ubiquitin linkage most

304 commonly associated with proteasomal degradation is K48. To determine whether K48-

305 linked ubiquitin is attached to MRE11, RAD50, RALY, or hnRNP-C we performed native

306 IPs of HA-ubiquitin, expressed in HEK293 cells together with E4orf6, and then compared

307 the degree of ubiquitination after treatment with deubiquitinating enzymes (DUBs) that

308 cleave either all ubiquitin linkages (DUB ${ }^{\mathrm{Pan}}$ ) or only K48-linked ubiquitin chains (DUB $\left.{ }^{\mathrm{K} 48}\right)^{47}$

309 (Fig. 3i; Supplementary Fig. 6g). MRE11 and RAD50 showed a clear decrease of high

310 molecular weight ubiquitin chains upon treatment with both DUBs, indicating that K48-

311 linked ubiquitin is attached to these substrates to induce proteasomal degradation. In

312 contrast, ubiquitination of RALY and hnRNP-C decreased with the DUBPan but not the

313 more specific DUB ${ }^{K 48}$. This suggests that RALY and hnRNP-C are substrates for non-

314 K48 linked ubiquitination, distinct from the K48-linked ubiquitin chains on degraded

315 substrates MRE11 and RAD50. Our data support a non-degradative role for

316 ubiquitination of hnRNP-C and RALY, although it is possible that degradation occurs

317 within a sub-population too small to distinguish by this global analysis. Together, these

318 data validate RALY and hnRNP-C as the first non-degraded cellular substrates identified

319 for the E1B55K/E4orf6 Ad5 ligase complex.

321 RALY and hnRNP-C are detrimental for viral late RNA processing. To determine 322 whether RALY and hnRNP-C impact Ad infection, we used siRNA to knockdown these 323 host proteins in HeLa and primary-like HBEC3-KT cells, and then infected with WT Ad5 324 and $\triangle E 1 B$ viruses (Fig. 4). Although RALY and hnRNP-C are not degraded during 325 infection, this approach allowed us to determine whether these RBPs are beneficial or 326 detrimental to virus infection. Knockdown of RALY and hnRNP-C did not affect viral 327 protein levels during WT Ad5 infection, suggesting that in the context of infection with a 328 fully competent virus their presence does not have a significant impact. Infection with $329 \Delta \mathrm{E} 1 \mathrm{~B}$ virus generated reduced viral late protein levels as compared to WT Ad5 (Fig. 4a).

330 Depletion of RALY and hnRNP-C rescued this viral late protein defect almost to the level 331 observed in WT Ad5 (Fig. 4a; Supplementary Fig. 7a and 7b). We examined whether 
332 knockdown of RALY and hnRNP-C also affects progeny production of the $\triangle E 1 B$ virus

333 (Fig. 4b). There was no difference between WT Ad5 and $\triangle \mathrm{E} 1 \mathrm{~B}$ at 8 hours post-infection

334 (hpi), before production of new infectious virions, confirming comparable virus input and

335 entry. By $24 \mathrm{hpi}$ the $\triangle \mathrm{E} 1 \mathrm{~B}$ virus produced $>100$-fold fewer viral particles than WT Ad5.

336 Knockdown of RALY and hnRNP-C had no effect on WT Ad5, but significantly increased

337 progeny production for the mutant virus (Fig. 4b). Similar rescue of the $\triangle E 1 B$ virus was

338 observed with RALY and hnRNP-C knockdown prior to infection in HBEC3-KT cells (Fig.

339 4b). These data suggest that RALY and hnRNP-C are detrimental to Ad infection and

340 that E1B55K/E4orf6-mediated ubiquitination relieves their restriction on virus production.

341 Since RALY and hnRNP-C are involved in RNA splicing and export, we hypothesized that

342 their depletion selectively increases late RNA processing without affecting DNA

343 replication and viral early RNAs. We therefore examined viral DNA replication by

344 quantifying genome accumulation using qPCR (Fig. 4c). There was a modest decrease

345 (2-fold) in DNA replication for the $\triangle \mathrm{E} 1 \mathrm{~B}$ virus as compared to WT Ad5, in agreement with

346 prior reports ${ }^{48}$. Viral DNA accumulation for both WT Ad5 and $\triangle \mathrm{E} 1 \mathrm{~B}$ was not significantly

347 affected by depletion of RALY and hnRNP-C (Fig. 4c), confirming that their effects are

348 mediated at a step after viral genome replication. We then quantified RNA levels of both

349 viral early (E1A) and late (MLP and fiber) transcripts (Fig. 4d). Levels of late but not early

350 transcripts decreased upon infection with $\triangle \mathrm{E} 1 \mathrm{~B}$ virus, which shows qualitative correlation

351 with the decrease in late proteins shown in in Fig. 1b. Depletion of RALY and hnRNP-C

352 rescued mRNA levels for MLP and fiber at both $18 \mathrm{hpi}$ and $24 \mathrm{hpi}$ during infection with

$353 \Delta$ E1B virus, to levels observed in WT Ad5 (Fig. 4d) without impacting the E1A transcript

354 (Supplementary Fig. 7c). Splicing efficiency of MLP and fiber was reduced in the $\triangle E 1 B$

355 virus and was rescued to WT Ad5 levels upon knockdown of RALY and hnRNP-C (Fig.

356 4e; Supplementary Fig. 7c). We also used FISH to examine the effect of RALY and

357 hnRNP-C depletion on export of fiber mRNA into the cytoplasm. siRNA treatment

358 increased the amount of cytoplasmic fiber RNA visible in $\triangle \mathrm{E} 1 \mathrm{~B}$ infection, while not

359 impacting WT Ad5 (Fig. 4f). Depletion of either RALY or hnRNP-C by itself increased

360 viral late protein, RNA levels, and splicing efficiency of the mutant virus, with hnRNP-C

361 knockdown having a more dramatic effect than RALY knockdown (Supplementary Fig.

362 7e-g). To connect the impact of RALY and hnRNP-C depletion on late stages of Ad 
363 infection with Cullin-dependent ubiquitination by the E1B55K/E4orf6 complex, we 364 combined siRNA-mediated knockdown with NEDDi treatment during WT Ad5 infection.

365 The NEDDi treatment decreased viral late RNA levels, splicing efficiency, and protein 366 production (Fig. $\mathbf{4 g - i )}$. Knockdown of RALY and hnRNP-C completely rescued the defect 367 caused by inhibition of Cullin function without impacting viral early proteins or RNA (Fig. 368 4g-i; Supplementary Fig. 7h-j). These data suggest that RALY and hnRNP-C are 369 detrimental to the late stages of Ad5 infection and that ubiquitination or depletion can 370 overcome this defect.

372 Infection causes global changes to hnRNP-C RNA binding. Our data suggest that 373 viral-mediated ubiquitination of RALY and hnRNP-C relieves a restriction on viral late 374 RNA processing without the need for proteasomal degradation. Non-degradative 375 ubiquitination has been reported to alter protein localization, for example by obscuring 376 nuclear localization sequences and preventing nuclear import ${ }^{49}$. We examined 377 localization of RALY and hnRNP-C by immunofluorescence (IF) in untreated HeLa cells 378 and during infection with either WT Ad5 or $\triangle \mathrm{E} 1 \mathrm{~B}$ virus (Supplementary Fig. 8a). Both 379 RALY and hnRNP-C showed a diffuse nuclear pattern in uninfected HeLa cells, in 380 accordance with the reported localization of both proteins ${ }^{37}$. Upon infection, both proteins 381 were excluded from viral replication centers marked by DBP or USP7 in a pattern that 382 matches viral RNA and other RBPs ${ }^{50,51}$. However, there was no obvious difference in 383 localization between $\mathrm{WT} A d 5$ and $\triangle \mathrm{E} 1 \mathrm{~B}$ infection, suggesting that viral-induced 384 ubiquitination does not specifically change their cellular localization. Since both RALY 385 and hnRNP-C are ubiquitinated within the coiled-coil domain that is involved in 386 multimerization and protein-RNA interaction (Fig. 3a), we examined whether overall 387 protein complex formation is affected by treating HeLa cells with disuccinimidyl suberate 388 (DSS) at various concentrations during mock, WT Ad5 or $\triangle \mathrm{E} 1 \mathrm{~B}$ infection 389 (Supplementary Fig. 8b). DSS is a cell-permeable crosslinker that forms stable amide 390 bonds between lysine residues in close proximity (less than $11.4 \AA$ ), crosslinking protein 391 complexes. DSS treatment caused a mobility shift of hnRNP-C and RALY, consistent 392 with previous reports of multimerization ${ }^{52}$. During WT Ad5 or $\triangle \mathrm{E} 1 \mathrm{~B}$ infections these 393 patterns did not change, suggesting that viral-induced ubiquitination does not significantly 
394 affect overall protein complex formation of hnRNP-C or RALY. Next, we employed 395 targeted proteomic identification of RNA-binding regions (RBR-ID) ${ }^{53,54}$ for hnRNP-C

396 (Supplementary Fig. 8c; Supplementary Table 5). We compared in triplicate SILAC397 labeled ${ }^{55} \mathrm{HeLa}$ cells that were uninfected or infected with Ad5 WT or $\triangle \mathrm{E} 1 \mathrm{~B}$. At 24 hpi we 398 performed 4sU-mediated protein-RNA photo-crosslinking of heavy-labeled cells, followed 399 by hnRNP-C IP, nuclease treatment and proteolytic cleavage. Peptides in the crosslinked 400 condition that bound RNA will retain RNA adducts, which causes a mass shift and loss of 401 signal when compared to peptides from non-crosslinked conditions. Signal loss thus 402 identifies which regions of a protein had direct contact with RNA in vivo. In addition, the 403 non-crosslinked data give insight into the hnRNP-C interactome and potential changes 404 upon Ad infection. In mock conditions, the most dramatic loss of signal was detected at 405 the RNA-recognition motif (RRM) within hnRNP-C (Fig. 5a). The RRM is the most well406 characterized RNA-binding domain in hnRNP-C and provides specificity for the poly-U 407 motif identified as the preferred binding site ${ }^{56}$. Surprisingly, upon both WT and $\triangle \mathrm{E} 1 \mathrm{~B}$ 408 infection the RRM interaction with RNA was dramatically decreased, while RNA 409 interactions within the coiled-coil domain increased (Fig. 5a). Approximately $\sim 20$ amino 410 acids downstream of the ubiquitination sites, we detected an RNA binding peak in mock 411 samples that was decreased in WT Ad5 but increased in the mutant virus (Fig. 5a). This 412 observation highlights a region of hnRNP-C potentially impacted by Ad-mediated 413 ubiquitination. Since these two RBPs interact strongly, we were also able to analyze RNA 414 binding for RALY from the hnRNP-C IP. Similar to hnRNP-C, we saw infection-mediated 415 changes in the interaction of the RRM with RNA, and potential ubiquitin-mediated 416 differences between $\mathrm{WT}$ and $\triangle \mathrm{E} 1 \mathrm{~B}$ infection close to the ubiquitination site 417 (Supplementary Fig. 8d). In contrast to the large differences observed for the RNA418 binding analysis, we only observed minimal differences in the hnRNP-C interactome 419 when comparing mock, WT, and $\triangle \mathrm{E} 1 \mathrm{~B}$ infection (Supplementary Fig. 8e; 420 Supplementary Tables 6). A global comparison of the interacting protein abundances 421 across conditions revealed a Pearson correlation coefficient of $>0.8$. In addition, the 20 422 most abundant hnRNP-C interactors did not show marked differences in interaction 423 abundance between mock, WT, and $\triangle \mathrm{E} 1 \mathrm{~B}$ infection, with the only exception being viral 424 proteins absent in mock (Supplementary Fig. 8f). In summary, RBR-ID revealed major 
Herrmann et al.

425 changes to RNA binding of hnRNP-C during infection and a potential ubiquitin-mediated

426 difference between Ad5 WT and $\triangle E 1 B$ infections.

Interaction of hnRNP-C and RALY with viral late RNA is increased when Admediated ubiquitination is disrupted. RBR-ID identifies sites of RNA binding within a

430 protein sequence but does not identify the RNA sequence that is bound. To determine 431 the impact of Ad-mediated ubiquitination on interaction of hnRNP-C with viral RNA we 432 performed crosslinking-immunoprecipitation (CLIP) followed by RT-qPCR for viral and 433 cellular transcripts (Supplementary Fig. 9a and 9b). The hnRNP-C transcript itself 434 served as a positive control for immunoprecipitation, while GAPDH RNA was a negative 435 control ${ }^{57}$. All viral late transcripts were detected above background under WT Ad5 436 conditions, however, there was a 2 to 4-fold increase in the amount of late RNA detected 437 during $\triangle \mathrm{E} 1 \mathrm{~B}$ infection. There was however no dramatic difference in the level of early 438 RNAs detected between WT Ad5 and mutant virus. This indicates that viral-induced 439 ubiquitination of hnRNP-C specifically decreases the interaction with viral late transcripts. 440 Since the overall stoichiometry for ubiquitination is low relative to the total protein 441 abundance, this could indicate that ubiquitination either has a dominant negative impact 442 on the overall protein pool or that the effect is localized. This approach showed linearity 443 over a ten-fold dilution of input material, and displayed the same trend of increased 444 binding to viral late RNA upon $\triangle \mathrm{E} 1 \mathrm{~B}$ infection (Supplementary Fig. 9c). In contrast, 445 hnRNP-C CLIP-qPCR without UV-crosslinking or a CLIP with an IgG control precipitated 446 minimal RNA (Supplementary Fig. 9d and 9e). Commercially available antibodies for 447 RALY were not suitable for this technique. Therefore, we created an inducible RALY448 Flag cell line and performed CLIP-qPCR by Flag immunoprecipitation. This demonstrated 449 that similarly to hnRNP-C, RALY interacts more with viral late RNA in $\triangle E 1 B$ infections, 450 while binding to early RNA is unchanged or even decreased (Supplementary Fig. 9f). 451 To support the idea that differences in hnRNP-C interaction with viral RNA are caused by 452 ubiquitination, we repeated the hnRNP-C CLIP-qPCR with inhibition of Cullin-dependent 453 ubiquitination during WT Ad5 infection (Fig. 5c, Supplementary Fig. 9g). Following the 454 trend with $\triangle \mathrm{E} 1 \mathrm{~B}$ infection, the interaction of hnRNP-C with viral late transcripts increased 455 at least 2-fold upon treatment with NEDDi, while there were only minor differences for 
Herrmann et al.

456 viral early and cellular transcripts. This experiment reinforces that hnRNP-C interaction

457 with viral late RNAs increases in the absence of the functional viral ubiquitin ligase

458 complex.

459 To determine whether hnRNP-C binding changes in an ubiquitin-mediated manner 460 during infection, we performed a global analysis of hnRNP-C binding sites comparing 461 mock, Ad5 WT, and $\triangle \mathrm{E} 1 \mathrm{~B}$ infection using enhanced CLIP followed by sequencing 462 (eCLIP-Seq ${ }^{58}$ ) (Fig. 5d; Supplementary Fig. 9h and 9i). We observed a dramatic 463 reduction of hnRNP-C binding to host RNAs upon infection (Fig. 5e; Supplementary Fig. 464 9j). More than 24,000 peaks were unique to mock condition, with only 3,000 identified 465 in all 3 conditions. Analysis of binding motifs revealed the known poly-U/poly-T binding 466 motif of hnRNP-C among common and mock specific peaks (Fig. 5f). We also detected 467 hnRNP-C peaks in host RNA that were only identified during WT and $\triangle E 1 B$ infection, 468 suggesting a potential role for ubiquitination in manipulating binding of hnRNP-C to 469 cellular transcripts (Supplementary Fig. 9k). The hnRNP-C poly-U motif was lacking in 470 these virus-specific peaks, supporting the RBR-ID data which show decrease of RNA 471 binding for the hnRNP-C RRM upon infection (Fig. 5a). We also analyzed hnRNP-C 472 binding sites on viral transcripts (Fig. $\mathbf{5 g}$ and $\mathbf{5 h}$ ). The number and location of hnRNP-C 473 peaks were different between WT and $\triangle \mathrm{E} 1 \mathrm{~B}$ infection. Analyzing peaks unique to WT or 474 mutant virus revealed that deletion of E1B55K increased hnRNP-C binding mainly in viral 475 late transcripts (Fig. 5i). Differences were especially pronounced in the L3-L5 region of 476 the major late transcription unit (Fig. 5g), which encodes viral hexon protein. These 477 results were consistent with our CLIP-qPCR data (Fig. 5b). In addition, there are several 478 hnRNP-C binding sites in viral late RNA regions such as MLP and fiber that are unique 479 to $\triangle \mathrm{E} 1 \mathrm{~B}$ infection (Fig. 5g). Finally, we analyzed motifs present at hnRNP-C binding sites 480 on viral transcripts. We saw no evidence of the canonical hnRNP-C poly-U motif 481 observed on host transcripts (Fig. 5j). The most prominent motif for infection-specific 482 hnRNP-C binding sites within both host and viral transcripts is very similar, suggesting a 483 potential shift to a new hnRNP-C recognition motif caused by Ad5 infection. In summary, 484 the RBR-ID and eCLIP-Seq data highlight major changes in hnRNP-C interaction with 485 RNA caused by infection. Together, these results support a mode in which ubiquitination 486 of hnRNP-C and RALY induced by the E1B55K/E4orf6 complex leads to reduced 
Herrmann et al.

487 interaction of these host RBPs with viral late RNA, thereby overcoming a detrimental 488 effect on viral RNA processing (Fig. 6).

\section{DISCUSSION}

Viruses commonly adapt cellular regulatory mechanisms towards efficient viral production. The E1B55K/E4orf6 complex is known to interact with the cellular Cullin5 ubiquitin ligase to redirect ubiquitination and to stimulate viral late mRNA nuclear export and late protein synthesis. Prior studies identified binding partners of the complex and a limited number of substrates $8,9,19-23,59-62$, however, these studies did not enrich for proteins specifically ubiquitinated by the E1B55K/E4orf6 complex or explicitly link potential cellular substrates to effects on viral RNA processing. Here we employed a systematic proteomics approach to identify cellular ubiquitination substrates of the viral E1B55K/E4orf6 complex by combining quantification and analysis of the ubiquitinome

500 and the associated whole cell proteome upon expression of E1B55K/E4orf6. We 501 identified 119 potential substrates, with specific enrichment of RBPs that may be involved 502 in viral RNA processing. In addition to RNA processing, functional analysis of the 503 predicted substrates highlighted other host pathways that may be manipulated by Ad5504 mediated ubiquitination: ubiquitin machinery and de-ubiquitinating enzymes, antigen 505 presentation, protein folding, cellular transport, and cell signaling (Supplementary Fig.

506 4a). We focused on two of the most highly ubiquitinated RBPs, RALY and hnRNP-C, 507 which we demonstrated to be the first non-degraded ubiquitination substrates of the Ad5 508 complex. We demonstrated differential interaction of hnRNP-C and RALY with viral late 509 transcripts in the presence of an active E1B55K/E4orf6 complex, supporting a model in 510 which RALY and hnRNP-C ubiquitination results in altered binding to viral late 511 ribonucleoprotein (RNP) complexes, to promote efficient processing of late RNA (Fig. 6).

512 Since hnRNP-C has reported roles in alternative splicing ${ }^{38,40,41}$, we propose that 513 ubiquitination by the Ad5-induced complex results in exclusion from viral RNP complexes

514 to promote splicing of late viral RNAs. Substrates of the E1B55K/E4orf6 complex can 515 vary across human Ad serotypes, although some target proteins fall within the same 516 cellular pathway ${ }^{63,64}$. It will be interesting to determine whether RBPs are similarly 517 modified between serotypes or whether effects on RNA processing are achieved through 
518 different substrates. There is a precedent for post-translational modification regulating 519 hnRNP-C affinity for RNA, with conjugation of the ubiquitin-like protein SUMO decreasing 520 the affinity of hnRNP-C for RNA ${ }^{65}$. Ubiquitin and related proteins have emerging roles in 521 regulating splicing by altering the properties and dynamics of spliceosomal complexes 522 through altered protein-protein interactions ${ }^{66}$. It is likely that RBPs such as RALY and 523 hnRNP-C are also functionally regulated through ubiquitination by cellular ubiquitin 524 ligases. Correlating changes to host splicing induced as a result of the impact of 525 ubiquitination during Ad infection may provide insights into host pathways that are altered 526 by ubiquitination of these RBPs. In addition to the ubiquitin-mediated changes in 527 interaction of hnRNP-C and RALY with viral late RNA, we also observed global changes 528 in the RNA-binding of hnRNP-C during infection, independent of the Ad ubiquitin ligase 529 complex (Fig. 5). Understanding how Ad induces the reduction of RNA-binding by the 530 hnRNP-C RRM and the associated changes in binding motif, may provide novel insights 531 into regulation of RBP function.

532 Manipulation of the host ubiquitin machinery during virus infection has traditionally 533 been studied in the context of proteasomal degradation and there are very few known 534 examples of viruses directing ubiquitin towards cellular substrates that are not 535 subsequently degraded ${ }^{1-3}$. This has been true for the Cullin5 ligase redirected by Ad 536 E1B55K/E4orf6 which was previously shown to induce degradation of proteins involved

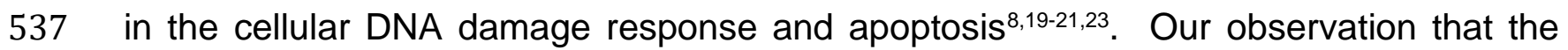
538 majority of potential cellular substrates of the E1B55K/E4orf6 complex appear to be 539 ubiquitinated without significant decrease in abundance suggests that a major aspect of 540 the activity of the viral assembled ligase is non-degradative ubiquitination. This finding 541 highlights the need to combine ubiquitinome analysis together with whole cell proteome 542 quantification when identifying outcomes of ubiquitination. Future studies of other viral 543 ligases should include this type of analysis of non-degradative ubiquitination in order to 544 ensure that all aspects of viral manipulation by ubiquitin are identified. We propose that 545 ubiquitination without the need for proteasome-mediated degradation provides increased 546 flexibility and more rapid approaches to counter host responses and redirect cellular 547 processes. Viral redirection of ubiquitination may present particularly good model 548 systems to study how ubiquitin ligases in general can facilitate both degradative and non- 
549 degradative ubiquitination of distinct substrates. Given the increasing appreciation that 550 cellular ubiquitin ligases (such as Cullin ligases) can facilitate the formation of multiple 551 different types of ubiquitin chains ${ }^{67-69}$, viral infections provide systems to decipher the 552 rules that govern outcomes of ubiquitination.

553 In addition to its contributions to fundamental knowledge of cellular and molecular 554 biology, Ad has also been developed as a vector for gene delivery and oncolytic cancer

555 treatment. Mutant viruses that lack E1B55K have been shown to replicate conditionally

556 in cancer cells, with selectivity that was initially suggested to be based on p53 inactivation

557 but is more likely due to preferential viral late mRNA export ${ }^{70-72}$. Since many cancers

558 have altered RNA processing, the $\mathrm{Ad} \triangle \mathrm{E} 1 \mathrm{~B}$ used for oncolytic therapies may be 559 complemented by defects in substrates of the E1B55K/E4orf6 complex. Our work 560 suggests that alterations in these substrates, such as the RBPs RALY and hnRNP-C, 561 may make tumor cells more susceptible to $\triangle \mathrm{E} 1 \mathrm{~B}$-based oncolytic viruses. 


\section{Herrmann et al.}

\section{Materials and Methods}

\section{Cell culture}

564 All cell lines were obtained from the American Type Culture Collection (ATCC) and

565 cultured at $37^{\circ} \mathrm{C}$ and $5 \% \mathrm{CO}_{2}$. HeLa (Cat\#: ATCC CCL-2), HEK293 (Cat\#: ATCC CRL-

566 1573), and U2OS cells (Cat\#: ATCC HTB-96) were grown in DMEM (Corning, Cat\#: 10-

567 013-CV) supplemented with 10\% v/v fetal bovine serum (FBS) (VWR, Cat\#: 89510-186)

568 and $1 \% \mathrm{v} / \mathrm{v}$ Pen/Strep $(100 \mathrm{U} / \mathrm{ml}$ of penicillin, $100 \mu \mathrm{g} / \mathrm{ml}$ of streptomycin, Gibco, Cat\#:

569 15140-122). A549 cells (Cat\#: ATCC CCL-185) were maintained in Ham's F-12K medium

570 (Gibco, Cat\#: 21127-022) supplemented with 10\% v/v FBS and 1\% v/v Pen/Strep.

571 Primary like HBEC3-KT (Cat\#: ATCC CRL-4051) were grown in Airway Epithelial Cell

572 Basal Medium (Cat\#: ATCC PCS-300-030) supplemented with Bronchial Epithelial Cell

573 Growth Kit (Cat\#: ATCC PCS-300-040) and 1\% v/v Pen/Strep. The RALY-Flag inducible

574 cell line was generated using a HeLa acceptor cell line kindly provided by E. Makeyev ${ }^{73}$

575 and used as previously reported. RALY-Flag was cloned from the pcDNA3.1 plasmid

576 described below and inserted into the inducible plasmid cassette using restriction

577 enzymes BsrGl and Agel. Sequence confirmed clones were transfected into the HeLa

578 acceptor cells along with plasmid encoding the Cre recombinase. Clones were selected

579 by puromycin $(1 \mu \mathrm{g} / \mathrm{mL})$ and induced with doxycycline $(0.5 \mu \mathrm{g} / \mathrm{mL})$ to express RALY-Flag.

580 Protein expression was verified by immunoblot. All cell lines tested negative for

581 mycoplasma using the LookOut Mycoplasma PCR Detection Kit (Sigma-Aldrich).

582

583 Viruses and infection 
584 Ad5 wild-type (WT) was purchased from ATCC. The Ad5 E1B55K-deletion mutant dl110

585 has been described previously ${ }^{10}$ and was a gift from G. Ketner. The E1 deletion mutant

586 recombinant adenovirus vectors expressing E1B55K (rAd E1B55K) ${ }^{35}$ and E4orf6 (rAd

587 E4orf6) ${ }^{19}$ were obtained from P. Branton. All viruses were propagated on HEK293 cells,

588 purified using two sequential rounds of ultracentrifugation in $\mathrm{CsCl}$ gradient and stored in

$58940 \% \mathrm{v} / \mathrm{v}$ glycerol at $-20^{\circ} \mathrm{C}$. Viral titers were determined by plaque assay on HEK293 cells

590 for all but rAd E4orf6. For this virus we assumed a plaque forming unit-to-particle ratio of

591 1:50. All infections were carried out using a multiplicity of infection (MOI) of 10 and

592 harvested at indicated hours post infection (hpi). Infections were performed on

593 monolayers of cells by dilution of the virus in respective low serum growth medium. After

$5942 \mathrm{~h}$ at $37^{\circ} \mathrm{C}$ additional full serum growth medium was added. For plaque assays, the virus

595 infection media was removed after $2 \mathrm{~h}$ and cells were washed 1x in PBS before addition

596 of full serum growth medium.

597

598 Plasmids, siRNA and transfection

599 Full-length RALY with a carboxyl-terminal Flag-tag (cDNA obtained from Dharmacon, 600 Cat\#: MHS6278-202857995) and hnRNP-C isoforms 1 and 2 with a carboxyl-terminal 601 Flag-tag (cDNA containing plasmids were a gift from K. Lynch) and RFP were cloned into 602 the pcDNA3.1 vector using the BamHI and Xbal restriction sites. The pRK5 vector 603 encoding Ad5 E4orf6 was generated by subcloning from purified Ad5 DNA as previously 604 described $^{74}$. The expression vector for HA-tagged tetra-ubiquitin as previously 605 described ${ }^{75}$ was a gift from R. Greenberg DNA transfections were performed using the 606 standard protocol for Lipofectamine2000 (Invitrogen). 
607 The following siRNAs were obtained from Dharmacon: non-targeting control (Cat\#: D-

608 001206-13-05), RALY (Cat\#: M-012392-00-0005) and hnRNP-C (Cat\#: M-011869-01-

609 0005; Cat\#: L-011869-03-0005 only used for hnRNP-C single knockdown in

610 supplementary Fig. 7). siRNA transfections were performed using the standard protocol

611 for Lipofectamine RNAiMAX (Invitrogen).

612

\section{Antibodies and inhibitors}

614 The following primary antibodies for viral proteins were obtained: Adenovirus late protein

615 antibody staining Hexon, Penton and Fiber (gift from J. Wilson ${ }^{76}$, species: rabbit, WB

616 1:10,000), Protein VII (gift from H. Wodrich ${ }^{77}$, Clone: Chimera 2-14, WB 1:200), DBP (gift

617 from A. Levine ${ }^{78}$, Clone: B6-8, WB 1:1000, IF 1:400), E1B55K (gift from A. Levine ${ }^{79}$,

618 Clone: 58K2A6, WB 1:500) and E4orf6 (gift from D. Ornelles ${ }^{80}$, Clone: RSA\#3, WB 1:500).

619 The following primary antibodies were used for cellular proteins: MRE11 (Novus

620 Biologicals, Catalog\#: NB100-142, WB 1:1000), BLM (Abcam, Catalog\#: ab476, WB

621 1:1000), Cullin5 (Bethyl Laboratories, Catalog\#: A302-173A, WB 1:200), Actin (Sigma-

622 Aldrich, Catalog\#: A5441-100UL, WB 1:5000), RALY (Bethyl Laboratories, Catalog\#:

623 A302-070A, WB 1:1000; Bethyl Laboratories, Catalog\#: A302-069A, IF 1:500, IP $5 \mu \mathrm{l}=5$

$624 \mu \mathrm{g}$ ), hnRNP-C (Santa Cruz Biotechnology, Catalog\#: sc-32308, WB 1:1000, IF 1:1000,

625 IP $25 \mu \mathrm{l}=5 \mu \mathrm{g}$ ), Tubulin (Santa Cruz Biotechnology, Catalog\#: sc-69969, WB 1:1000),

626 Flag (Sigma-Aldrich, Catalog\#: F7425-.2MG, WB 1:1000; Sigma-Aldrich, Catalog\#:

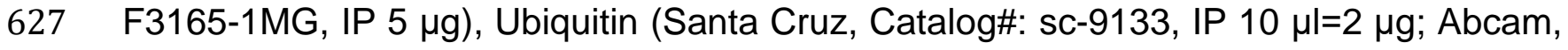

628 Catalog\#: ab7780, IP 5 l), NBS1 (Novus Biologicals, Catalog\#: NB100-143, WB 1:1000), 
629 RAD50 (GeneTex, Catalog\#: GTX70228, WB 1:1000) and USP7 (Bethyl Laboratories,

630 Catalog\#: A300-033A, IF 1:500).

631 Horseradish peroxidase-conjugated (HRP) secondary antibodies for immunoblot were

632 purchased from Jackson Laboratories. Anti-mouse IgG conjugated to HRP for

633 immunoblot of immunoprecipitation samples (used in Fig. 3b) was purchased from Abcam

634 (Cat\#: ab131368). Fluorophore-conjugated secondaries for immunofluorescence were

635 purchased from Life Technologies.

636 Cycloheximide (CHX) was purchased from Calbiochem (Cat\#: 293764), dissolved in

637 DMSO to a stock concentration of $25 \mathrm{mM}$ and used at a final concentration of $25 \mu \mathrm{M}$.

638 NEDDylation inhibitor MLN4924 was purchased from Sigma-Aldrich (Cat\#: 505477),

639 dissolved in DMSO to a stock concentration of $1 \mathrm{mM}$ and used at a final concentration of

$6403 \mu \mathrm{M}$. Proteasome inhibitor MG132 was purchased from Sigma-Aldrich (Cat\#: 474791) at

641 a concentration of $10 \mathrm{mM}$ in DMSO and used at a final concentration of $20 \mu \mathrm{M}$.

642

643 Immunoblotting

644 Protein samples were prepared using lithium dodecyl sulfate (LDS) loading buffer 645 (NuPage) supplemented with $25 \mathrm{mM}$ dithiothreitol (DTT) and boiled at $95^{\circ} \mathrm{C}$ for $10 \mathrm{~min}$.

646 Equal amounts of protein lysate were separated by SDS-PAGE and transferred onto a 647 nitrocellulose membrane (Millipore) at $30 \mathrm{~V}$ for at least $60 \mathrm{~min}$ (overnight for ubiquitination 648 assays). Membranes were stained with Ponceau to confirm equal loading and blocked in $6495 \% \mathrm{w} / \mathrm{v}$ milk in TBST supplemented with $0.05 \% \mathrm{w} / \mathrm{v}$ sodium azide. Membranes were 650 incubated with primary antibodies overnight, washed for 30 min in TBST, incubated with 651 HRP-conjugated secondary for $1 \mathrm{~h}$ and washed again for $30 \mathrm{~min}$ in TBST. Proteins were 
652 visualized with Pierce ECL Western Blotting Substrate (Thermo Scientific) and detected

653 using a Syngene G-Box. Images were processed and assembled in Adobe CS6.

654 Immunoblots were quantified by pixel densitometry using the Syngene GeneTools 655 software.

\section{Immunofluorescence}

658 HeLa cells were grown on coverslips in 24-well plates, infected with indicated viruses and 659 fixed at $24 \mathrm{hpi}$ in 4\% w/v paraformaldehyde in PBS for 10 mins. Cells were permeabilized 660 with $0.5 \% \mathrm{v} / \mathrm{v}$ Triton-X in PBS for 10 mins. The samples were blocked in $3 \% \mathrm{w} / \mathrm{v}$ BSA in 661 PBS (+ $0.05 \% \mathrm{w} / \mathrm{v}$ sodium azide) for 30 mins, incubated with primary antibodies in $3 \%$ $662 \mathrm{w} / \mathrm{v}$ BSA in PBS (+ 0.05\% w/v sodium azide) for $1 \mathrm{~h}$, followed by secondary antibodies

663 and 4,6-diamidino-2-phenylindole (DAPI) for $2 \mathrm{~h}$. Secondary antibodies used were Alexa 664 Fluor $\alpha$-rabbit 488 and $\alpha$-mouse 555. Coverslips were mounted onto glass slides using 665 ProLong Gold Antifade Reagent (Cell Signaling Technologies). Immunofluorescence was 666 visualized using a Zeiss LSM 710 Confocal microscope (Cell and Developmental 667 Microscopy Core at UPenn) and ZEN 2011 software. Images were processed in ImageJ 668 and assembled in Adobe CS6.

670 RNA Fluorescence in situ hybridization

671 RNA FISH was performed following previously established protocols ${ }^{81}$, with the following 672 modifications. Thirty-two singly labeled DNA oligonucleotides targeting the Fiber open

673 reading frame were designed using the Stellaris smFISH probe designer and ordered with 674 a 3' mdC-TEG-Amino label from LGC Biosearch. Fiber FISH probes were pooled and 
675 labeled with ATTO 647N NHS-Ester (ATTO-TEC, Cat\#: AD 647N-31), isopropanol 676 precipitated and purified by HPLC as previously described ${ }^{81}$. GAPDH probes labeled with 677 Cy3 were used as a counterstain to demarcate cytoplasmic boundaries and were a kind 678 gift from Sydney Schaffer, University of Pennsylvania ${ }^{82}$. All probe sequences can be 679 found in Supplementary Table 7. HeLa cells were grown on coverslips, harvested, fixed, 680 and permeabilized as described for conventional immunofluorescence above. After 681 permeabilization, cells on coverslips were equilibrated in Wash Buffer (2X SSC, 10\% 682 formamide) before being inverted over $30 \mu \mathrm{l}$ Hybridization Buffer (2X SSC, 10\% 683 formamide, 10\% dextran sulphate) containing $500 \mathrm{nM}$ Fiber and GAPDH FISH probes 684 and incubated at $37^{\circ} \mathrm{C}$ in a humidified chamber overnight. The following day coverslips 685 were washed twice with Wash Buffer for 30 minutes at $37^{\circ} \mathrm{C}$ with DAPI added to the 686 second wash, briefly washed three times at room temperature with $2 \mathrm{X} \mathrm{SSC}$, and then 687 affixed to glass slides using clear nail polish. Images were acquired on a Zeiss LSM 710 688 microscope with ten $z$-stacks of $0.7 \mu \mathrm{m}$ each in the $z$-direction. Images were deconvoluted 689 by maximum intensity projection in the z-direction using ImageJ. Fiber RNA localization 690 was scored as described in Supplementary Figure 1 over 41-160 individual cells. 691 Representative images were further processed in ImageJ and assembled in Adobe CS6.

693 RNA isolation and RT-qPCR

694 Total RNA was isolated from infected cells at the indicated timepoints using the RNeasy 695 Micro Kit (Qiagen). Complementary DNA (cDNA) was synthesized using $1 \mu \mathrm{gg}$ of input 696 RNA and the High Capacity RNA-to-cDNA Kit (Thermo Fisher). Quantitative PCR was 697 performed by standard protocol using diluted cDNA, primers for different viral and cellular 
698 transcripts (see Supplementary Table 7 for complete list of primers) and SYBR Green

699 (Thermo Scientific) using the QuantStudio 7 Flex Real-Time PCR System (Thermo

700 Scientific). The relative values for each transcript were normalized to a control RNA (actin

701 or HPRT).

702

703 RNA Transcription and Stability Profiling

704 To assess relative RNA transcription rate and RNA half-life, cells were treated with 200

$705 \mu \mathrm{M}$ 4-thiouridine (4sU; Sigma T4509) for exactly 30 min. Infection was stopped and RNA

706 harvested using $1 \mathrm{ml}$ TRIzol (Thermo Fisher Scientific), following manufacturer's

707 instructions. A fraction of the total RNA was reserved as input, and the remaining 4sU-

708 labeled nascent RNA was biotinylated using MTSEA-Biotin-XX (Biotium; 90066) as

709 previously described ${ }^{83,84}$. Nascent RNA was separated from unlabeled RNA using MyOne

710 C1 Streptavidin Dynabeads (Thermo Fisher Scientific; 65-001), biotin was removed from

711 nascent RNA using $100 \mathrm{mM}$ dithiothreitol (DTT), and RNA was isopropanol precipitated.

712 Total RNA $(1 \mu \mathrm{g})$ and an equivalent volume of nascent RNA were converted to cDNA and

713 qPCR was performed as described above. Relative transcription rates were determined

714 by the $\Delta \Delta \mathrm{Ct}$ method to compare nascent transcript levels between control and siRNA

715 treated cells normalized to nascent GAPDH RNA. RNA half-life was determined using the

716 previously described formula $t_{1 / 2}=-t \times[\ln (2) / D R]$ where $t$ is the $4 \mathrm{sU}$ labeling time $(0.5 \mathrm{~h})$

717 and $D R$ is the decay rate defined as Nascent/Total $R N A^{85}$. Half-lives were normalized to

718 the half-life of GAPDH set at $8 \mathrm{~h}$ as previously determined ${ }^{86}$.

720 RNA decay measurement using Actinomycin D 
721 To determine the decay of viral mRNA species, HeLa cells infected with either Ad5 WT

722 or $\Delta \mathrm{E} 1 \mathrm{~B}$ were treated with $10 \mu \mathrm{M}$ Actinomycin D (Cayman Chemical, Cat\#: 11421) at 24

723 hpi. RNA harvested using RLT buffer (from Qiagen RNA isolation kit) at 0, 1, 2, 4, 6, and

7248 hours after treatment. RNA levels were quantified using RT-qPCR and normalized to 0

725 hours of Actinomycin D to determine RNA decay.

726

727 Viral genome accumulation by qPCR

728 Infected cells were harvested by trypsinization at 4 and $24 \mathrm{hpi}$ and total DNA was isolated

729 using the PureLink Genomic DNA kit (Invitrogen). qPCR was performed using primers for

730 the Ad5 DBP and cellular tubulin (see Supplementary Table 7 for primers). Values for

731 DBP were normalized internally to tubulin and to the 4 hpi timepoint to control for any

732 variations in virus input. qPCR was performed using the standard protocol for SYBR

733 Green and analyzed with the QuantStudio 7 Flex Real-Time PCR System.

734

735 Plaque assay

736 Infected cells seeded in 12-well plates were harvested by scraping at the indicated

737 timepoints and lysed by three cycles of freeze-thawing. Cell debris was removed from

738 lysates by centrifugation at max speed $(21,130 \mathrm{~g}), 4^{\circ} \mathrm{C}, 5 \mathrm{~min}$. Lysates were diluted

739 serially in DMEM supplemented with $2 \%$ v/v FBS and 1\% v/v Pen/Strep to infect HEK293

740 cells seeded in 12 -well plates. After incubation for $2 \mathrm{~h}$ at $37^{\circ} \mathrm{C}$, the infection media was

741 removed, and cells were overlaid with DMEM containing $0.45 \% \mathrm{w} / \mathrm{v}$ SeaPlaque agarose

742 (Lonza) in addition to $2 \%$ v/v FBS and 1\% v/v Pen/Strep. Plaques were stained using 1\%

$743 \mathrm{w} / \mathrm{v}$ crystal violet in $50 \% \mathrm{v} / \mathrm{v}$ ethanol between 6 to 7 days post-infection. 


\section{Herrmann et al.}

\section{Immunoprecipitation}

746 Approximately $2 \times 10^{7}$ cells were harvested, washed, pelleted and flash frozen for each

747 immunoprecipitation. For IP of hnRNP-C and RALY $50 \mu \mathrm{l}$ of Protein G Dynabeads

748 (Thermo Fisher) per sample were washed 3x in IP buffer (50 mM HEPES pH 7.4, 150

$749 \mathrm{mM} \mathrm{KCl}, 2 \mathrm{mM}$ EDTA, 0.5\% v/v NP-40, $0.5 \mathrm{mM}$ DTT, 1x cOmplete Protease Inhibitor

750 Cocktail (Roche)) and incubated with $5 \mu \mathrm{g}$ of antibody ( $\alpha$-hnRNP-C or $\alpha-R A L Y)$ rotating

751 at $4^{\circ} \mathrm{C}$ for $2 \mathrm{~h}$. Cell pellets were resuspended in $1 \mathrm{ml} \mathrm{IP}$ buffer and incubated for $1 \mathrm{~h}$ on

752 ice. Samples were sonicated with a Diagenode Biorupter on low setting for $30 \mathrm{~s}$ on and

$75330 \mathrm{~s}$ off for ten rounds at $4^{\circ} \mathrm{C}$ and spun at max speed $(21,130 \mathrm{~g})$ for $10 \mathrm{~min}$ at $4^{\circ} \mathrm{C} .300 \mu \mathrm{l}$

754 of sample were added to washed beads and incubated rotating at $4^{\circ} \mathrm{C}$ for $2 \mathrm{~h}$. Beads were

755 washed $4 x$ in IP wash (same as above but with only $0.05 \%$ v/v NP-40). Samples were

756 eluted in $50 \mu \mathrm{l}$ 1x LDS sample buffer with $25 \mathrm{mM}$ DTT by boiling for 10 min at $95^{\circ} \mathrm{C}$ and

757 further processed for analysis by immunoblot.

758 The following changes were made to the protocol for IP of E1B55K: IP buffer contained

$75950 \mathrm{mM}$ Tris- $\mathrm{HCl} \mathrm{pH}$ 7.4, 0.1\% v/v Triton X-100, $150 \mathrm{mM} \mathrm{NaCl,} 50 \mathrm{mM} \mathrm{NaF}, 1$ mM Na $\mathrm{VO}_{4}$

$7601 \times$ cOmplete Protease Inhibitor Cocktail.

761

762 Denaturing in vivo ubiquitination assay

763 Approximately $1 \times 10^{7}$ cells were washed, pelleted and stored at $-80^{\circ} \mathrm{C}$ for each

764 immunoprecipitation. For HEK293 cells, the pellets were thawed on ice and resuspended

765 in $100 \mu$ l of Lysis buffer (1\% w/v SDS, 5 mM EDTA, 10 mM DTT, 1x cOmplete Protease

766 Inhibitor Cocktail) with $1 \mu$ l Benzonase (Sigma-Aldrich) by vortexing. Samples were 
767 incubated on ice for $5 \mathrm{~min}$ and then further denatured by heating to $95^{\circ} \mathrm{C}$ for $5 \min .900$

$768 \mu$ of Wash buffer (10 mM Tris-HCl pH 7.4, 1 mM EDTA, 1 mM EGTA, 150 mM NaCl, 1\%

769 v/v Triton X-100, 0.2 mM Na $3 V_{4}, 1 \times$ cOmplete Protease Inhibitor Cocktail), passed 10

770 times through a $23 \mathrm{G}$ syringe and spun at max speed $(21,130 \mathrm{~g})$ for $5 \mathrm{~min}$ at $4^{\circ} \mathrm{C}$. A

771 minimum of $800 \mu \mathrm{l}$ of sample was added to $50 \mu \mathrm{l}$ washed Pierce Anti-HA Magnetic beads

772 (Thermo Fisher). Sample was incubated with beads rotating for $1 \mathrm{~h}$ at $4^{\circ} \mathrm{C}$, washed $3 \mathrm{x}$ in

773 Wash buffer and eluted in 1x LDS sample buffer with $25 \mathrm{mM}$ DTT for further processing

774 by immunoblot.

775 The following changes were made to the protocol for HeLa cells: the Lysis buffer

776 contained $1 \% \mathrm{w} / \mathrm{v}$ SDS in PBS, Tris buffered saline with Tween-20 was used as wash

777 buffer, Protein G Dynabeads incubated for $1 \mathrm{~h}$ with a mix of both $\alpha$-ubiquitin antibodies

778 listed above were used for the IP.

779

780 De-ubiquitination assay

781 Approximately $1 \times 10^{7} \mathrm{HEK} 293$ cells were washed, pelleted and stored at $-80^{\circ} \mathrm{C}$ for each

782 immunoprecipitation. The pellets were resuspended in $1 \mathrm{ml} \mathrm{IP}$ buffer $\mathrm{B}$ ( $20 \mathrm{mM}$ HEPES-

$783 \mathrm{KOH} \mathrm{pH} \mathrm{7.4,} 110 \mathrm{mM}$ potassium acetate, $2 \mathrm{mM} \mathrm{MgCl}_{2}, 0.1 \% \mathrm{v} / \mathrm{v}$ Tween-20, $0.1 \% \mathrm{v} / \mathrm{v}$

784 Triton X-100, $150 \mathrm{mM} \mathrm{NaCl}, 1 \mathrm{mM}$ DTT, $0.1 \mathrm{mM}$ PTSF) containing 1x cOmplete Protease

785 Inhibitor Cocktail, 20 MM PR-619 (LifeSensors, Cat\#: SI9619-5X5MG), 5 mM 1,10-

786 phenanthroline (LifeSensors, Cat\#: SI9649), and $1 \mu \mathrm{l} / \mathrm{ml}$ Benzonase (Sigma-Alrich).

787 Samples were incubated on ice for $30 \mathrm{~min}$, sonicated with a Diagenode Biorupter on low

788 setting for $30 \mathrm{~s}$ on and $30 \mathrm{~s}$ off for five rounds at $4^{\circ} \mathrm{C}$ and spun at max speed $(21,130 \mathrm{~g})$

789 for 5 min at $4^{\circ} \mathrm{C} .925 \mu \mathrm{l}$ of sample was added to $100 \mu \mathrm{l}$ washed Pierce Anti-HA Magnetic 
790 beads (Thermo Fisher). Sample was incubated with beads rotating for $2 \mathrm{~h}$ at $4^{\circ} \mathrm{C}$, washed

$7913 x$ in IP buffer B, resuspended in $100 \mu$ of IP buffer B and split into three $30 \mu$ liquots.

$7921 \mu \mathrm{l}$ of $20 \mathrm{mM}$ PR-619 was added to sample 1 (untreated), $1 \mu \mathrm{l}$ of USP2 (LifeSensors,

793 Cat\#: DB501) was added to sample 2 (DUB ${ }^{\text {PAN }}$ ) and $2 \mu$ of OTUB1 (LifeSensors, Cat\#:

794 DB201) was added to sample $3\left(\mathrm{DUB}^{\mathrm{K} 48}\right)$. Samples were incubated at $30^{\circ} \mathrm{C}$ for a minimum

795 of $1 \mathrm{~h}$. Samples were eluted by addition of $10 \mu \mathrm{l} 4 \mathrm{x}$ LDS sample buffer with $100 \mathrm{mM}$ DTT

796 and boiling at $95^{\circ} \mathrm{C}$ for $10 \mathrm{~min}$ for further processing by immunoblotting.

797

\section{$798 \quad$ CLIP-qPCR}

799 The CLIP protocol was adapted from existing protocols ${ }^{58}$. In short, approximately $2 \times 10^{7}$ 800 cells were crosslinked on ice with $0.8 \mathrm{~J} / \mathrm{cm}^{2}$ UV $254 \mathrm{~nm}$ in a UV Stratalinker 2400

801 (Stratagene), washed in PBS with $2 \mathrm{mM}$ EDTA and $0.2 \mathrm{mM} \mathrm{PMSF}$, flash frozen in liquid 802 nitrogen and stored at $-80^{\circ} \mathrm{C} .50 \mu \mathrm{l}$ of Protein G Dynabeads per sample were washed $3 \mathrm{x}$ 803 in iCLIP lysis buffer A (50 mM Tris- $\mathrm{HCl}$ pH 7.4, $100 \mathrm{mM} \mathrm{NaCl}, 0.2 \% \mathrm{v} / \mathrm{v} \mathrm{NP}-40,0.1 \% \mathrm{w} / \mathrm{v}$ 804 SDS, $0.5 \%$ w/v Sodium deoxycholate, $1 \times$ cOmplete Protease Inhibitor Cocktail), 805 resuspended in $100 \mu \mathrm{l}$ iCLIP lysis buffer $A$ and incubated with $5 \mu \mathrm{g}$ of $\alpha$-hnRNP-C 806 antibody, $5 \mu \mathrm{g}$ of $\alpha$-Flag antibody (mouse), or $5 \mu \mathrm{l}$ of Normal Mouse Serum Control

807 (Thermo Fisher) rotating $1 \mathrm{~h}$ at $4^{\circ} \mathrm{C}$. Cell pellets were resuspended in $1 \mathrm{ml}$ of iCLIP lysis 808 buffer B (same as buffer A but with $1 \% \mathrm{v} / \mathrm{v}$ NP-40 and $11 \mu \mathrm{l}$ of Murine RNase inhibitor

809 (NEB) per $1 \mathrm{ml}$ ) and incubated on ice for $15 \mathrm{~min}$. Samples were sonicated with a 810 Diagenode Biorupter on low setting for $30 \mathrm{~s}$ on and $30 \mathrm{~s}$ off for five rounds at $4^{\circ} \mathrm{C} .2 \mu \mathrm{l}$ of

811 TURBO DNase (Thermo Fisher) were added and samples incubated at $37^{\circ} \mathrm{C}$ for $6 \mathrm{~min}$.

812 Lysates were cleared by centrifugation at max speed $(21,130 \mathrm{~g})$ for $15 \mathrm{~min}$ at $4^{\circ} \mathrm{C}$ and 
813 supernatants transferred to a new tube. $300 \mu \mathrm{l}$ of lysate were added to washed beads

814 and incubated rotating at $4^{\circ} \mathrm{C}$ for $2 \mathrm{~h}$. Beads were washed $2 \mathrm{x}$ in High Salt buffer $(50 \mathrm{mM}$

815 Tris- $\mathrm{HCl} \mathrm{pH} 7.4,1 \mathrm{M} \mathrm{NaCl}, 1 \mathrm{mM}$ EDTA, 0.2\% v/v NP-40, 0.1\% w/v SDS, $0.5 \% \mathrm{w} / \mathrm{v}$

816 Sodium deoxycholate), 2x in Wash buffer (20 mM Tris- $\mathrm{HCl} \mathrm{pH} \mathrm{7.4,} 10 \mathrm{mM} \mathrm{MgCl}, 0.2 \%$

$817 \mathrm{v} / \mathrm{v}$ Tween-20) and 2x in Proteinase $\mathrm{K}$ buffer (100mM Tris- $\mathrm{HCl} \mathrm{pH}$ 7.4, $50 \mathrm{mM} \mathrm{NaCl}, 10$

$818 \mathrm{mM}$ EDTA, $0.2 \% \mathrm{w} / \mathrm{v}$ SDS). Beads were resuspended in $50 \mu \mathrm{l}$ Proteinase $\mathrm{K}$ buffer and 10

$819 \mu \mathrm{l}$ removed and processed for immunoblot analysis. $10 \mu \mathrm{l}$ of Proteinase K (NEB) and $2 \mu \mathrm{l}$

820 Murine RNase Inhibitor were added to the remaining beads or to $30 \mu \mathrm{l}$ of input (10\%) and

821 incubated at $50^{\circ} \mathrm{C}$ for $1 \mathrm{~h}$. The RNA was extracted using a standard protocol for TRlzol

822 (Thermo Fisher) and further processed for RT-qPCR.

823

824 seCLIP-Seq

825 Sample preparation

826 The CLIP protocol was adapted from existing protocols ${ }^{87}$. In short, approximately $2 \times 10^{7}$

827 HeLa cells were crosslinked on ice with $0.8 \mathrm{~J} / \mathrm{cm}^{2}$ UV $254 \mathrm{~nm}$ in a UV Stratalinker 2400

828 (Stratagene), washed in PBS with $2 \mathrm{mM}$ EDTA and $0.2 \mathrm{mM} \mathrm{PMSF}$, flash frozen in liquid

829 nitrogen and stored at $-80^{\circ} \mathrm{C}$. Protein G Dynabeads ( $100 \mu$ l per sample) were washed $3 x$

830 in iCLIP lysis buffer A (see CLIP-qPCR), resuspended in $100 \mu \mathrm{l}$ iCLIP lysis buffer $A$ and

831 incubated with $10 \mu \mathrm{g}$ of $\alpha$-hnRNP-C antibody rotating $1 \mathrm{~h}$ at RT. Cell pellets were

832 resuspended in $1 \mathrm{ml}$ of iCLIP lysis buffer B and incubated on ice for $15 \mathrm{~min}$. Samples

833 were sonicated with a Diagenode Biorupter on low setting for $30 \mathrm{~s}$ on and $30 \mathrm{~s}$ off for five

834 rounds at $4^{\circ} \mathrm{C}$. Samples were incubated with $2 \mu$ of TURBO DNase (Thermo Fisher) and

$83510 \mu \mathrm{l}$ of $1: 10$ diluted RNase I (Thermo Fisher) in Thermomixer at $1200 \mathrm{rpm}$ at $37^{\circ} \mathrm{C}$ for 5

$836 \min$, samples placed on ice and $22 \mu$ SUPERase.In RNase Inhibitor was added. Cleared 
837 lysate $(500 \mu \mathrm{l})$ was added to washed beads and incubated rotating at $4^{\circ} \mathrm{C}$ for $2 \mathrm{~h}$. Beads

838 were washed 2x in High Salt buffer, 2x in Wash buffer and 2x FastAP buffer. FastAP

839 master mix $(100 \mu \mathrm{l})$ and FastAP enzyme $(8 \mu \mathrm{l})$ was added and samples were incubated

840 with a Thermomixer at $1200 \mathrm{rpm}$ at $37^{\circ} \mathrm{C}$ for $15 \mathrm{~min}$. T4 PNK enzyme $(7 \mu \mathrm{l})$ and $300 \mathrm{PNK}$

841 master mix were added and samples were incubated with a Thermomixer at $1200 \mathrm{rpm}$ at

$84237^{\circ} \mathrm{C}$ for $20 \mathrm{~min}$. Beads were washed and resuspended in Ligase buffer with $2.5 \mu \mathrm{RNA}$

843 Ligase high conc., $2.5 \mu \mathrm{l}$ of RNA adapters (3SR_RNA), and incubated at RT for $75 \mathrm{~min}$.

844 Beads were washed and a fraction saved for immunoblotting. For the remaining fraction,

845 beads were resuspended in lysis buffer with DTT, eluted by incubation in Thermomixer,

$8461200 \mathrm{rpm}, 70^{\circ} \mathrm{C}$, run on SDS-PAGE and transferred onto Nitrocellulose o/n, 30V. Lanes

847 for the RBP band (plus $75 \mathrm{kDa}$ ) and size-matched input were cut from the membranes

848 RNA was eluted with $20 \mu$ l of Proteinase K (Thermo Fisher) in a Thermomixer at 1200

$849 \mathrm{rpm}$ at $50^{\circ} \mathrm{C}$ for $1 \mathrm{~h}$. RNA was extracted with acid phenol/chloroform/isoamyl alcohol $(\mathrm{pH}$

850 4.5), and concentrated using RNA Clean and Concentrator (Zymo). Size-matched inputs

851 were ligated to 3SR_RNA. All RNA samples were reverse transcribed with $0.9 \mu \mathrm{l}$

852 AffinityScript Enzyme at $55^{\circ} \mathrm{C}$ for 45 min with RT primer SR_RTv2. RNA and excess

853 primers were removed with $3.5 \mu \mathrm{l}$ ExoSAP-IT $1 \mathrm{M} \mathrm{NaOH}$. cDNA was purified using $10 \mu \mathrm{l}$

854 MyONE Silane beads and ligated to 5' linker SR_DNA o/n at RT. After clean up, cDNA

855 was quantified by qPCR using NEBNext universal and index primers (NEB E7335S).

856 Libraries were indexed using NEBNext High-Fidelity PCR Master Mix (NEB M0541S) for

85711 cycles (size-matched input) or 15 cycles (hnRNP-C IP). Libraries were size selected

858 by 1.0x AmpureXP beads (Beckman Coulter A63880), quantified by QuBit HS DNA and

859 Bioanalyzer High Sensitivity DNA assay, and pooled for sequencing. 
Herrmann et al.

860 Data analysis

861 Preprocessing involved adapter cutting using cutadapt (v. 1.18) ${ }^{88}$ and extracting the UMIs

862 using umi_tools ( $v$ 1.0.0 $)^{89}$. Alignment was achieved using GSNAP (v 2019-09-12) ${ }^{90}$.

863 Reads were aligned to the human and adenovirus 5 genome simultaneously. After the

864 alignment we used umi_tools to deduplicate reads based on the UMIs, which was

865 followed by removing all non-unique reads. We then used clipper (v0.1.4 $)^{91}$ to find 866 significant enriched IP peaks over the input on the human genome. To identify enriched

867 peaks on the virus genome we employed a sliding window approach, by counting 868 fragments overlapping 10bp wide windows along both the forward and reverse strand on

869 the genome. If two consecutive windows were significantly enriched over input, they were 870 merged into one peak. Motif analysis was conducted using the Homer suite ${ }^{92}$.

\section{Analyzing protein complexes by crosslinking}

873 Cells were crosslinked using disuccinimidyl suberate (DSS, Thermo Fisher) dissolved to

$874100 \mathrm{mM}$ in DMSO and further diluted to $0.1 \mathrm{mM}, 0.3 \mathrm{mM}$ and $1 \mathrm{mM}$ in PBS. Cells seeded 875 as a monolayer in 6-well plates were washed once with PBS, overlaid with $500 \mu \mathrm{l}$ with 876 PBS or the different DSS dilutions and incubated at room temperature for $30 \mathrm{~min}$. The 877 reaction was quenched by addition of $500 \mu \mathrm{l}$ of $20 \mathrm{mM}$ Tris- $\mathrm{HCl} \mathrm{pH} 7.4$, washed twice 878 with PBS and further processed for immunoblot analysis.

879

880 Di-glycine remnant profiling by mass spectrometry

$881 \quad$ Cell lysis and initial desalting 
882 Approximately $10 \mathrm{mg}$ of input was generated from $5 \times 15 \mathrm{~cm}$ plates of HeLa cells 883 transduced with rAd E1B55K and rAd E4orf6 constructs for $0 \mathrm{~h}$ (mock), $6 \mathrm{~h}, 8 \mathrm{~h}$, and 10 884 h. Each timepoint was produced in biological triplicate. Cell were harvested with $0.25 \%$ 885 Trypsin (Gibco), washed $1 \mathrm{x}$ in PBS, flash frozen in liquid nitrogen and stored at $-80^{\circ} \mathrm{C}$. 886 Pellets were thawed, resuspended in $1 \mathrm{ml}$ of lysis buffer (6 M urea, $2 \mathrm{M}$ thiourea, in 50 $887 \mathrm{mM}$ ammonium bicarbonate $\mathrm{pH} 8.0$ ) with $1 \mathrm{x}$ Halt Protease Cocktail inhibitor solution, and 888 incubated for $\sim 5 \mathrm{~min}$ on ice. Samples were then diluted 10 -fold in $50 \mathrm{mM}$ ammonium 889 bicarbonate, reduced with $10 \mathrm{mM}$ DTT, alkylated with $20 \mathrm{mM}$ iodoacetamide, and 890 digested with trypsin protease overnight. Digestion was quenched by acidification to $\mathrm{pH}$

8912 with trifluoroacetic acid (TFA) and samples were desalted over Waters tC18 SepPak 892 cartridges (Cat\#: 036805). A 10\% aliquot was set aside for global proteomic analysis and 893 all samples were dried to completion.

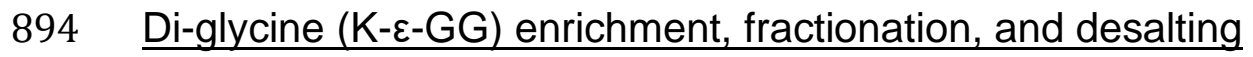

895 A Cell Signaling PTMScan ubiquitin remnant motif kit (Cat\#: 5562) was used to enrich for 896 peptides that had been ubiquitinated. Aliquoted beads were cross-linked for 30 minutes 897 in $100 \mathrm{mM}$ sodium borate and $20 \mathrm{mM}$ dimethyl pimelimidate (Thermo Scientific), following 898 the protocol outlined by Udeshi et. al. ${ }^{28}$. Tryptic peptides were resuspended in IAP buffer

899 (50 mM MOPS, pH 7.2, $10 \mathrm{mM}$ sodium phosphate, $50 \mathrm{mM} \mathrm{NaCl}$ ) and immunoprecipitated 900 with the provided antibody for $2 \mathrm{~h}$ at $4^{\circ} \mathrm{C}$. Samples were eluted in LC-MS grade water 901 (Thermo Fisher) with $0.15 \%$ v/v TFA and separated into either 3 high-pH fractions 902 (enriched ubiquitinated peptides) or 7 high-pH fractions (global proteome) over C18 903 columns (The Nest Group, MicroSpin column C18 silica, part\#: SEM SS18V, lot\#: 
Herrmann et al.

904 091317). Fractionated samples were desalted a final time over Oligo R3 reverse-phase

905 resin (Thermo Scientific, Cat\#:1-1339-03).

906 Data acquisition and search parameters

907 All solvents used in analysis of MS samples were LC-MS grade. Samples were analyzed

908 with an Easy-nLC system (Thermo Fisher) running $0.1 \% \mathrm{v} / \mathrm{v}$ formic acid (Buffer $A$ ) and

$90980 \% \mathrm{v} / \mathrm{v}$ acetonitrile with $0.1 \% \mathrm{v} / \mathrm{v}$ formic acid (Buffer B), coupled to an Orbitrap Fusion

910 Tribrid mass spectrometer. Peptides were separated using a $75 \mu \mathrm{m}$ i.d. silica capillary

911 column packed in-house with Repro-Sil Pur C18-AQ $3 \mu \mathrm{m}$ resin and eluted with a gradient

912 of $3-38 \%$ Buffer B over 85 minutes. Full MS scans from $300-1500 \mathrm{~m} / \mathrm{z}$ were analyzed in

913 the Orbitrap at 120,000 FWHM resolution and $5 \times 10^{5}$ AGC target value, for $50 \mathrm{~ms}$

914 maximum injection time. lons were selected for MS2 analysis with an isolation window of

$9152 \mathrm{~m} / \mathrm{z}$, for a maximum injection time of $50 \mathrm{~ms}$, to a target AGC of $5 \times 10^{4}$.

916 MS raw files were analyzed by MaxQuant software version 1.6.0.16, and MS2 spectra

917 were searched against a target + reverse database with the Andromeda search engine

918 using the Human UniProt FASTA database [9606] (reviewed, canonical entries;

919 downloaded November 2017) and adenovirus serotype 5 UniProt FASTA database

920 (reviewed, canonical entries; downloaded February 2018). The search included variable

921 modifications of methionine oxidation, N-terminal acetylation, and GlyGly on lysine

922 residues, with a fixed modification of carbamidomethyl cysteine. For global proteome

923 samples, iBAQ quantification was performed on unique+razor peptides using unmodified,

924 oxidized methionine, and $\mathrm{N}$-terminally acetylated forms. Trypsin cleavage was specified

925 with up to 2 missed cleavages allowed. Match between runs was enabled, but restricted

926 to matches within a single biological replicate by separating replicates into independent 
Herrmann et al.

927 searches. Match between runs parameters included a retention time alignment window

928 of $20 \mathrm{~min}$ and a match time window of $0.7 \mathrm{~min}$. False discovery rate (FDR) was set to

9290.01.

930

931 Proteomics and bioinformatics analysis

932 Data normalization and filtering

933 MaxQuant output was filtered to remove identified contaminant and reverse proteins.

934 MaxQuant "Intensity" and "iBAQ"93 label free quantification values were used to measure

935 abundances for the K- - -GG and WCP data, respectively. Abundances were transformed

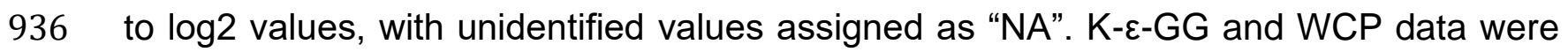

937 normalized separately. Data were normalized by subtracting the sample medians from

$938 \log 2$ transformed abundances within replicates. Both the $\mathrm{K \varepsilon GG}$ and the WCP datasets

939 were filtered at each timepoint to require quantification in at least 2 of 3 replicates to be

940 included in the calculations of fold change, z-score, or for hypothesis testing. Data that

941 contained less than 2 replicate quantifications in each timepoint was removed entirely

942 from the analysis. Peptides or proteins are considered uniquely identified in one timepoint

943 compared to another if there were at least 2 replicate quantifications for one timepoint

944 and 0 replicate quantifications for the compared timepoint.

945 Fold change, $\mathrm{p}$-value, and z-score calculations

946 The fold change across timepoints was calculated by comparing the log2 transformed,

947 normalized peptide or protein abundances for compared timepoints. Fold changes were

948 calculated both on a per-replicate basis and by comparing averaged abundances across

949 timepoints. Hypothesis testing was performed using unpaired, two-tailed Students t-tests, 
950 when comparing log2 transformed, normalized replicate abundances across timepoints.

951 Hypothesis testing using one-sided t-tests, with null hypothesis of fold change equal 0 ,

952 was implemented when evaluating log2 fold changes. Multiple testing correction was not

953 performed. Peptide ubiquitin intensity Z-scores were used to measure relative ubiquitin

954 abundances for a peptide at the respective timepoint. Z-scores were calculated by

955 averaging the peptide intensities for each replicate identification within the timepoint and

956 comparing to the mean and standard deviation of averaged values within that timepoint.

957 Protein ubiquitin abundance calculation

958 The di-glycine technique quantifies peptide-based abundance of the K- $\varepsilon$-GG modification.

959 In order to quantify protein-based $\mathrm{K}-\varepsilon-\mathrm{GG}$ abundance changes, we implemented a

960 calculation to combine the peptide-based fold changes for cases in which multiple $\mathrm{K}-\varepsilon$ -

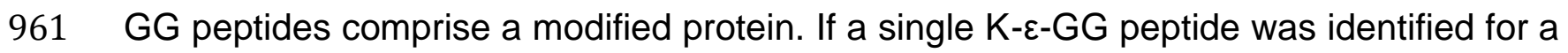

962 modified protein, that K- $\varepsilon-G G$ peptide abundance fold change represented the protein-

963 based $\mathrm{K}-\varepsilon-\mathrm{GG}$ fold change. For cases in which multiple $\mathrm{K}-\varepsilon-\mathrm{GG}$ peptides were quantified

964 for a single protein, the fold changes of each peptide were weighted by the abundance of

965 that peptide and the weighted fold changes were averaged to calculate the protein-based

966 K-ع-GG fold change. In cases for which a peptide was uniquely identified in the mock or

$96710 \mathrm{~h}$ transduction timepoint, a log2 fold change of plus or minus 7 , respectively,

968 representing the largest fold changes identified in the dataset, was assigned to this

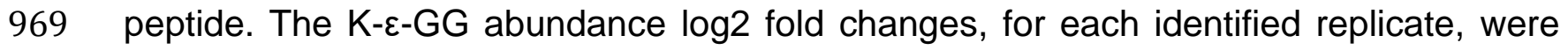

970 normalized by the total protein abundance log2 fold change of the corresponding replicate

971 of the same protein in the corresponding whole cell proteome. The replicate-based

972 normalized log2 fold changes were averaged and hypothesis testing was performed for 
973 the log2 fold changes using onesided t-tests. The normalization of the K- $\varepsilon$-GG fold change

974 by total protein fold change was performed to identify differentially increased or decreased

975 ubiquitination, beyond what would be expected if modification abundance was driven

976 solely by changes in total protein abundance.

$977 \quad \mathrm{~K}-\varepsilon-\mathrm{GG}$ and whole cell proteome comparison

978 The protein-based $\mathrm{K}-\varepsilon-\mathrm{GG}$ and corresponding whole cell proteome data were compared

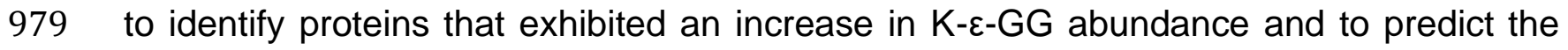

980 effect of ubiquitination on total protein abundance. Proteins that exhibited a protein-

981 based, normalized K-ع-GG log2 fold change $>1$ were classified as being increased in

982 ubiquitination in response to E1B55K/E4orf6 expression. Proteins that exhibited whole

983 cell proteome log2 fold change greater than the mean fold change $+/-1$ standard

984 deviation, or which were uniquely identified in the 0 or 10 hour timepoint, were classified

985 as increased or decreased in total protein abundance. Proteins for which total protein

986 expression did not deviate more than $+/-1$ standard deviation from the mean fold change

987 were classified as unchanged in protein abundance in response to E1B55K/E4orf6

988 expression. Proteins that were ubiquitinated and decreased in total protein abundance

989 were predicted to be potential substrates of E1B55K/E4orf6 ubiquitin-mediated

990 degradation. Proteins that were ubiquitinated and unchanged in total protein abundance

991 were predicted to be non-degraded substrates of E1B55K/E4orf6.

992 Gene ontology and protein-protein interaction network analysis

993 The proteins that exhibited increased protein-based ubiquitination were analyzed using

994 the ReactomeFI plug-in (6.1.0) ${ }^{36}$ within the Cytoscape network visualization software

$995(3.4 .0)^{94}$. The protein-protein interaction network was generated using the Gene Set 
996 analysis within the "2016" ReactomeFI network version with "linker genes" included. The

997 network was clustered using the in-built ReactomeFI clustering algorithm. Gene ontology

998 "Molecular Function", "Biological Processes" and Reactome Pathway analysis was

999 performed within the ReactomeFI application for the entire network as well as for each

1000 clustered module. Network node attributes included size, which corresponded to degree

1001 of increased ubiquitination, and color, which corresponded to total protein increase or

1002 decrease. Network edges were set to non-directed, solid lines for all types of Reactome

1003 protein-protein interactions.

1004

1005 Targeted hnRNP-C RBR-ID

1006 Cell growth

1007 Heavy and light media were prepared by supplementing SILAC DMEM (Thermo \#88364)

1008 with $800 \mu \mathrm{M}$ of Lysine (Sigma \#L8662-25G) and $400 \mu \mathrm{M}$ Arginine (Sigma \#A8094-25G)

1009 for light or K8 (Silantes \#211604102) and R10 isotopes (Silantes \#201604102) for heavy,

1010 and $120 \mathrm{mg} / \mathrm{L}$ Proline (Sigma \#P0380-100G). Media was then filtered and adjusted to

1011 10\% dialyzed FBS (HyClone \#SH30079.03) and 1\% penicillin-streptomycin. Heavy

1012 isotope labeling in HeLa cells was confirmed by mass spectrometry. Cells were either

1013 mock-treated or infected with Ad5 WT Ad5 or $\Delta \mathrm{E} 1 \mathrm{~B}$ at an MOI of 10. At $20 \mathrm{hpi}$, media

1014 was exchanged and heavy-labeled cells were pulsed with $500 \mu \mathrm{M} 4 \mathrm{sU}$, with light-labeled

1015 cells serving as non-treated controls. At $24 \mathrm{hpi}$, all samples were washed with cold PBS

1016 and crosslinked at $1.0 \mathrm{~J} / \mathrm{cm}^{2}$ with $310 \mathrm{~nm}$ UV-B. Cells were then harvested, heavy/light

1017 pairs were combined 1:1, and aliquoted for further analysis.

1018 hnRNP-C IP 
1019 Approximately $1 \times 10^{7}$ pooled heavy and light HeLa cells were used for one hnRNP-C IP.

$102050 \mu$ l of Protein G Dynabeads (Thermo Fisher) per sample were washed $3 x$ in IP buffer

1021 (20 mM HEPES-KOH pH 7.4, $110 \mathrm{mM}$ potassium acetate, $2 \mathrm{mM} \mathrm{MgCl}_{2}, 0.1 \%$ Tween-20,

$10220.1 \%$ Triton, $150 \mathrm{mM} \mathrm{NaCl}, 1 \mathrm{mM}$ DTT, $0.1 \mathrm{mM}$ PMSF, 1x cOmplete Protease Inhibitor

1023 Cocktail (Roche)) and incubated with $5 \mu \mathrm{g}$ of $\alpha$-hnRNP-C antibody rotating at RT for $1 \mathrm{~h}$.

1024 Cell pellets were resuspended in $500 \mu \mathrm{IP}$ buffer, after $10 \mathrm{~min} 1.5 \mu \mathrm{l}$ benzonase (Sigma-

1025 Aldrich, Cat\#: E1014) were added and the sample was incubated for $1 \mathrm{~h}$ on ice. Samples

1026 were sonicated with a Diagenode Biorupter on low setting for $30 \mathrm{~s}$ on and $30 \mathrm{~s}$ off for ten

1027 rounds at $4{ }^{\circ} \mathrm{C}$ and spun at max speed $(21,130 \mathrm{~g})$ for $10 \mathrm{~min}$ at $4{ }^{\circ} \mathrm{C} .450 \mu \mathrm{l}$ of sample

1028 were added to washed beads and incubated rotating at $4{ }^{\circ} \mathrm{C}$ for $2 \mathrm{~h}$. Beads were washed

1029 3x with IP buffer before proteins were eluted in $0.1 \mathrm{M}$ glycine $(\mathrm{pH} 2.4)$ for 10 min at RT,

1030 and elution was quenched with an equal volume of $0.1 \mathrm{M} \mathrm{Tris-}-\mathrm{HCl}(\mathrm{pH} 8.0)$.

1031 Mass spectrometry sample prep

1032 Immunoprecipitated samples were reduced with $10 \mathrm{mM}$ DTT for $30 \mathrm{~min}$ at RT and

1033 alkylated with $20 \mathrm{mM}$ iodoacetamide for $45 \mathrm{~min}$ at RT in the dark. Samples were adjusted

1034 to $10 \mathrm{mM} \mathrm{CaCl}_{2}$ and split into two aliquots. One set of aliquots was digested at RT with

1035 chymotrypsin at a $\sim 1: 25$ ratio and the other with trypsin at a $\sim 1: 30$ ratio. Digestions were

1036 quenched after $\sim 16$ hrs by addition of TFA to $\mathrm{pH} 2$. Samples were then desalted over

1037 Oligo R3 reverse-phase resin (Thermo Scientific, Cat\#1-1339-03).

1038 Data acquisition

1039 Peptide quantification by LC-MS/MS was performed on a Thermo Fisher Ultimate 3000

1040 Dionex $^{\mathrm{TM}}$ liquid chromatography system and a Thermo Q-Exactive HF- $\mathrm{X}^{\mathrm{TM}}$ mass

1041 spectrometer. The mobile phases consisted of $0.1 \%$ formic acid aqueous (mobile phase 
1042 A) and $0.1 \%$ formic acid $80 \%$ acetonitrile (mobile phase B) with a gradient of $5-45 \%$ over

104348 min and a 60 min total gradient. Samples were quantified by $A_{280}$ absorbance and 1

$1044 \mu \mathrm{g}$ of each was injected. Trypsin samples were run with MS1 settings of $250-1100 \mathrm{~m} / \mathrm{z}$

1045 window, a resolution of 60,000, AGC target of 5e5, and MIT (maximum inject time) of 54

1046 ms. MS2 scans were collected in data dependent mode with a TopN loop count of 10,

1047 resolution of 15,000, AGC target of 1e5, and MIT of 100ms. Chymotrypsin samples were

1048 run on the same LC gradient with MS1 settings of 250-1100 m/z window, a resolution of

104960,000 , AGC target of 1e6, and MIT of $60 \mathrm{~ms}$. MS2 scans were collected in data

1050 dependent mode with a TopN loop count of 10, resolution of 15,000, AGC target of 5e5,

1051 and MIT of $120 \mathrm{~ms}$. Fragmentation was performed with HCD using stepped normalized

1052 collision energies (NCE) of $25,27,30 \%{ }^{95}$.

1053 Data processing

1054 Data files were processed by Sequest ${ }^{\mathrm{TM}}$ within Proteome Discoverer ${ }^{\mathrm{TM}}$ (PD) 2.3 workflow

1055 nodes. Searching parameters were set to find mass offsets of 8.014 Da for heavy $\mathrm{K}(+8)$

1056 lysine and 10.008 Da for heavy $\mathrm{R}(+10)$ arginine for the SILAC heavy pairs ${ }^{55}$. Additionally,

1057 phosphorylation (79.966 Da) and methylation (14.015Da) were searched on both viral and

1058 host proteins. A human protein FASTA and adenovirus type 5 specific FASTA files

1059 downloaded directly from Uniprot were used to process the raw files ${ }^{96}$. No imputation was

1060 used across data files. A 1\% FDR level cutoff was applied at the peptide level by

1061 Percolator and the protein level. The use of Minora Feature Detector ${ }^{\mathrm{TM}}$ was used to

1062 identify SILAC pairs and identify non-sequenced peptides between runs ${ }^{97}$. Post-

1063 processing of the data files was performed in R Studio and peptide abundances were

1064 normalized to their respective proteins. If each peptide was identified in each sample, the 
Herrmann et al.

1065 heavy/light pairs $p$-values were determined by a Student's t-test as previously used in

1066 both the original RBR-ID paper ${ }^{53}$ and the subsequent SILAC targeted RBR-ID paper ${ }^{54}$.

1067 Score plots and fold change plots were generated using the mapping function from the

1068 original RBR-ID paper ${ }^{53}$.

1070 hnRNP-C interactome analysis

1071 In the targeted RBR-ID experiment, the "light" control sample contains the global

1072 interactome data for the targeted protein, hnRNP-C, in the absence of any RNA-protein

1073 crosslinking. The "light" control data for mock, Ad5 WT, and $\Delta \mathrm{E} 1 \mathrm{~B}$ infections were

1074 compared to identify the proteins that interact with hnRNP-C in each of these conditions

1075 and to quantify changes in interactions induced by WT or $\Delta \mathrm{E} 1 \mathrm{~B}$ infection. Three biological

1076 replicates were generated for each condition and each biological replicate was analyzed

1077 in two technical replicates. The "light" protein abundance data for each replicate was

1078 transformed by $\log 2$ and the identified protein abundances were normalized by the

1079 abundance of hnRNP-C in the respective replicate. The protein abundance values for the

1080 two technical replicates were averaged within each biological replicate. The protein

1081 abundance values for the three biological replicates within each condition were then

1082 averaged. When computing averages, unidentified values were not included in the

1083 calculation. Z-scores were calculated by comparing the average abundance of the protein

1084 in the respective condition to the mean and standard deviation of all averaged

1085 abundances for that condition. The $z$-score was calculated only proteins with abundance

1086 quantified in at least 2 replicates for the respective condition. Fold changes were

1087 calculated by comparing protein average abundance values for compared conditions. 
1088 Hypothesis testing was performed by using an unpaired t-test to compare log2 normalized

1089 protein abundance values for each replicate within compared conditions. Correlations

1090 were analyzed for log2 normalized abundances using the cor function (Pearson

1091 correlation coefficient) and visualized using the corrplot package in the R software

1092 environment ${ }^{98}$.

1093

1094 Statistics and reproducibility

1095 Each experiment was carried out at least in triplicate with reproducible results. The 1096 sample size was chosen to provide enough statistical power apply parametric test

1097 (unpaired, two-tailed Student's t-test unless otherwise noted). Details regarding statistical

1098 analysis are reported in each figure legend and $p$-values for each analysis can be found

1099 in Supplementary Table 8.

1100

1101 Data availability

1102 All mass spectrometry data for this study are deposited in the CHORUS database

1103 (dataset identifier and DOI will be provided upon acceptance of manuscript). The seCLIP-

1104 Seq data have been deposited in NCBI's Gene Expression Omnibus ${ }^{99}$ and are accessible

1105 through GEO Series accession number GSE145411

1106 (https://www.ncbi.nlm.nih.gov/geo/query/acc.cgi?acc=GSE145411). Additional

1107 supporting data are available from the corresponding author upon request.

1108

1109 Code availability 
1110 The proteomics data were analyzed using standard methods. The implementation of the

1111 analysis was performed using $\mathrm{R}$ software. The scripts are available from the

1112 corresponding author upon request or can be accessed via GitHub.

1113 https://github.com/JosephDybas/AdenovirusProteomics

1114

\section{Acknowledgements}

1116 We thank members of the Weitzman Lab for insightful discussions and input. We thank

1117 P. Choi for help with seCLIP-Seq, and G. Yeo and E. Van Nostrand for their input

1118 regarding analysis of corresponding data. We are grateful to A. Berk, P. Branton, R.

1119 Greenberg, G. Ketner, A. Levine, K. Lynch, D. Ornelles, J. Wilson, and H. Wodrich for

1120 generous gifts of reagents. We thank S. Schaffer for technical advice, and D. Avgousti,

1121 L. Busino, P. Choi, K. Lynch, and J. Weitzman for careful reading of the manuscript. We

1122 thank the UPenn Cell and Developmental Biology Microscopy Core for imaging

1123 assistance. This research was supported by NIAID grants R01-Al145266 (MDW), R01-

1124 Al121321 (MDW) and R01-Al118891 (BAG), and NCl grant R01-CA97093 (MDW).

1125 Additional support came from the NCl T32 Training Grant in Tumor Virology T32-

1126 CA115299 (AMP) and Individual National Research Service Awards F32-Al147587

1127 (JMD) and F32-Al138432 (AMP) from the National Institutes of Health.

\section{Author Contributions}

1130 M.D.W., C.H., J.M.D. and J.C.L. conceived of the project. C.H. performed the experiments

1131 and received assistance from J.C.L., A.M.P. and E.T.K. C.H. prepared figures with input

1132 from other authors. J.M.D. performed the bioinformatics and proteomics data analysis. 
1133 J.C.L. and R.L. performed mass spectrometry. A.M.P. performed RNA FISH. A.M.P.,

1134 C.E.P., and C.H. performed RT-qPCR, CLIP-qPCR, and seCLIP-Seq sample

1135 preparation. K.E.H. performed bioinformatics analysis of seCLIP-Seq data. M.C.

1136 performed microscopy. C.H., J.C.L., and E.T.K. performed immunoprecipitation. C.H.,

1137 J.M.D., and M.D.W. wrote the manuscript with input from the other authors. M.D.W. and

1138 B.A.G. supervised the research.

1139

1140 
Herrmann et al.

\section{References}

1142

11431 Isaacson, M. K. \& Ploegh, H. L. Ubiquitination, ubiquitin-like modifiers, and

1144

1145 deubiquitination in viral infection. Cell host \& microbe 5, 559-570 (2009).

1146

2 Luo, H. Interplay between the virus and the ubiquitin-proteasome system: molecular mechanism of viral pathogenesis. Curr Opin Virol 17, 1-10 (2016).

1147 Dybas, J. M., Herrmann, C. \& Weitzman, M. D. Ubiquitination at the interface of tumor viruses and DNA damage responses. Curr Opin Virol 32, 40-47 (2018).

1149 Komander, D. \& Rape, M. The ubiquitin code. Annu Rev Biochem 81, 203-229

1150 (2012).

1151 Oh, E., Akopian, D. \& Rape, M. Principles of Ubiquitin-Dependent Signaling. Annu

1152 Rev Cell Dev Biol 34, 137-162 (2018).

1153 Kulathu, Y. \& Komander, D. Atypical ubiquitylation - the unexplored world of polyubiquitin beyond Lys48 and Lys63 linkages. Nature reviews. Molecular cell biology 13, 508-523 (2012).

1157

7 Petroski, M. D. \& Deshaies, R. J. Function and regulation of cullin-RING ubiquitin ligases. Nature reviews. Molecular cell biology 6, 9-20 (2005).

1159

1160

1161

8 Querido, E. et al. Degradation of p53 by adenovirus E4orf6 and E1B55K proteins
occurs via a novel mechanism involving a Cullin-containing complex. Genes Dev 15, 3104-3117 (2001).

1162

1163

1164

9 Harada, J. N., Shevchenko, A., Shevchenko, A., Pallas, D. C. \& Berk, A. J. Analysis of the adenovirus $\mathrm{E} 1 \mathrm{~B}-55 \mathrm{~K}$-anchored proteome reveals its link to ubiquitination machinery. J Virol 76, 9194-9206 (2002).

1165

10 Babiss, L. E. \& Ginsberg, H. S. Adenovirus type 5 early region $1 b$ gene product is required for efficient shutoff of host protein synthesis. J Virol 50, 202-212 (1984).

1166

11 Babiss, L. E., Ginsberg, H. S. \& Darnell, J. E., Jr. Adenovirus E1B proteins are required for accumulation of late viral mRNA and for effects on cellular mRNA

1167

1168

1169 translation and transport. Mol Cell Biol 5, 2552-2558 (1985).

1170

12 Halbert, D. N., Cutt, J. R. \& Shenk, T. Adenovirus early region 4 encodes functions required for efficient DNA replication, late gene expression, and host cell shutoff.

1171

1172 $J$ Virol 56, 250-257 (1985).

1173

1174

1175

1176

1177

1178

1179

1180

1181

1182

1183

Pilder, S., Moore, M., Logan, J. \& Shenk, T. The adenovirus E1B-55K transforming polypeptide modulates transport or cytoplasmic stabilization of viral and host cell mRNAs. Mol Cell Biol 6, 470-476 (1986).

14 Bridge, E. \& Ketner, G. Redundant control of adenovirus late gene expression by early region 4. J Virol 63, 631-638 (1989).

15 Bridge, E. \& Ketner, G. Interaction of adenoviral E4 and E1b products in late gene expression. Virology 174, 345-353 (1990).

16 Sandler, A. B. \& Ketner, G. Adenovirus early region 4 is essential for normal stability of late nuclear RNAs. J Virol 63, 624-630 (1989).

17 Woo, J. L. \& Berk, A. J. Adenovirus ubiquitin-protein ligase stimulates viral late mRNA nuclear export. J Virol 81, 575-587 (2007).

18 Blanchette, P. et al. Control of mRNA export by adenovirus E4orf6 and E1B55K proteins during productive infection requires E4orf6 ubiquitin ligase activity. $J$ Virol 82, 2642-2651 (2008). 
Herrmann et al.

118619 Querido, E. et al. Regulation of p53 levels by the E1B 55-kilodalton protein and E4orf6 in adenovirus-infected cells. J Virol 71, 3788-3798 (1997).

20 Stracker, T. H., Carson, C. T. \& Weitzman, M. D. Adenovirus oncoproteins inactivate the Mre11-Rad50-NBS1 DNA repair complex. Nature 418, 348-352 (2002).

1190

1191

21 Baker, A., Rohleder, K. J., Hanakahi, L. A. \& Ketner, G. Adenovirus E4 34k and E1b 55k oncoproteins target host DNA ligase IV for proteasomal degradation. J Virol 81, 7034-7040 (2007).

1194

22 Dallaire, F., Blanchette, P., Groitl, P., Dobner, T. \& Branton, P. E. Identification of integrin alpha3 as a new substrate of the adenovirus E4orf6/E1B 55-kilodalton E3 ubiquitin ligase complex. J Virol 83, 5329-5338 (2009).

1195

1196

1197

23 Orazio, N. I., Naeger, C. M., Karlseder, J. \& Weitzman, M. D. The adenovirus E1b55K/E4orf6 complex induces degradation of the Bloom helicase during infection. J Virol 85, 1887-1892 (2011).

1200

24 Cathomen, T. \& Weitzman, M. D. A functional complex of adenovirus proteins E1B$55 \mathrm{kDa}$ and E4orf6 is necessary to modulate the expression level of p53 but not its transcriptional activity. J Virol 74, 11407-11412 (2000).

1202

1203

25 Carson, C. T. et al. The Mre11 complex is required for ATM activation and the G2/M checkpoint. Embo j 22, 6610-6620 (2003).

1204

1205

26 Schwartz, R. A. et al. Distinct requirements of adenovirus E1b55K protein for degradation of cellular substrates. J Virol 82, 9043-9055 (2008).

1207

$27 \mathrm{Xu}, \mathrm{G}$., Paige, J. S. \& Jaffrey, S. R. Global analysis of lysine ubiquitination by ubiquitin remnant immunoaffinity profiling. Nature biotechnology 28, 868-873 (2010).

1209

1210

28 Udeshi, N. D., Mertins, P., Svinkina, T. \& Carr, S. A. Large-scale identification of ubiquitination sites by mass spectrometry. Nat Protoc 8, 1950-1960 (2013).

1212 Soucy, T. A. et al. An inhibitor of NEDD8-activating enzyme as a new approach to treat cancer. Nature 458, 732-736 (2009).

1214

30 Hori, T. et al. Covalent modification of all members of human cullin family proteins

1215 by NEDD8. Oncogene 18, 6829-6834 (1999).

1216

31 Schwechheimer, C. NEDD8-its role in the regulation of Cullin-RING ligases. Curr Opin Plant Biol 45, 112-119 (2018).

1217

1218

Zhou, P. \& Howley, P. M. Ubiquitination and degradation of the substrate recognition subunits of SCF ubiquitin-protein ligases. Mol Cell 2, 571-580 (1998). Tudek, A., Schmid, M. \& Jensen, T. H. Escaping nuclear decay: the significance of mRNA export for gene expression. Curr Genet 65, 473-476 (2019).

1223

1224

1225

1226

1227

1228

1229

36 Fabregat, A. et al. The Reactome Pathway Knowledgebase. Nucleic Acids Res 46, Stewart, M. Polyadenylation and nuclear export of mRNAs. The Journal of biological chemistry 294, 2977-2987 (2019).

35 Marcellus, R. C., Teodoro, J. G., Charbonneau, R., Shore, G. C. \& Branton, P. E. Expression of p53 in Saos-2 osteosarcoma cells induces apoptosis which can be inhibited by Bcl-2 or the adenovirus E1B-55 kDa protein. Cell Growth Differ 7, 1643-1650 (1996).

1230 D649-D655 (2018).

37 www.proteinatlas.org. 
Herrmann et al.

$123138 \quad$ Konig, J. et al. iCLIP reveals the function of hnRNP particles in splicing at individual nucleotide resolution. Nat Struct Mol Biol 17, 909-915 (2010).

39 McCloskey, A., Taniguchi, I., Shinmyozu, K. \& Ohno, M. hnRNP C tetramer measures RNA length to classify RNA polymerase II transcripts for export. Science 335, 1643-1646 (2012).

1235

1236

40 Zarnack, K. et al. Direct competition between hnRNP C and U2AF65 protects the transcriptome from the exonization of Alu elements. Cell 152, 453-466 (2013).

1237

1238

41 Cornella, N. et al. The hnRNP RALY regulates transcription and cell proliferation by modulating the expression of specific factors including the proliferation marker E2F1. The Journal of biological chemistry 292, 19674-19692 (2017).

1242

42 Rossi, A. et al. Identification and dynamic changes of RNAs isolated from RALYcontaining ribonucleoprotein complexes. Nucleic Acids Res 45, 6775-6792 (2017).

1243 Bondy-Chorney, E. et al. RNA binding protein RALY promotes Protein Arginine Methyltransferase 1 alternatively spliced isoform v2 relative expression and metastatic potential in breast cancer cells. Int J Biochem Cell Biol 91, 124-135 (2017).

44 van Eekelen, C. et al. Sequence dependent interaction of hnRNP proteins with late adenoviral transcripts. Nucleic Acids Res 10, 7115-7131 (1982).

45 Tenzer, S. et al. Proteome-wide characterization of the RNA-binding protein RALYinteractome using the in vivo-biotinylation-pulldown-quant (iBioPQ) approach. $J$ Proteome Res 12, 2869-2884 (2013).

46 Graham, F. L., Smiley, J., Russell, W. C. \& Nairn, R. Characteristics of a human cell line transformed by DNA from human adenovirus type 5 . The Journal of general virology 36, 59-74 (1977).

47 Mevissen, T. E. T. \& Komander, D. Mechanisms of Deubiquitinase Specificity and Regulation. Annu Rev Biochem 86, 159-192 (2017).

1257

48 Chahal, J. S. \& Flint, S. J. Timely synthesis of the adenovirus type 5 E1B 55kilodalton protein is required for efficient genome replication in normal human cells. $J$ Virol 86, 3064-3072 (2012).

1261

1262

1263

1264

1265

1266

1267

1268

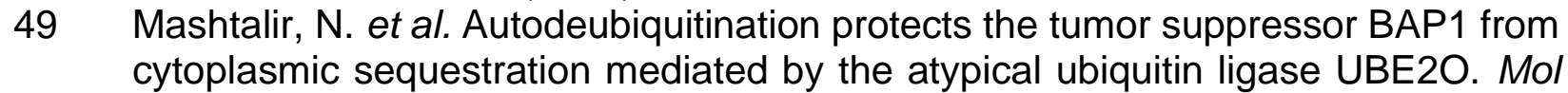
Cell 54, 392-406 (2014).

50 Bridge, E. \& Pettersson, U. Nuclear organization of adenovirus RNA biogenesis. Exp Cell Res 229, 233-239 (1996).

51 Pombo, A., Ferreira, J., Bridge, E. \& Carmo-Fonseca, M. Adenovirus replication and transcription sites are spatially separated in the nucleus of infected cells. EMBO J 13, 5075-5085 (1994).

52 Huang, M. et al. The C-protein tetramer binds 230 to 240 nucleotides of pre-mRNA and nucleates the assembly of $40 \mathrm{~S}$ heterogeneous nuclear ribonucleoprotein particles. Mol Cell Biol 14, 518-533 (1994).

$53 \mathrm{He}, \mathrm{C}$. et al. High-Resolution Mapping of RNA-Binding Regions in the Nuclear Proteome of Embryonic Stem Cells. Mol Cell 64, 416-430 (2016).

54 Zhang, Q. et al. RNA exploits an exposed regulatory site to inhibit the enzymatic activity of PRC2. Nat Struct Mol Biol 26, 237-247 (2019). 
Herrmann et al.

127555 Ong, S. E. et al. Stable isotope labeling by amino acids in cell culture, SILAC, as a simple and accurate approach to expression proteomics. Mol Cell Proteomics 1, 376-386 (2002).

56 Gorlach, M., Burd, C. G. \& Dreyfuss, G. The determinants of RNA-binding specificity of the heterogeneous nuclear ribonucleoprotein $\mathrm{C}$ proteins. The Journal of biological chemistry 269, 23074-23078 (1994).

1281

57 Van Nostrand, E. L. et al. A Large-Scale Binding and Functional Map of Human

1282

1283 RNA Binding Proteins. bioRxiv, 179648 (2018).

1284

1285

1286 Van Nostrand, E. L. et al. Robust transcriptome-wide discovery of RNA-binding protein binding sites with enhanced CLIP (eCLIP). Nat Methods 13, 508-514 (2016).

59 Dallaire, F., Blanchette, P. \& Branton, P. E. A proteomic approach to identify candidate substrates of human adenovirus E4orf6-E1B55K and other viral cullinbased E3 ubiquitin ligases. J Viro/ 83, 12172-12184 (2009).

transcript and protein identification. Nat Methods 9, 1207-1211 (2012).

$61 \mathrm{Fu}, \mathrm{Y}$. R. et al. Comparison of protein expression during wild-type, and E1B-55kdeletion, adenovirus infection using quantitative time-course proteomics. The Journal of general virology 98, 1377-1388 (2017).

62 Hung, G. \& Flint, S. J. Normal human cell proteins that interact with the adenovirus type 5 E1B 55kDa protein. Virology 504, 12-24 (2017).

63 Cheng, C. Y. et al. The E4orf6/E1B55K E3 ubiquitin ligase complexes of human adenoviruses exhibit heterogeneity in composition and substrate specificity. $J$ Virol 85, 765-775 (2011).

1319

65 Vassileva, M. T. \& Matunis, M. J. SUMO modification of heterogeneous nuclear ribonucleoproteins. Mol Cell Biol 24, 3623-3632 (2004).

66 Chanarat, S. \& Mishra, S. K. Emerging Roles of Ubiquitin-like Proteins in PremRNA Splicing. Trends Biochem Sci 43, 896-907 (2018).

67 Chan, C. H. et al. The Skp2-SCF E3 ligase regulates Akt ubiquitination, glycolysis, herceptin sensitivity, and tumorigenesis. Cell 149, 1098-1111 (2012).

68 Lee, S. W. et al. Skp2-dependent ubiquitination and activation of LKB1 is essential for cancer cell survival under energy stress. Mol Cell 57, 1022-1033 (2015).

69 Zhang, Q. et al. FBXW7 Facilitates Nonhomologous End-Joining via K63-Linked Polyubiquitylation of XRCC4. Mol Cell 61, 419-433 (2016).

70 Bischoff, J. R. et al. An adenovirus mutant that replicates selectively in p53deficient human tumor cells. Science 274, 373-376 (1996).

71 Goodrum, F. D. \& Ornelles, D. A. p53 status does not determine outcome of E1B 55-kilodalton mutant adenovirus lytic infection. J Virol 72, 9479-9490 (1998).

72 O'Shea, C. C. et al. Late viral RNA export, rather than p53 inactivation, determines ONYX-015 tumor selectivity. Cancer Cell 6, 611-623 (2004).

73 Khandelia, P., Yap, K. \& Makeyev, E. V. Streamlined platform for short hairpin RNA interference and transgenesis in cultured mammalian cells. Proceedings of 
Herrmann et al.

the National Academy of Sciences of the United States of America 108, 1279912804 (2011).

74 Grifman, M. et al. Overexpression of cyclin A inhibits augmentation of recombinant adeno-associated virus transduction by the adenovirus E4orf6 protein. $J$ Virol 73, 10010-10019 (1999).

75 Sobhian, B. et al. RAP80 targets BRCA1 to specific ubiquitin structures at DNA damage sites. Science 316, 1198-1202 (2007).

76 Kozarsky, K. F., Jooss, K., Donahee, M., Strauss, J. F., 3rd \& Wilson, J. M. Effective treatment of familial hypercholesterolaemia in the mouse model using adenovirus-mediated transfer of the VLDL receptor gene. Nat Genet 13, 54-62 (1996).

77 Komatsu, T., Dacheux, D., Kreppel, F., Nagata, K. \& Wodrich, H. A Method for Visualization of Incoming Adenovirus Chromatin Complexes in Fixed and Living Cells. PLoS One 10, e0137102 (2015).

78 Reich, N. C., Sarnow, P., Duprey, E. \& Levine, A. J. Monoclonal antibodies which recognize native and denatured forms of the adenovirus DNA-binding protein. Virology 128, 480-484 (1983).

79 Sarnow, P., Sullivan, C. A. \& Levine, A. J. A monoclonal antibody detecting the adenovirus type 5-E1b-58Kd tumor antigen: characterization of the E1b-58Kd tumor antigen in adenovirus-infected and -transformed cells. Virology 120, 510517 (1982).

80 Marton, M. J., Baim, S. B., Ornelles, D. A. \& Shenk, T. The adenovirus E4 17kilodalton protein complexes with the cellular transcription factor $\mathrm{E} 2 \mathrm{~F}$, altering its DNA-binding properties and stimulating E1A-independent accumulation of E2 mRNA. J Virol 64, 2345-2359 (1990).

81 Raj, A., van den Bogaard, P., Rifkin, S. A., van Oudenaarden, A. \& Tyagi, S. Imaging individual mRNA molecules using multiple singly labeled probes. Nat Methods 5, 877-879 (2008).

82 Shaffer, S. M. et al. Rare cell variability and drug-induced reprogramming as a mode of cancer drug resistance. Nature 546, 431-435 (2017).

83 Poling, B. C., Price, A. M., Luftig, M. A. \& Cullen, B. R. The Epstein-Barr virus miRBHRF1 microRNAs regulate viral gene expression in cis. Virology 512, 113-123 (2017).

84 Russo, J., Heck, A. M., Wilusz, J. \& Wilusz, C. J. Metabolic labeling and recovery of nascent RNA to accurately quantify mRNA stability. Methods 120, 39-48 (2017).

85 Price, A. M., Messinger, J. E. \& Luftig, M. A. c-Myc Represses Transcription of Epstein-Barr Virus Latent Membrane Protein 1 Early after Primary B Cell Infection. $J$ Virol 92 (2018).

86 Dolken, L. et al. High-resolution gene expression profiling for simultaneous kinetic parameter analysis of RNA synthesis and decay. RNA 14, 1959-1972 (2008).

87 Van Nostrand, E. L. et al. Robust, Cost-Effective Profiling of RNA Binding Protein Targets with Single-end Enhanced Crosslinking and Immunoprecipitation (seCLIP). Methods Mol Biol 1648, 177-200 (2017).

88 Martin, M. Cutadapt removes adapter sequences from high-throughput sequencing reads. 201117,3 (2011). 
Herrmann et al.

136589 Smith, T., Heger, A. \& Sudbery, I. UMI-tools: modeling sequencing errors in Unique Molecular Identifiers to improve quantification accuracy. Genome Res 27, 491-499 (2017).

$90 \mathrm{Wu}, \mathrm{T}$. D. \& Nacu, S. Fast and SNP-tolerant detection of complex variants and splicing in short reads. Bioinformatics 26, 873-881 (2010).

91 Lovci, M. T. et al. Rbfox proteins regulate alternative mRNA splicing through evolutionarily conserved RNA bridges. Nat Struct Mol Biol 20, 1434-1442 (2013). Heinz, S. et al. Simple combinations of lineage-determining transcription factors prime cis-regulatory elements required for macrophage and $\mathrm{B}$ cell identities. $\mathrm{Mol}$ Cell 38, 576-589 (2010).

93 Schwanhausser, B. et al. Global quantification of mammalian gene expression control. Nature 473, 337-342 (2011).

94 Shannon, P. et al. Cytoscape: a software environment for integrated models of biomolecular interaction networks. Genome Res 13, 2498-2504 (2003).

95 Jedrychowski, M. P. et al. Evaluation of HCD- and CID-type Fragmentation Within Their Respective Detection Platforms For Murine Phosphoproteomics. Molecular \&amp; Cellular Proteomics 10, M111.009910 (2011).

96 Consortium, T. U. UniProt: a worldwide hub of protein knowledge. Nucleic Acids Research 47, D506-D515 (2018).

97 The, M., MacCoss, M. J., Noble, W. S. \& Kall, L. Fast and Accurate Protein False Discovery Rates on Large-Scale Proteomics Data Sets with Percolator 3.0. J Am Soc Mass Spectrom 27, 1719-1727 (2016).

98 Wei, T. \& Simko, V. R package "corrplot": Visualization of a Correlation Matrix (Version 0.84). Available from https://github.com/taiyun/corrplot (2017). expression and hybridization array data repository. Nucleic Acids Res 30, 207-210 (2002). 
a

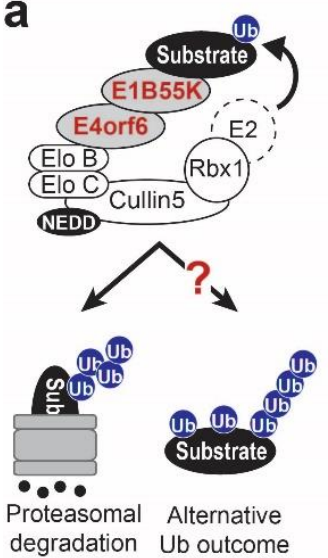

b

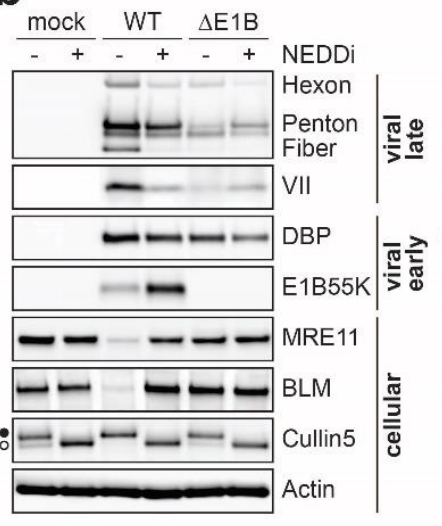

C

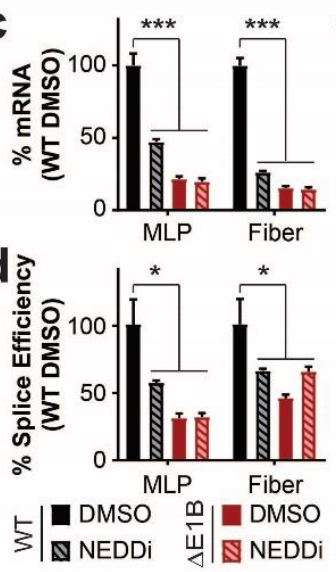

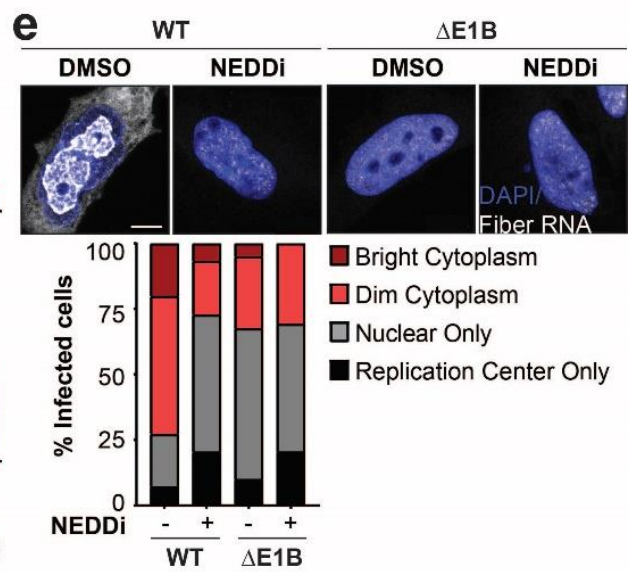

Figure 1 | E1B55K deletion or inhibition of Cullin-mediated ubiquitination decreases adenovirus late RNA splicing and RNA processing overall. a, The E1B55K/E4orf6 complex redirects substrate recognition of the host Cullin5 ubiquitin ligase to target proteins for proteasomal degradation or induce alternative outcomes of ubiquitination. b-e, HeLa cells infected with wildtype (WT) or E1B55K-deleted ( $\triangle \mathrm{E} 1 \mathrm{~B})$ Ad5 at multiplicity of infection $(\mathrm{MOI})$ of 10. Cells were treated with either DMSO or NEDDi (neddylation inhibitor MLN4924) at 8 hours post-infection (hpi) and assayed at $24 \mathrm{hpi} . \mathbf{b}$, Immunoblot analysis of viral and cellular protein abundance. The neddylated $(\bullet)$ and unmodified $(\circ)$ forms of Cullin5 are indicated. Results are representative of three biological experiments. c, Bar graph representing spliced RNA levels of viral late transcripts for the major late promoter (MLP) and fiber by quantitative reverse transcription PCR (RT-qPCR). Shown is mean+s.d., $n$ equals three biological experiments. d, Bar graph representing splicing efficiency as the ratio of spliced to unspliced transcripts of MLP and fiber relative to the WT DMSO control by RT-qPCR. Shown is mean+s.d., $n$ equals three biological experiments. e, RNA FISH visualizing the localization of fiber transcripts (white) in relation to nuclear DNA stained with DAPI (blue) and quantification of observed pattern for $>50 \mathrm{HeLa}$ cells. Scale bar $10 \mu \mathrm{m}$. Statistical significance was calculated using an unpaired, two-tailed Student's t-test, ${ }^{*} p<0.05,{ }^{* * *} p<0.005$. 


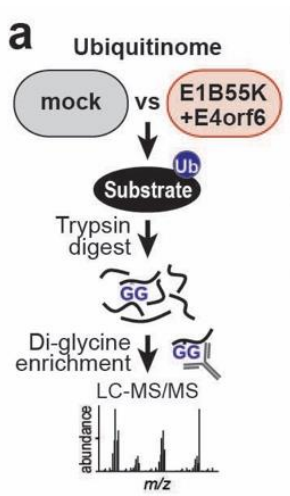

Whole cell proteome

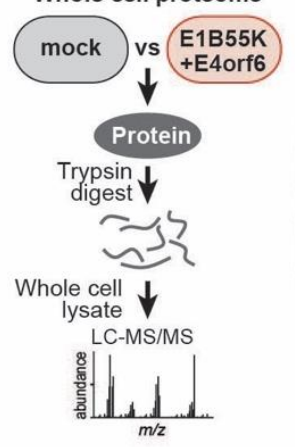

g

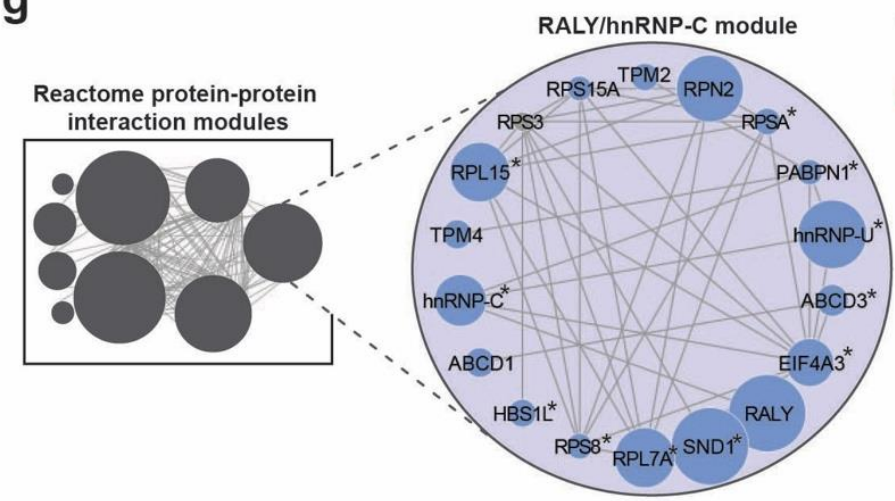

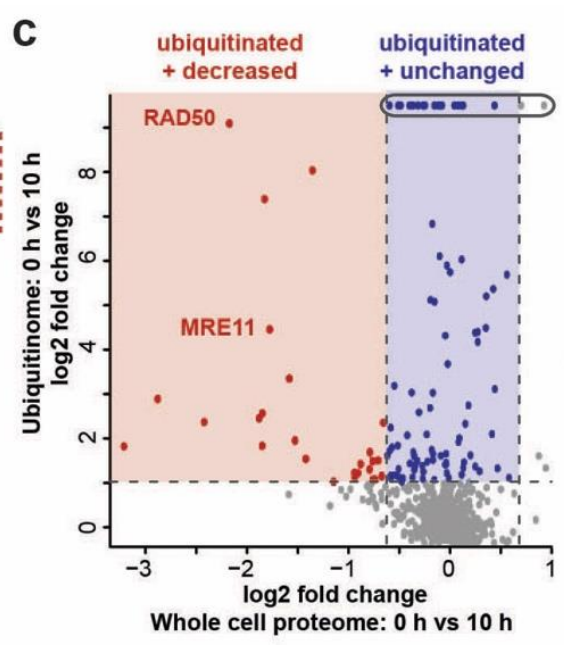

e

e Go-Term analysis: Molecular Function

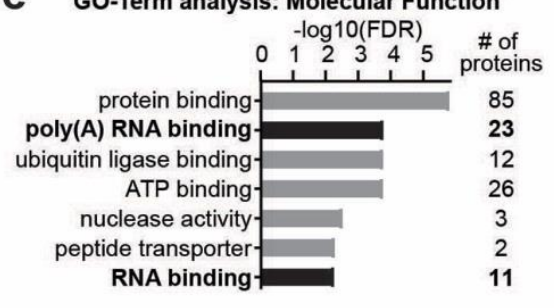

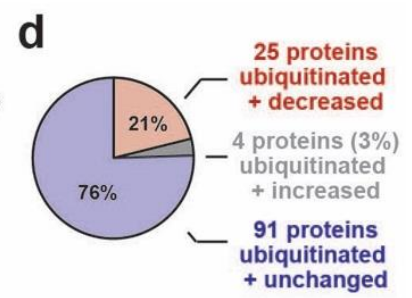

f No Ub detected at $0 \mathrm{~h}$

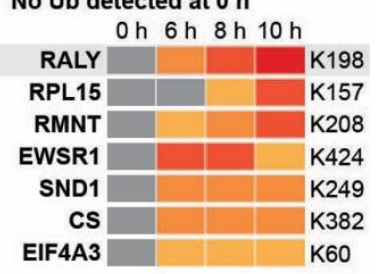

Ub detected at $\mathbf{O} \mathrm{h}$
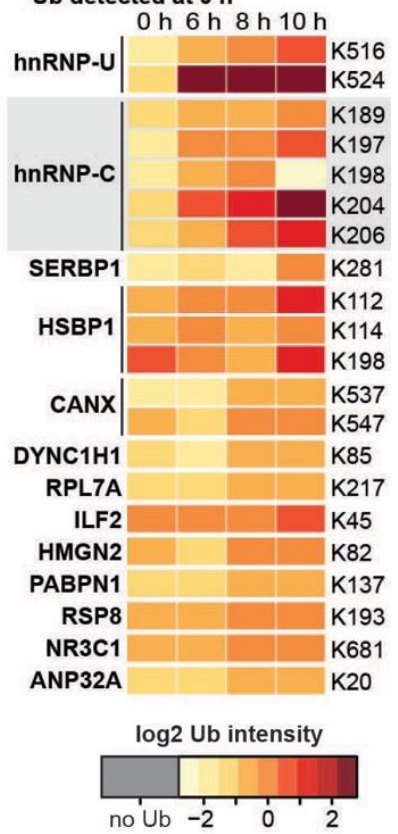

Figure 2 | Unbiased proteomics reveals RNA-binding proteins among putative non-degraded substrates of the Ad E1B55K/E4orf6 complex. a, Proteomics workflow for identification of E1B55K/E4orf6 substrates. HeLa cells were transduced with recombinant Ad vectors expressing E1B55K and E4orf6 $(\mathrm{MOI}=10)$, and subjected to both di-glycine remnant profiling $(\mathrm{K}-\varepsilon$ GG) to identify ubiquitinated lysine residues and whole cell proteomics to determine protein abundance. $\mathbf{b}$, Volcano plots showing log2 fold-changes between $0 \mathrm{~h}$ and $10 \mathrm{~h}$ for ubiquitination (above) and protein abundance (below). For ubiquitination, individual peptides containing the modified lysine residues are normalized to protein abundance. Peptides and proteins with a fold change $> \pm$ s.e.m. and p-value $<0.05$ are considered significantly changed and highlighted in dark grey. Ubiquitinated peptides and proteins corresponding to known E1B55K/E4orf6 substrates are highlighted in red. $\mathrm{n}$ equals three biological replicates. c, Scatter plot integrating changes in protein abundance (X-axis) and ubiquitination (Y-axis). Putative degraded substrates are shown in red (increased ubiquitination, decreased protein abundance), putative non-degraded substrates are shown in blue (increased ubiquitination, no significant change in protein abundance). Known degraded substrates MRE11 and RAD50 are indicated. Blue dots circled at the top indicate proteins that were only ubiquitinated upon expression of E1B55K/E4orf6 and were not detected as ubiquitinated in mock conditions. d, Bar graph representing gene ontology (GO) analysis of all predicted substrates by molecular functions. Categories containing RNA-binding proteins are highlighted. e, Predicted substrates that either decrease (red), increase (grey) or remain unchanged (blue) in their protein abundance during expression of E1B55K/E4orf6. f, Heat map of all ubiquitinated lysine residues within RNA-binding proteins with a normalized log2 abundance z-score $>-0.5$ and maximum log2 fold-change $>1$ over the time course of E1B55K/E4orf6 transduction. The colors in the heat map correspond to the average $z$-score of the ubiquitination and are indicated in the accompanying scale. Highly ubiquitinated proteins RALY and hnRNP-C are highlighted. g, The Reactome-FI application in Cytoscape was utilized to generate a protein-protein interaction network in which nodes represent proteins and edges represent Reactome-based protein-protein interactions. Shown is the single module containing RALY and hnRNP-C. Node size corresponds to relative protein-based ubiquitination log2 fold change and node color corresponds to whole cell proteome log2 fold change following $10 \mathrm{~h}$ transduction of E1B55K/E4orf6. * denotes proteins that have a reported role during different viral infections. 
a RALY and hnRNP-C structure

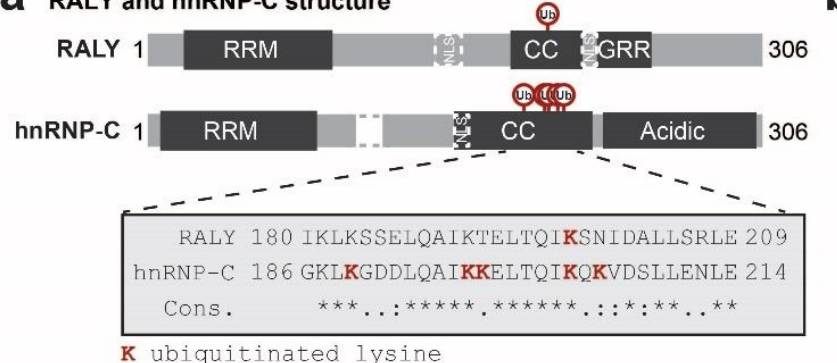

b

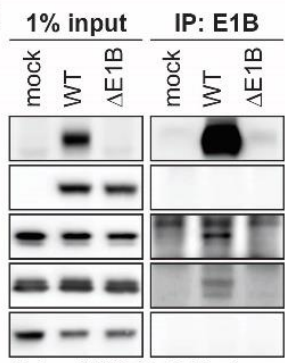

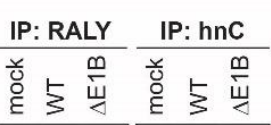

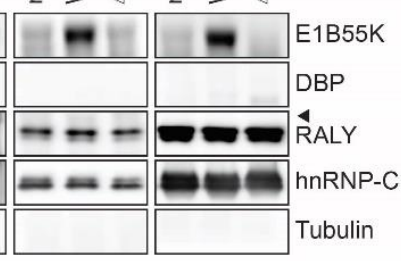

HeLa, MOI 10, 24 hpi

C
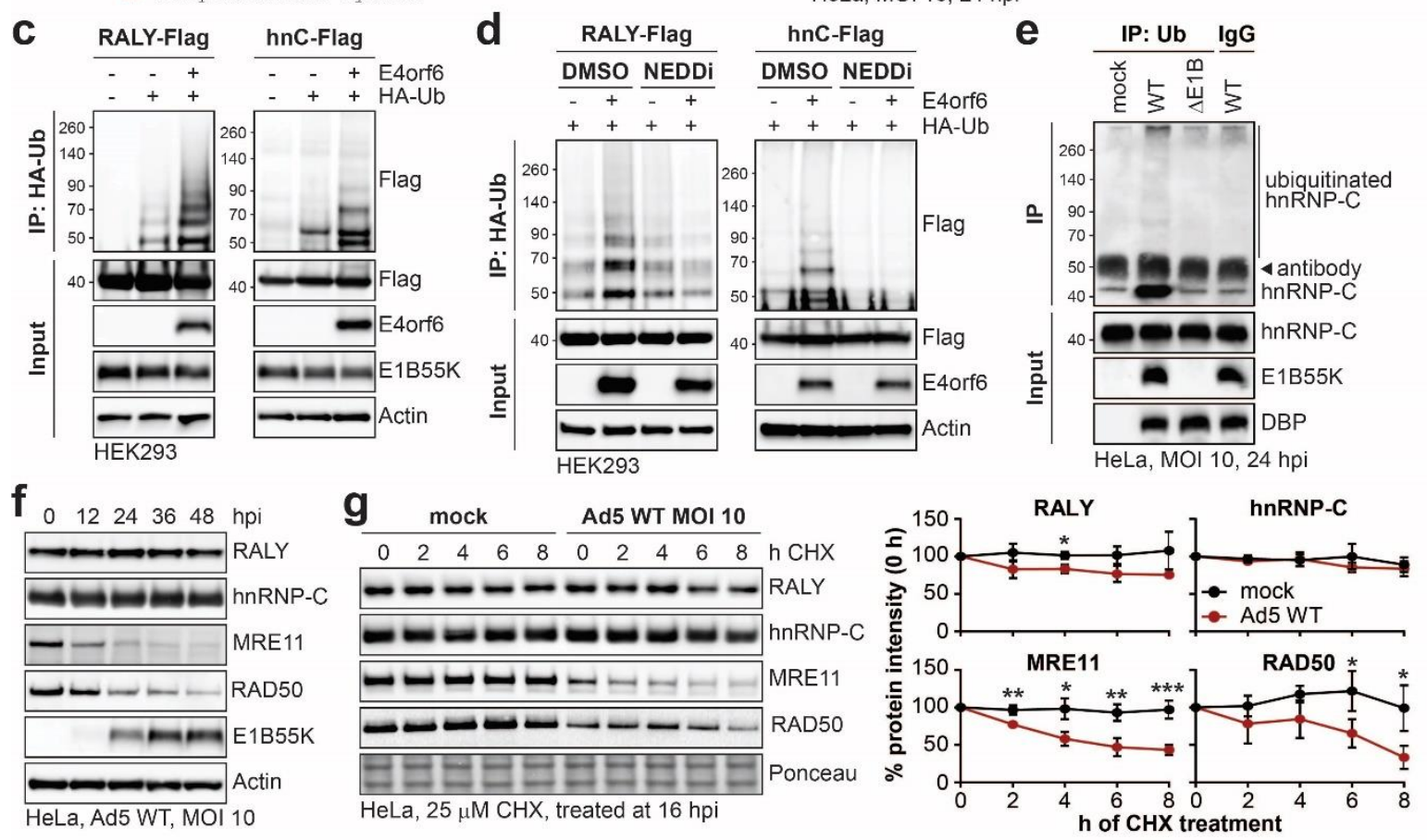

h

a, Ad5 WT, MOI 10

HeLa, $25 \mu \mathrm{M} \mathrm{CHX}$, treated at $16 \mathrm{hpi}$

i
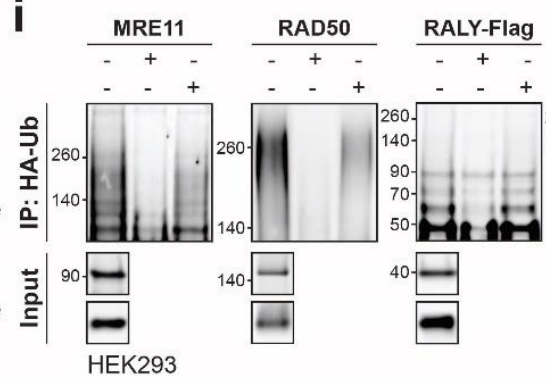

$\frac{\text { hnC-Flag }}{-+-}$ DUBPAN DMSO MG132 $\frac{\text { DMSO MG132 }}{-++\frac{1}{-++}}$

DMSO MG132
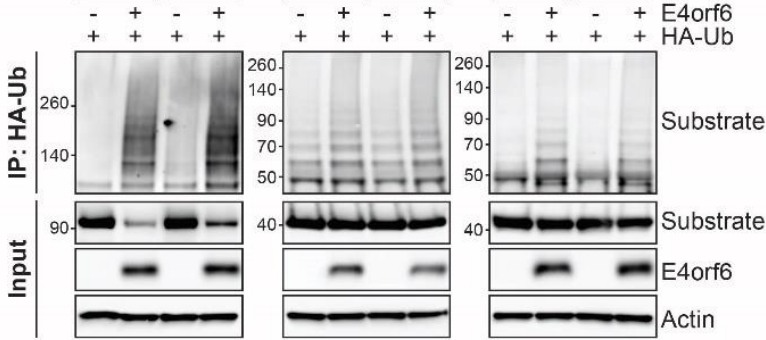

HEK293, $20 \mu \mathrm{M}$ MG132, treated $3 \mathrm{~h}$ prior to harvest

Figure 3 | RALY and hnRNP-C are non-degraded substrates of the Ad E1B55K/E4orf6 complex ubiquitin ligase activity. a, Domain structure of RALY and hnRNP-C. RRM = RNA recognition motif, NLS = nuclear localization sequence, $C C=$ coiled-coil region, $\mathrm{GRR}=$ glycine rich region. $C \mathrm{C}$ region shown below contains all the lysine residues with increased ubiquitination upon E1B55K/E4orf6 expression highlighted in red. b, Immunoblot analysis of E1B55K, RALY, and hnRNP-C immunoprecipitations (IP) probing for pull-down of viral and cellular proteins during mock, WT and $\triangle E 1 B$ infection of HeLa cells at MOI of 10 for $24 \mathrm{hpi}$. The viral protein DBP and cellular protein Tubulin served as negative controls and were not isolated with any condition. 4 denotes the signal of the antibody heavy chain. c, HEK293 cells transfected with the indicated constructs for $24 \mathrm{~h}$ followed by denaturing IP with HA antibody and immunoblot analysis of RALY-Flag or hnRNP-C-Flag. d, HEK293 cells transfected with the indicated constructs for $24 \mathrm{~h}$ and treated with DMSO or NEDDi $6 \mathrm{~h}$ prior to harvest followed by denaturing IP with HA antibody and immunoblot analysis of RALY-Flag or hnRNP-C-Flag. e, Immunoblot of denaturing hnRNP-C IP probing for ubiquitin during mock, WT and $\triangle \mathrm{E} 1 \mathrm{~B}$ infections at $\mathrm{MOI}$ of 10 for $24 \mathrm{~h}$. 4 indicates non-specific signal of the antibody heavy chain. $\mathbf{f}$, Immunoblot analysis of protein levels over a time course of Ad5 WT infection (MOI=10) of HeLa cells. $\mathbf{g}$, Immunoblot analysis and quantification of RALY, hnRNP-C, MRE11, and RAD50 over a time course of cycloheximide (CHX) treatment of mock or Ad5 WT infected HeLa cells. Quantification showing mean+s.d. of three biological replicates. Statistical significance was calculated using an unpaired, two-tailed Student's t-test, ${ }^{*} \mathrm{p}<0.05,{ }^{* *} \mathrm{p}<0.01,{ }^{* *} \mathrm{p}<0.005 . \mathbf{h}, \mathrm{HEK} 293$ cells transfected with the indicated constructs for $24 \mathrm{~h}$ 
bioRxiv preprint doi: https://doi.org/10.1101/2020.06.05.136671; this version posted June 5, 2020. The copyright holder for this preprint (which was not certified by peer review) is the author/funder. All rights reserved. No reuse allowed without permission.

and treated with DMSO or proteasome inhibitor MG132 $3 \mathrm{~h}$ prior to harvest followed by denaturing IP with HA antibody and immunoblot analysis of MRE11, RALY-Flag, and hnRNP-C-Flag. i, HEK293 cells transfected with the indicated constructs for 24 $\mathrm{h}$ followed by denaturing IP with HA antibody, treatment with the indicated deubiquitinating enzymes (DUBs) and immunoblot analysis of MRE11, RAD50, RALY-Flag, and hnRNP-C-Flag. All immunoblots are representative of at least three biological replicates. Size markers in $\mathrm{kDa}$ are shown for ubiquitination immunoblots. 

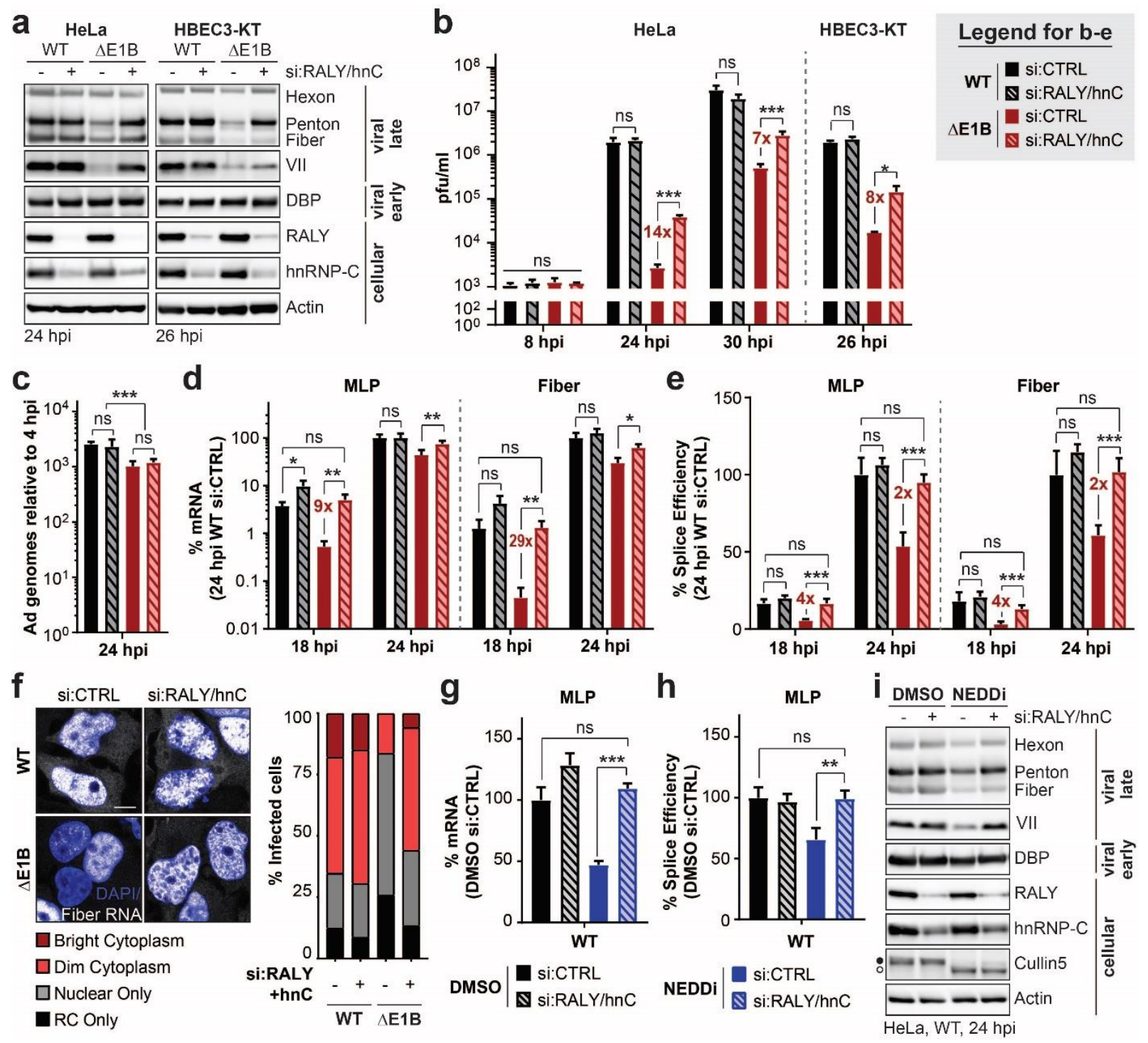

Figure 4 | Knockdown of RALY and hnRNP-C rescues the RNA processing defect caused by the absence of a functional E1B55K/E4orf6 complex. a-f, HeLa cells or HBEC3-KT (only a,b) transfected with control (si:CTRL) or RALY and hnRNP-C (si:RALY/hnC) siRNA $24 \mathrm{~h}$ prior to infection with Ad5 WT or $\triangle \mathrm{E} 1 \mathrm{~B}$ (MOI 10), harvested at respective time points. a, Immunoblot analysis of viral and cellular protein levels. b, Bar graph representing plaque assays for viral progeny. pfu = plaque forming units. c, Bar graph representing qPCR of viral genomes normalized to input. d, Bar graph representing spliced RNA levels of viral late transcripts MLP and fiber measured by RT-qPCR. e, Bar graph representing splicing efficiency as defined as the ratio of spliced to unspliced transcripts of MLP and fiber measured by RT-qPCR. f, RNA FISH visualizing the localization of fiber transcripts (white) in relation to nuclear DNA stained with DAPI (blue) and quantification of observed pattern for $>100 \mathrm{HeLa}$ cells. RC - replication center. Scale bar $10 \mu \mathrm{m}$. g-i. HeLa cells transfected with control (si:CTRL) or RALY and hnRNP-C (si:RALY/hnC) siRNA $24 \mathrm{~h}$ prior to infection with Ad5 WT (MOI=10), treated with either DMSO or NEDDi at 8 hpi and processed at 24 hpi. g, Bar graph representing spliced RNA levels of MLP measured by RT-qPCR. $\mathbf{h}$, Bar graph representing splicing efficiency as defined as the ratio of spliced to unspliced transcripts of MLP measured by RT-qPCR. i Immunoblot analysis of viral and cellular protein levels, with neddylated $(\bullet)$ and unmodified $(\circ)$ forms of Cullin5 indicated. All immunoblots are representative of at least three biological experiments. All graphs show the mean+s.d. with $n$ equals three biological replicates. Statistical significance was calculated using an unpaired, two-tailed Student's t-test, ${ }^{*} p<0.05,{ }^{* *} p<0.01,{ }^{* * *} p<0.005$. 
a

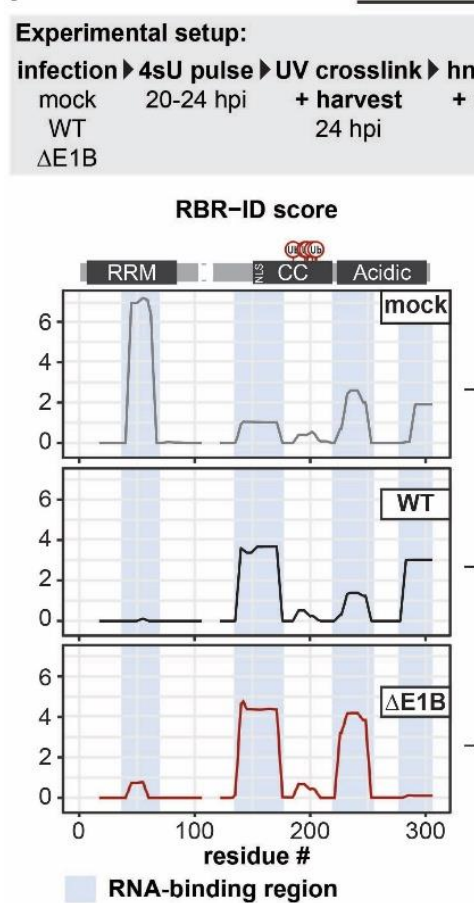

$\underline{\text { hnRNP-C RBR-ID }}$
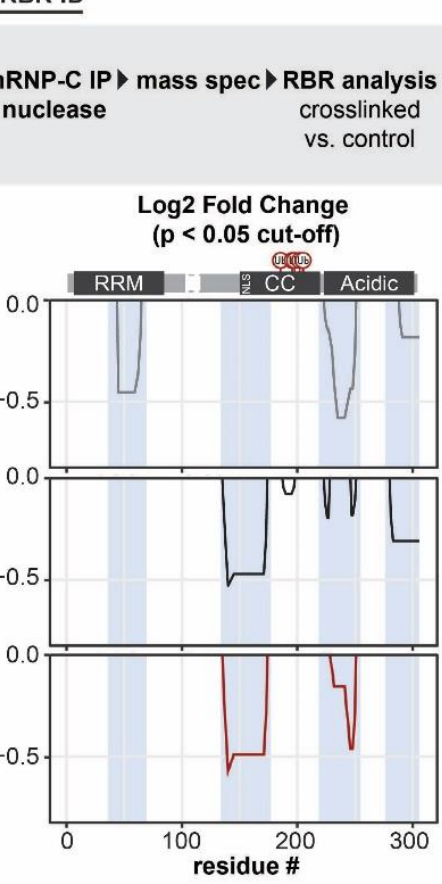

b
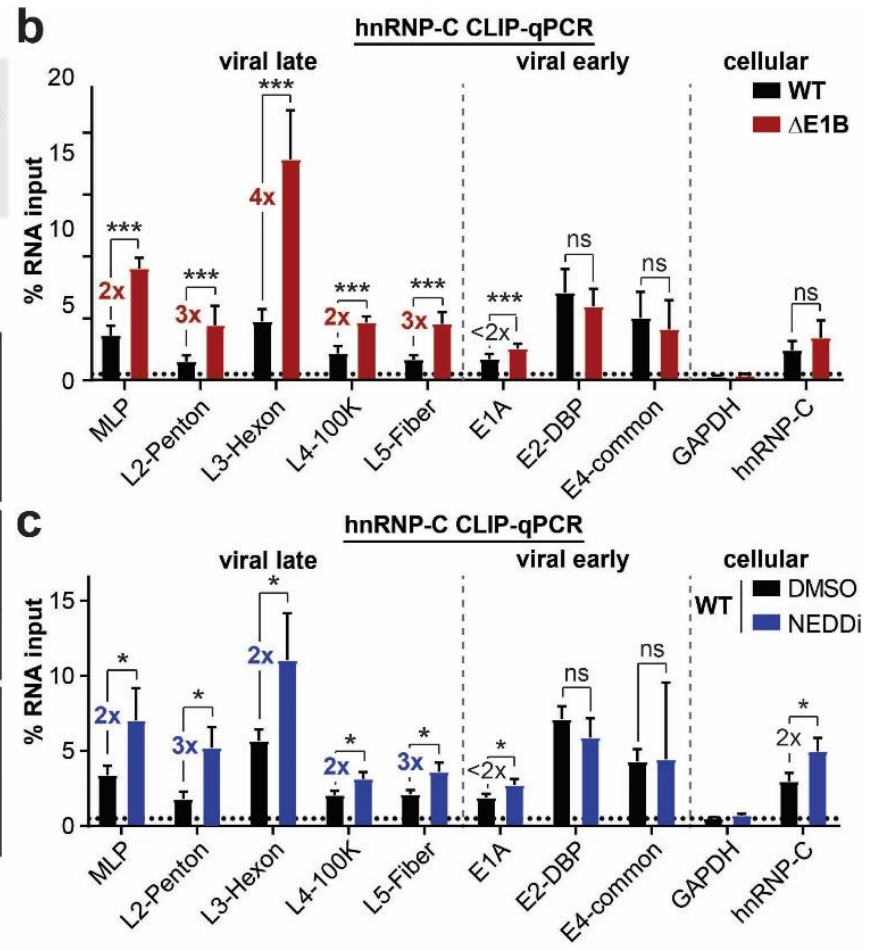

d hnRNP-C eCLIP-Seq $\mathbf{C}$ hnRNP-C cellular peaks
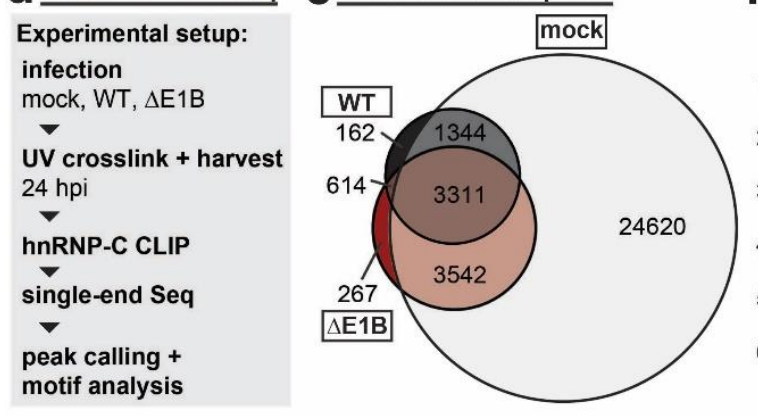

f hnRNP-C binding motifs cellular transcripts

\begin{tabular}{|c|c|c|c|c|c|}
\hline $\mathrm{m}$ & alue & Mock & -value & Virus only & P-value \\
\hline IIIIIITISA & 200 & GGGATTACAG & -1763 & CCAG & $1 e-30$ \\
\hline ACTCCAG & 1e-166 & C्ATGACCCTCC & e-1704 & CAGGTGGGAGTT & 1e-30 \\
\hline TCCCAGCCTGGA & |1e-164 & 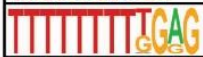 & e-1694 & GGTCTGGCCCTG & $1 e-22$ \\
\hline 4 CTCCCEAGTACG & $1 e-161$ & CAGTCCAGTGAT & -1504 & AGAGTCCCGT & 1e-20 \\
\hline 5 GAGTCTTCCTCT & $1 e-132$ & TCRTGGCCTCA & -1483 & GAGTACCTGGGA & \\
\hline CACETGGCTGG & $1 e-124$ & GTACCTGGGA & 1e-1251 & AGGGGCTGTGGG & $1 e-$ \\
\hline
\end{tabular}

\section{g hnRNP-C viral peaks}

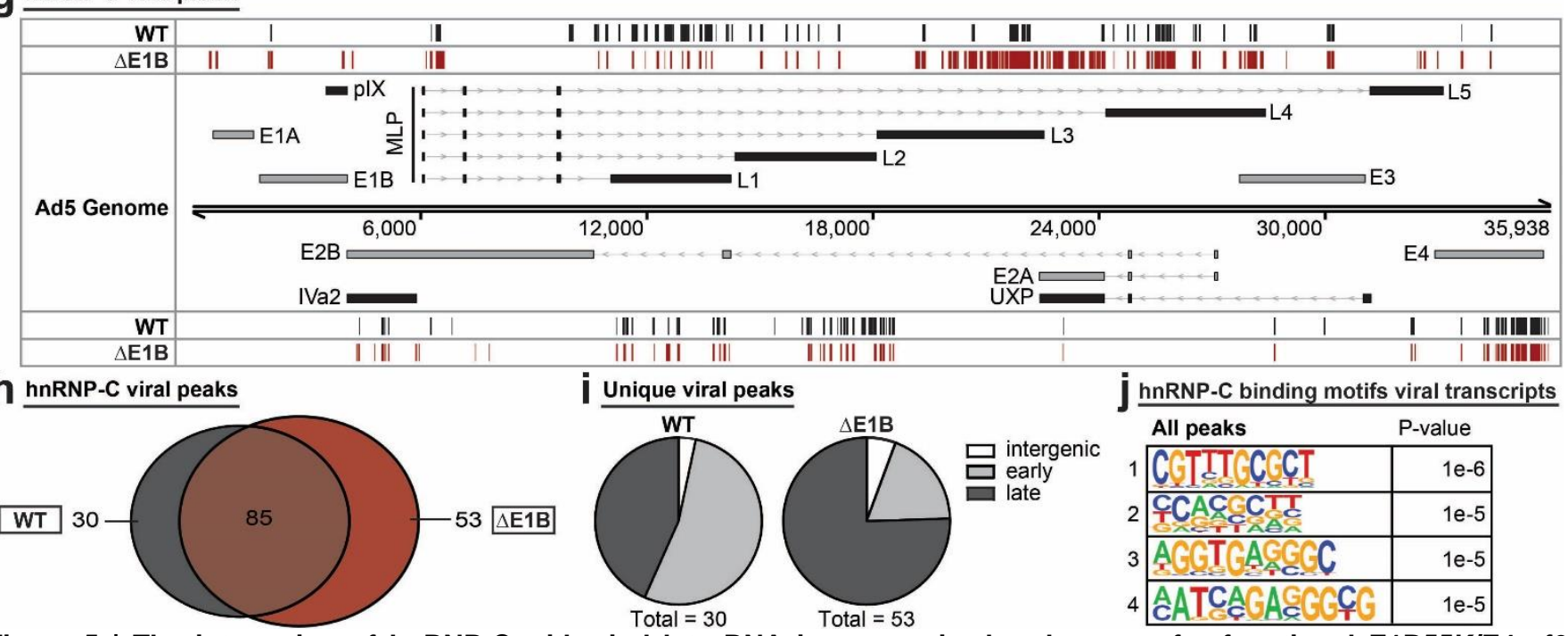

Figure 5 | The interaction of hnRNP-C with viral late RNA increases in the absence of a functional E1B55K/E4orf6 complex. a, RBR-ID (RNA-binding region identification) for hnRNP-C comparing mock (grey), Ad5 WT (black), and $\triangle \mathrm{E} 1 \mathrm{~B}$ (red) at $24 \mathrm{hpi}$ with MOI 10. Shown are the experimental setup (above), smoothed residue-level RBR-ID score plotted along the primary sequence (left), and smoothed residue-level fold-change between crosslinked and control conditions with a significance threshold of $p<0.05$ (right). hnRNP-C domain structure with ubiquitination sites is shown above graphs. RNA-binding regions are 
bioRxiv preprint doi: https://doi.org/10.1101/2020.06.05.136671; this version posted June 5, 2020. The copyright holder for this preprint (which was not certified by peer review) is the author/funder. All rights reserved. No reuse allowed without permission.

highlighted in blue shaded area. $\mathbf{b}$, HeLa cells infected with either WT Ad5 or $\triangle \mathrm{E} 1 \mathrm{~B}(\mathrm{MOI}=10)$, UV-crosslinked and harvested at $24 \mathrm{hpi}$, subjected to hnRNP-C CLIP and RT-qPCR for viral early and late transcripts. GAPDH is a cellular negative control. hnRNP$\mathrm{C}$ is a cellular positive control. c, HeLa cells infected with WT Ad5 (MOI=10), treated with either DMSO or NEDDi at 8 hpi, UVcrosslinked and harvested at $24 \mathrm{hpi}$, subjected to hnRNP-C CLIP and RT-qPCR for viral early and late transcripts. GAPDH is a cellular negative control. hnRNP-C is a cellular positive control. Graphs show mean+s.d, $n$ equals six (b) or three (c) biological replicates. Statistical significance was calculated using an unpaired, two-tailed Student's t-test, ${ }^{*} p<0.05$, ${ }^{* *} p<0.01$, ${ }^{* * *} p<$ 0.005. d, Experimental setup for hnRNP-C eCLIP-Seq. e, Venn diagram showing the overlap of hnRNP-C peaks called in host transcripts for mock (grey), Ad5 WT (black), and $\triangle \mathrm{E} 1 \mathrm{~B}$ (red). f, Top six motifs identified for hnRNP-C binding sites in host transcripts present in all 3 conditions (left), mock only (middle), and virus only (right, WT only $+\Delta \mathrm{E} 1 \mathrm{~B}$ only $+\mathrm{WT}$ and $\Delta \mathrm{E} 1 \mathrm{~B}$ ). $\mathbf{g}$, hnRNP-C peaks called for Ad transcripts in Ad5 WT (black) and $\triangle \mathrm{E} 1 \mathrm{~B}$ (red) infection on the forward strand (above) and reverse strand (below). The simplified schematic of the viral transcriptome shows forward facing transcription units above the genome and reverse facing transcription units below. Viral genes are color-coded to denote early (grey) and late (black) transcription units. Lines with arrows denote introns and bars are exonic regions. $\mathbf{h}$, Venn diagram showing the overlap of hnRNP-C peaks called in viral transcripts for Ad5 WT (black) and $\triangle \mathrm{E} 1 \mathrm{~B}$ (red). i. Pie charts of unique peaks for WT and $\Delta \mathrm{E} 1 \mathrm{~B}$ showing the location in intergenic, early, or late transcription units. j, Top four motifs identified for hnRNP-C binding sites in viral transcripts present in any of the conditions. 
bioRxiv preprint doi: https://doi.org/10.1101/2020.06.05.136671; this version posted June 5, 2020. The copyright holder for this preprint (which was not certified by peer review) is the author/funder. All rights reserved. No reuse allowed without permission.
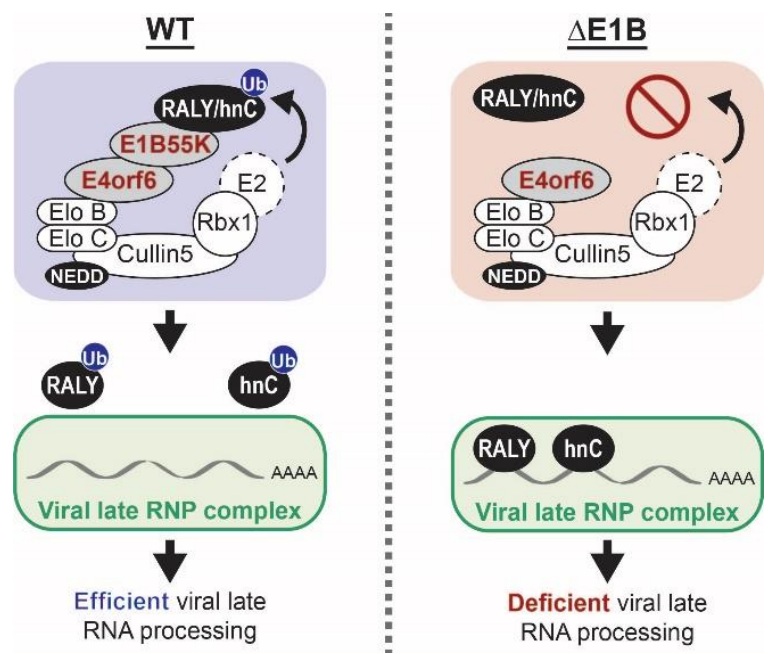

Figure 6 | Non-degradative ubiquitination of RNA-binding proteins promotes efficient adenoviral RNA processing. During wild-type (WT) Ad5 infection the E1B55K/E4orf6 complex induces ubiquitination of RNA-binding proteins RALY and hnRNP-C to facilitate efficient viral late RNA processing. Ubiquitination regulates interaction of these host proteins with viral RNA to facilitate viral infection. In the absence of the E1B55K/E4orf6 complex ubiquitin ligase activity, the RBPs bind more to viral late mRNAs and limit RNA processing and protein production. RNP - ribonucleoprotein. 


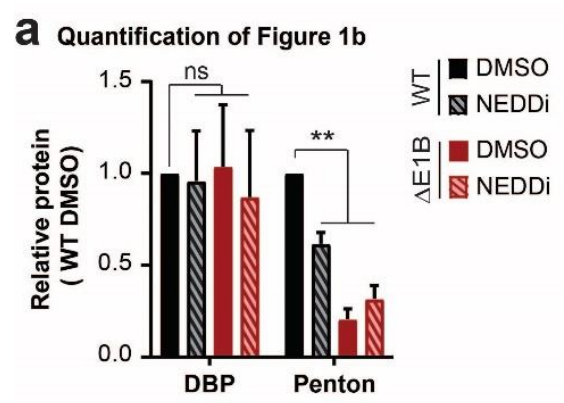

C RNA decay (by Actinomycin D treatment)

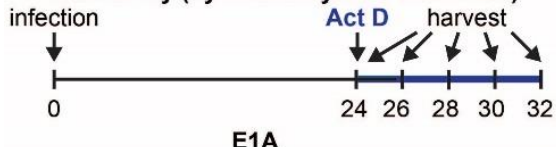

D Transcription rate and RNA half-life (by 4sU metabolic labeling)
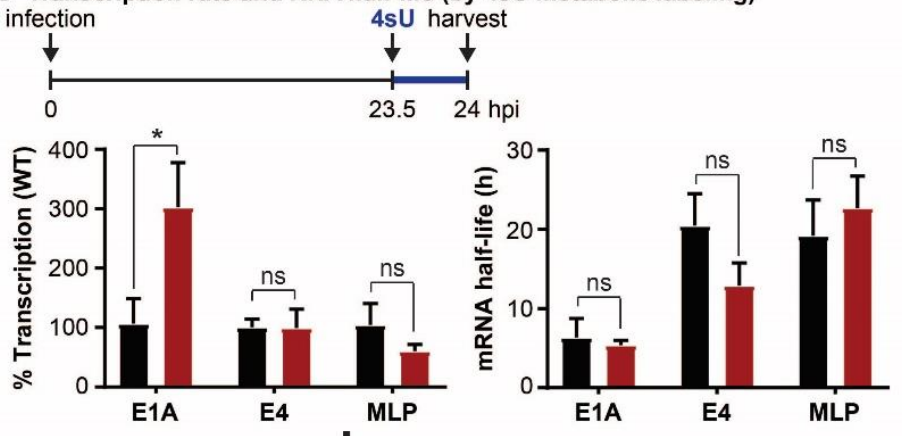

d

E1A pre-mRNA (Early):

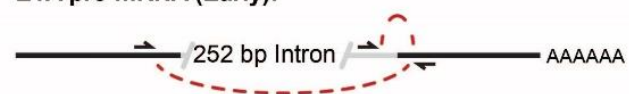

MLP

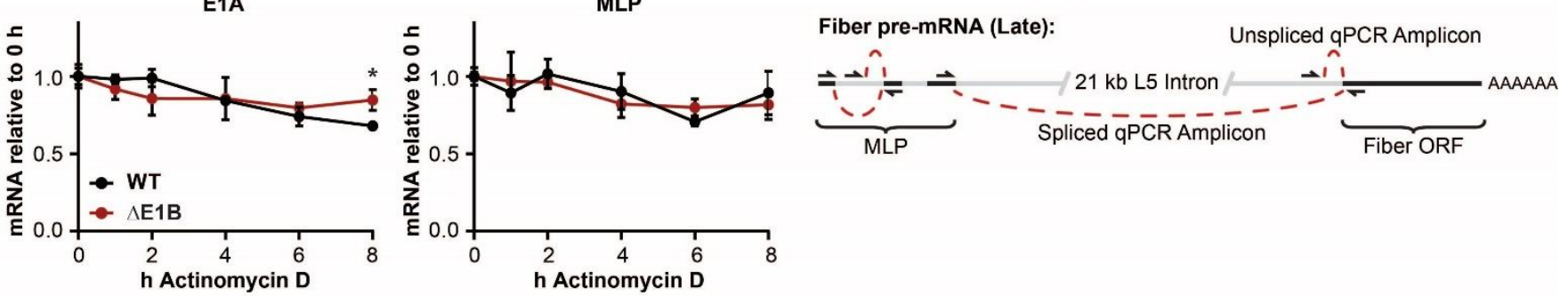

C e1A RnA levels $\quad \mathbf{g}$ FISH classifications for Fiber in Figure 1e

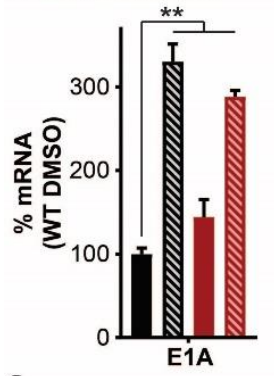

f E1A Splicing

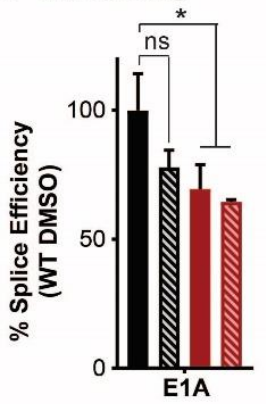

々 $\mid \begin{aligned} & \mathbf{D} \mathrm{DMSO} \\ & \mathbf{\mathbb { N }} \mathrm{NEDDi}\end{aligned}$

$\cong$ DMSO

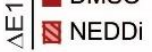
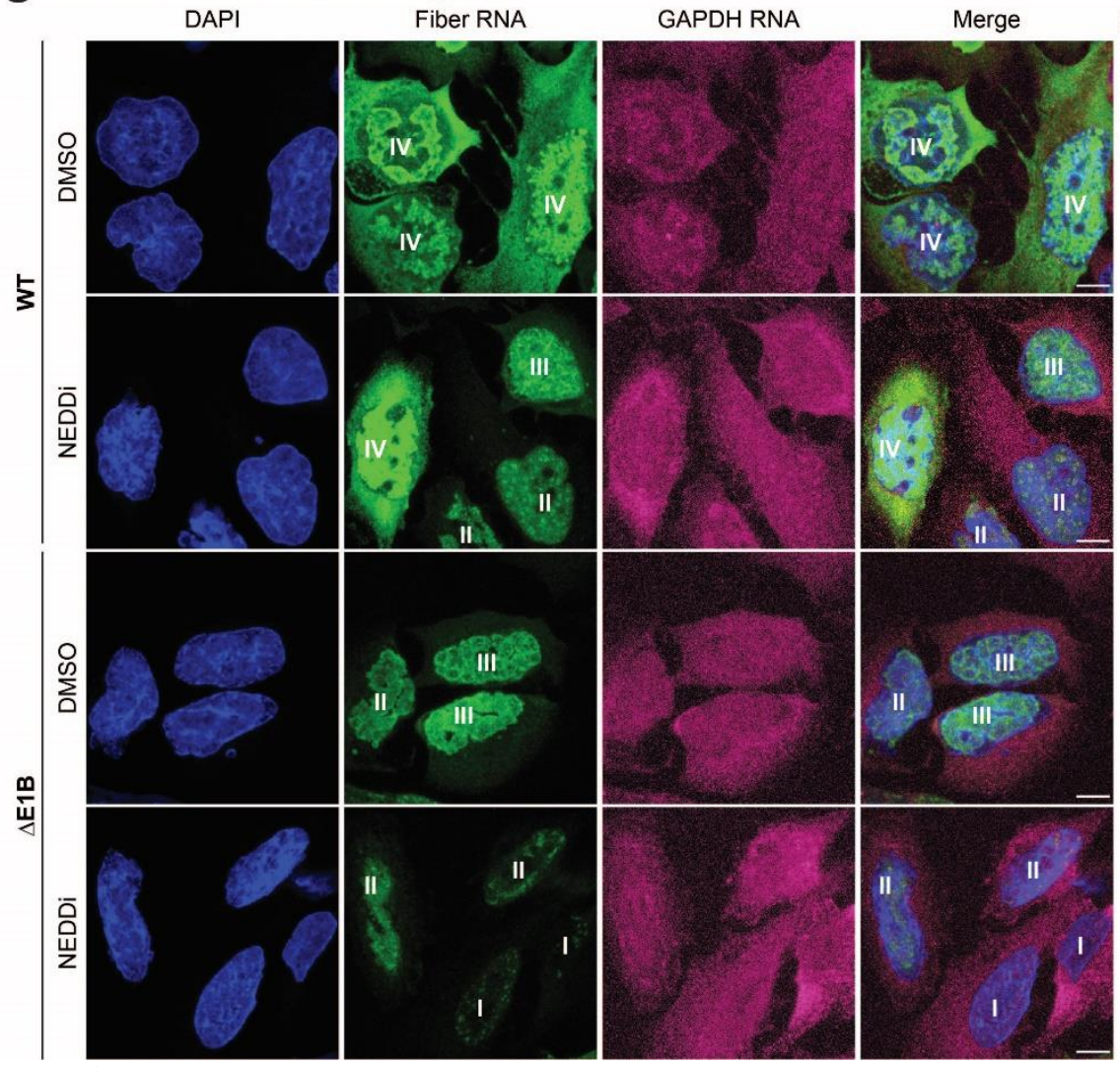

Classification:

I - Replication Center (RC) Only

II - Nuclear Only

III - Dim Cytoplasm

IV - Bright Cytoplasm

Supplementary Figure 1 E1B55K deletion or inhibition of Cullin-mediated ubiquitination does not decrease late RNA transcription and decay or early RNA processing. a, Quantification of immunoblot shown in Figure $1 \mathrm{~b}$ in triplicate. $\mathbf{b}$, Analysis of nascent transcription and mRNA half-life by labeling RNA with 4-thiouridine (4sU) for 30 min at $23.5 \mathrm{hpi}$ in HeLa cells infected with WT or $\triangle \mathrm{E} 1 \mathrm{~B}$ Ad5 at $\mathrm{MOI}=10$. Nascent 4sU-labeled RNA was purified for RT-qPCR for determining relative transcription rates of two early (E1A and E4) and one late (MLP) viral RNA. mRNA half-life was approximated using the ratio of nascent and total input RNA levels normalized to GAPDH. c, Analysis of decay of viral early (E1A) and late (MLP) RNA species by Actinomycin D 
bioRxiv preprint doi: https://doi.org/10.1101/2020.06.05.136671; this version posted June 5, 2020. The copyright holder for this preprint (which was not certified by peer review) is the author/funder. All rights reserved. No reuse allowed without permission.

pulse at $24 \mathrm{hpi}$ in HeLa cells infected with WT or $\triangle$ E1B Ad5 at MOI 10 by normalization to input levels. d, Schematic illustrating primer design to differentiate spliced and unspliced viral transcripts. e-g, HeLa cells infected with WT or $\triangle E 1 B$ Ad5 (MOI=10) in the presence of DMSO or NEDDi (neddylation inhibitor MLN2449) added at 8 hours post-infection (hpi). Cells were harvested for RNA analysis at 24 hpi. e, Bar graph representing spliced RNA levels of viral early transcripts E1A by RT-qPCR, f, Bar graph representing splicing efficiency as the ratio of spliced to unspliced transcripts of E1A relative to the WT DMSO control by RTqPCR. g, RNA FISH visualizing the localization of fiber (green) and GAPDH (magenta) transcripts in relation to nuclear DNA stained with DAPI (blue). Nuclei are labeled with the classification of each cell according to the pattern of fiber used for Figure 1d. Scale bar $10 \mu \mathrm{m}$. Shown is mean+s.d., $n$ equals at least three biological experiments. Statistical significance was calculated using a paired (a) or unpaired (others), two-tailed Student's t-test, ${ }^{*} p<0.05$, ${ }^{* \star} p<0.01$. 

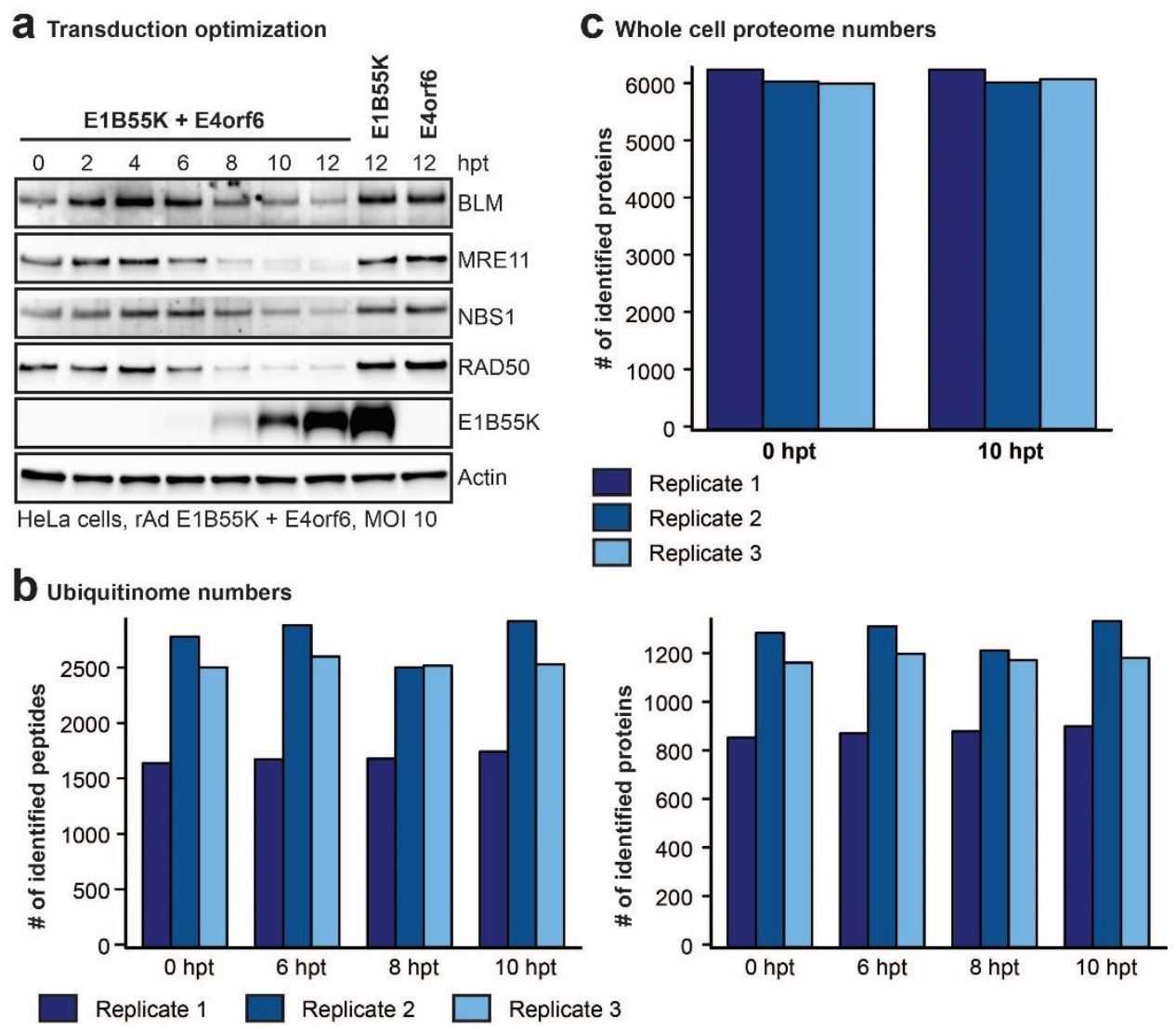

Supplementary Figure 2 | Quantification of number of peptides and proteins identified in di-glycine remnant profiling and whole cell proteome data sets. a-c, HeLa cells transduced with $\mathrm{rAd}$ E1B55K/E4orf6 at MOI 10. a, Immunoblot of time course of E1B55K/E4of6 expression showing degradation kinetics of known substrates. hpt = hours post transduction. $\mathbf{b}$, Numbers of peptides and corresponding proteins identified following K- $\varepsilon$-GG antibody enrichment in di-glycine remnant combined with mass spectrometry analysis at $0,6,8$, and 10 hours post E1B55K/E4orf6 expression. c, Number of proteins identified by whole cell proteomics analysis at time 0 and 10 hours post E1B55K/E4orf6 expression. b,c, Dark blue, medium blue, and light blue bars indicate the counts for three individual biological replicates. 
bioRxiv preprint doi: https://doi.org/10.1101/2020.06.05.136671; this version posted June 5, 2020. The copyright holder for this preprint (which was not certified by peer review) is the author/funder. All rights reserved. No reuse allowed without permission.

A Bar graphs for RNA-binding protein ubiquitination and abundance

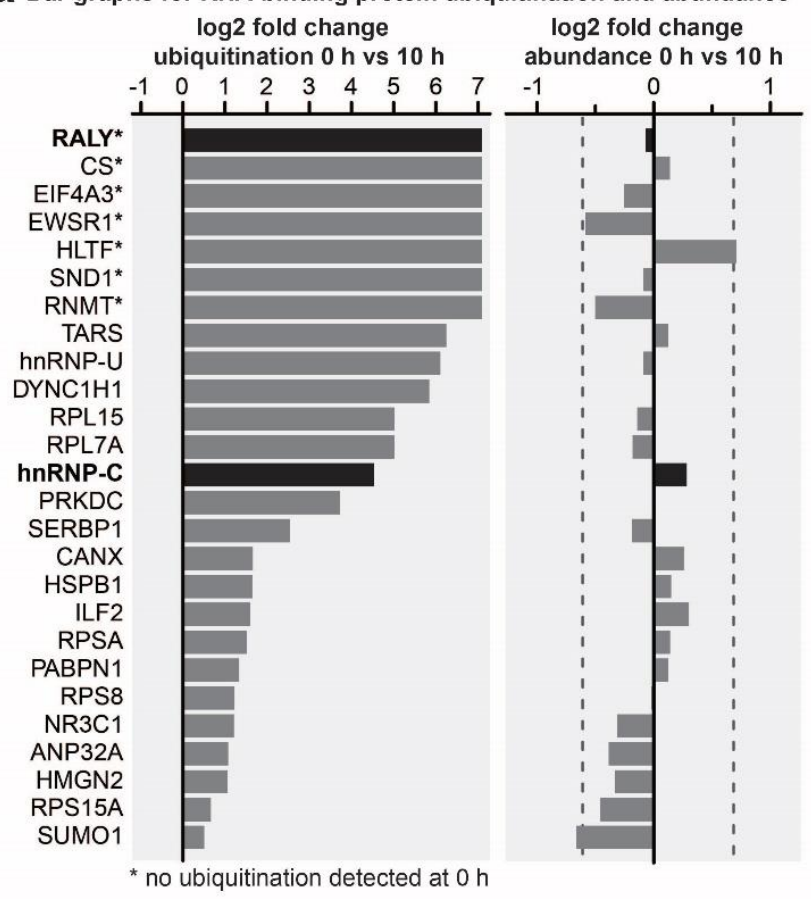

b RNA-binding protein heat map

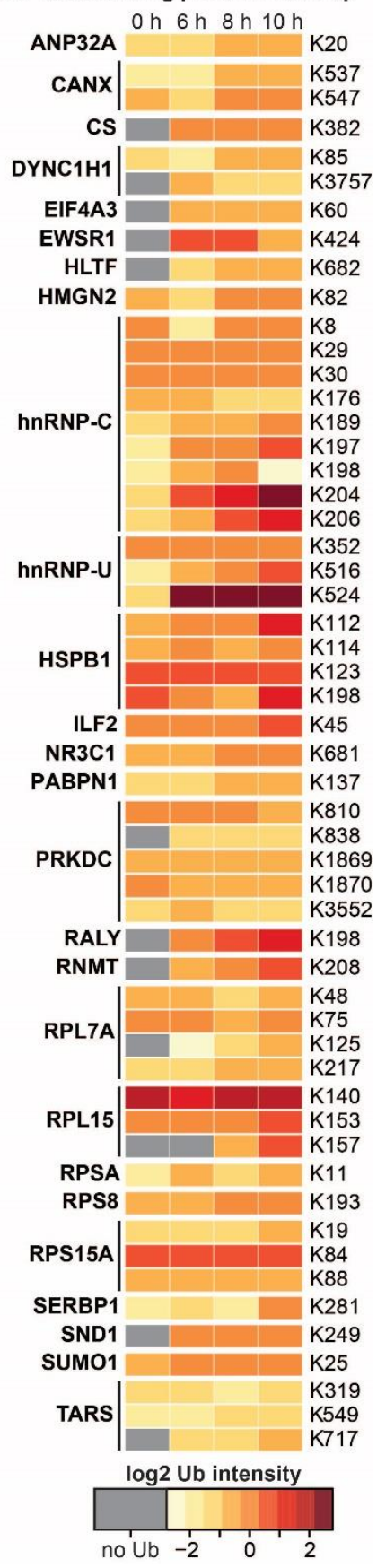

Supplementary Figure 3 | Di-glycine remnant profiling and whole cell proteome data for RNA-binding proteins enriched within the predicted E1B55K/E4orf6 substrates. a-b, Gene ontology analysis identified RNA-binding proteins enriched in the set of proteins that exhibited an increase in normalized protein-based ubiquitin abundance of log2 fold change $>1$ following $10 \mathrm{~h}$ transduction of E1B55K/E4orf6. a, Enriched RNA-binding protein, ubiquitination log2 fold changes (left) and whole cell protein abundance log2 fold changes (right) following $10 \mathrm{~h}$ transduction by E1B55K/E4orf6. b, Heat map showing relative ubiquitination of the respective lysine residues quantified by di-glycine remnant profiling analysis at $0,6,8$, and $10 \mathrm{~h}$ of E1B55K/E4orf6 expression for peptides within enriched RNA-binding proteins. Heat map color gradient is based on low (yellow) to high (red) ubiquitin abundance and grey indicates "not identified" at that time point. 
bioRxiv preprint doi: https://doi.org/10.1101/2020.06.05.136671; this version posted June 5, 2020. The copyright holder for this preprint (which was not certified by peer review) is the author/funder. All rights reserved. No reuse allowed without permission.

A Protein-protein interaction network of identified potential E1B55K/E4orf6 substrates

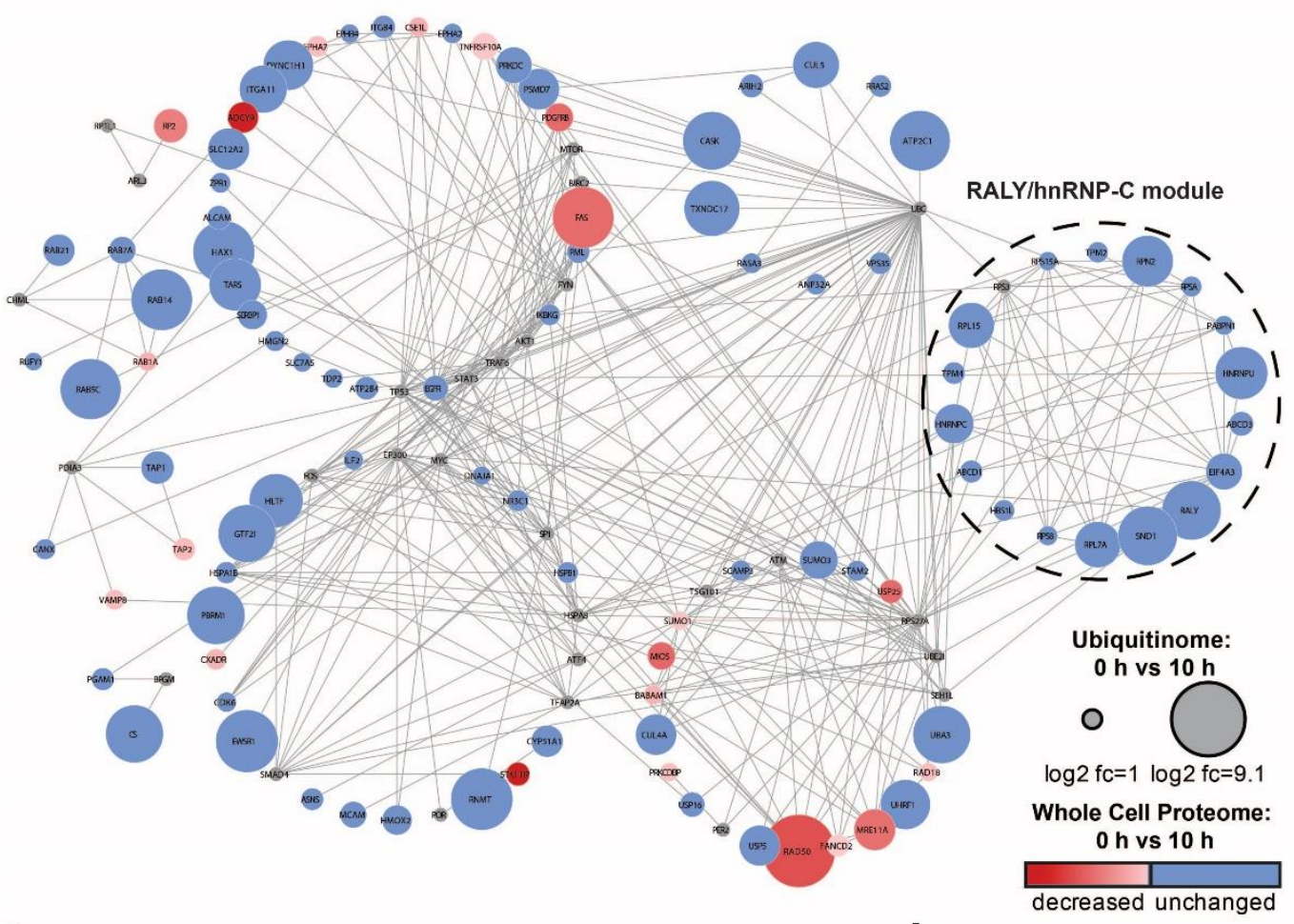

$\begin{array}{lcc}\text { b Go-term analysis for RALY/hnRNP-C } \text { module } \\ \text { Pathway } & -\log 10 \text { (FDR) } & \text { \# Genes } \\ \text { Poly(A) RNA binding } & 6.61 & 11 \\ \text { RNA binding } & 5.14 & 7 \\ \text { Constituent of ribosome } & 4.43 & 5\end{array}$

C Bar graphs for RALY/hnRNP-C module ubiquitination and protein abundance

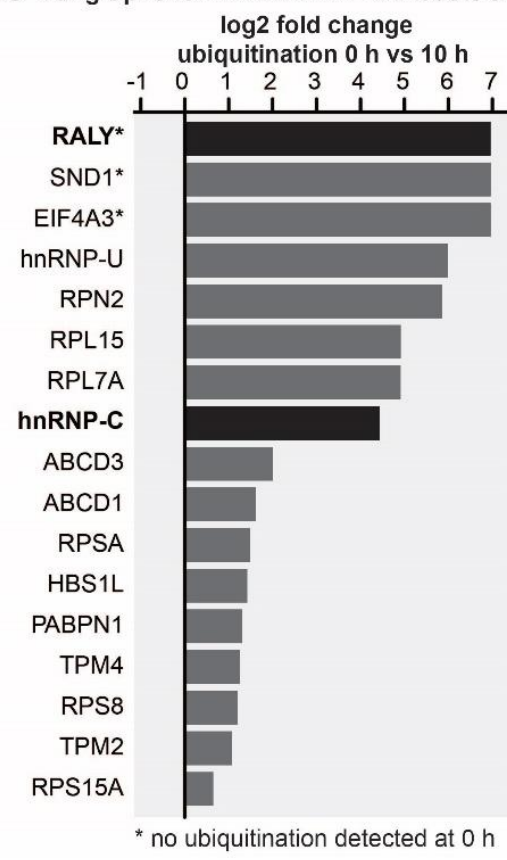
log2 fold change abundance $0 \mathrm{~h}$ vs $10 \mathrm{~h}$

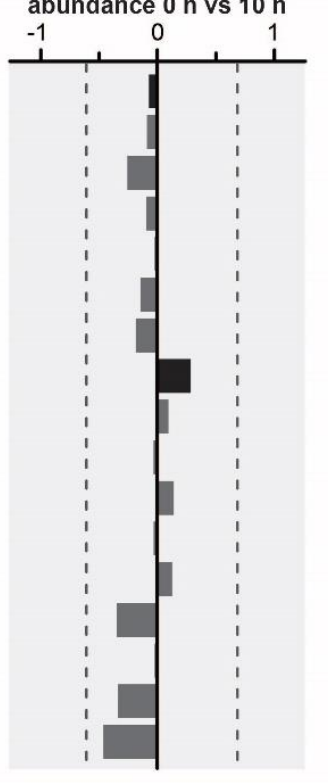

d Heat map for module
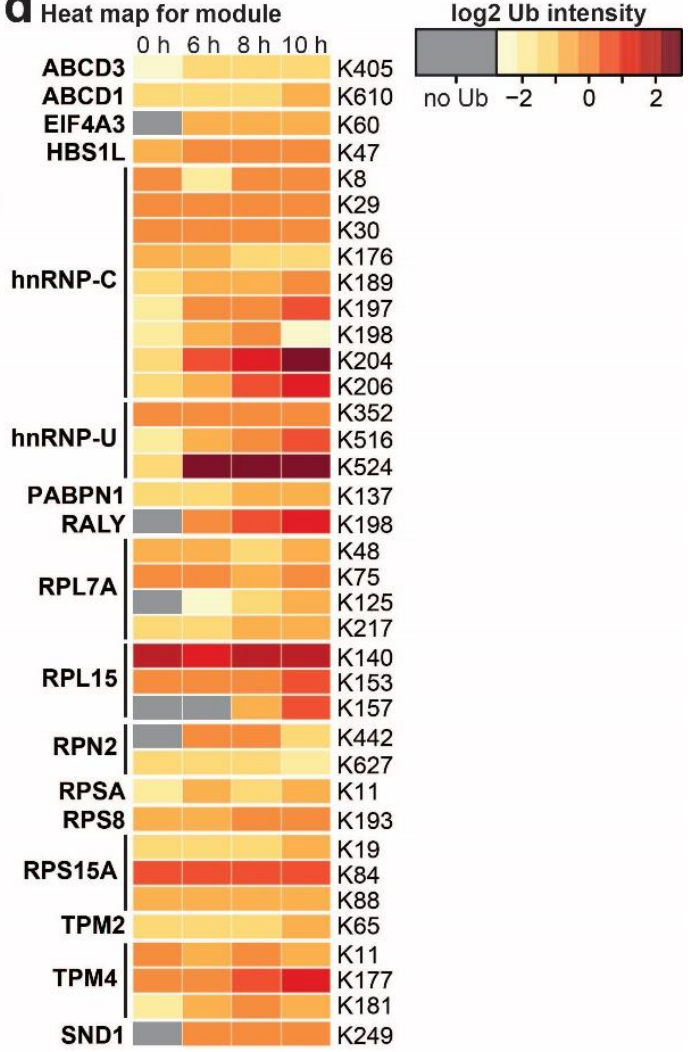

Supplementary Figure 4 | Network analysis of predicted E1B55K/E4orf6 substrates identifies a "RALY/hnRNP-C module" enriched for RNA-binding proteins. a, The Reactome-FI application in Cytoscape was utilized to generate a protein-protein interaction network in which nodes represent proteins and edges represent Reactome-based protein-protein interactions. Node size corresponds to relative protein-based ubiquitination log2 fold change and node color corresponds to whole cell proteome log2 fold change following $10 \mathrm{~h}$ transduction of E1B55K/E4orf6. Protein-protein interaction network of proteins that exhibited normalized 
bioRxiv preprint doi: https://doi.org/10.1101/2020.06.05.136671; this version posted June 5, 2020. The copyright holder for this preprint (which was not certified by peer review) is the author/funder. All rights reserved. No reuse allowed without permission.

protein-based ubiquitin abundance log2 fold change $>1$ following $10 \mathrm{~h}$ transduction of E1B55K/E4orf6. Reactome-FI interaction module analysis was performed to generate clusters of highly interacting proteins. $\mathbf{b}$, Gene ontology analysis for molecular function identified enrichment of RNA-binding and Poly $(A)$ RNA-binding proteins within the RALY/hnRNP-C network module shown in Figure 2g. c, RALY/hnRNP-C network module protein ubiquitin log2 fold changes (left) and whole cell protein abundance log2 fold changes (right) comparing 0 and $10 \mathrm{~h}$ post-transduction with E1B55K/E4orf6. d, Heat map showing relative ubiquitin abundance quantified by di-glycine remnant profiling analysis at $0,6,8$, and $10 \mathrm{~h}$ post E1B55K/E4orf6 transduction for peptides from proteins within the RALY/hnRNP-C network module. Heat map color gradient is based on low (yellow) to high (red) ubiquitination and grey indicates "not identified" at that time point. 
a RALY K198 ubiquitination

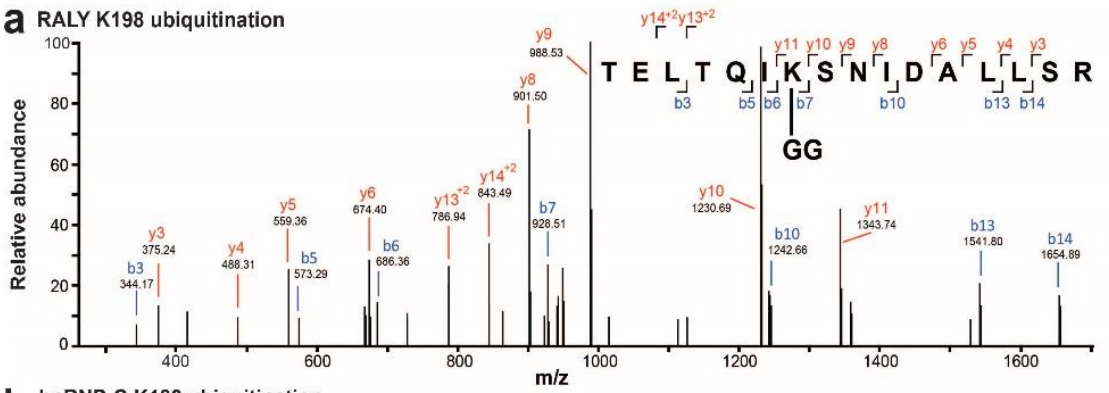

b hnRNP-C K189 ubiquitination

b
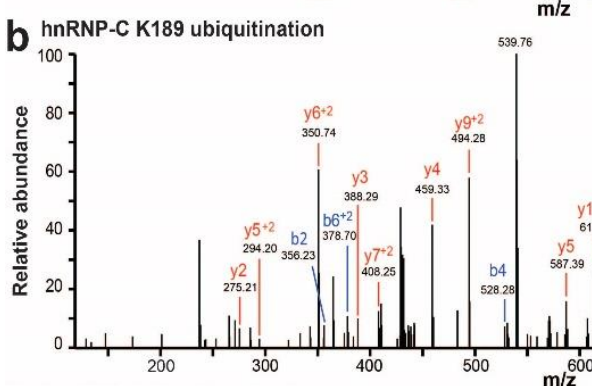

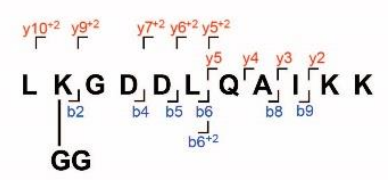

C hnRNP-C K197 ubiquitination

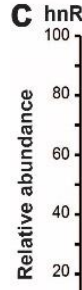

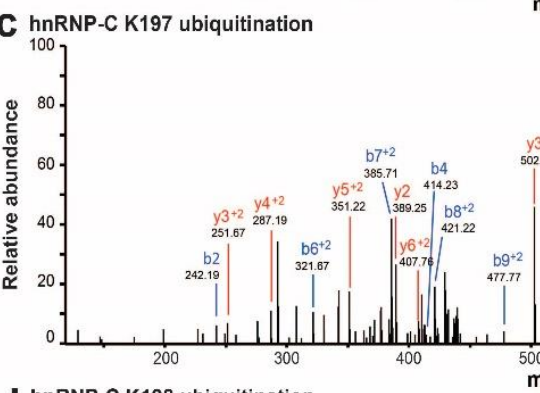

d hnRNP-C K198 ubiquitination

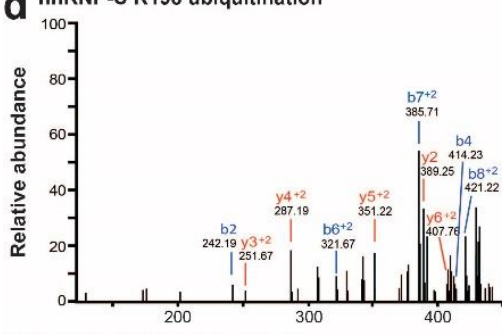

$\mathrm{m} / \mathbf{z}$
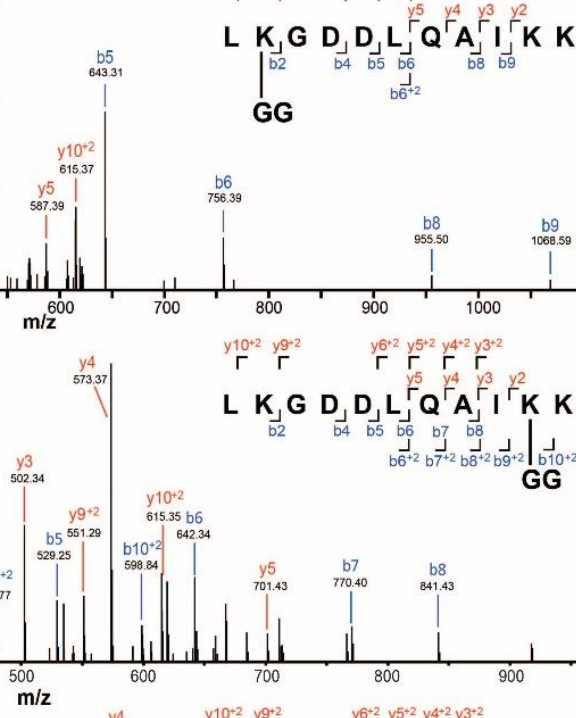

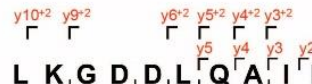

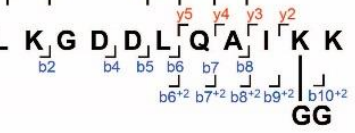

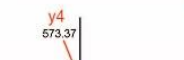

e hnRNP-C K204 ubiquitination

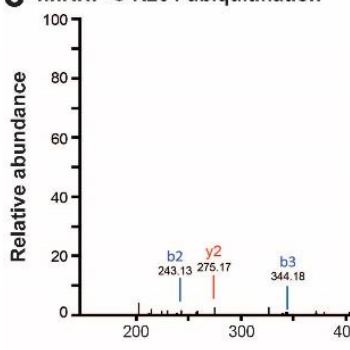

f hnRNP-C K206 ubiquitination

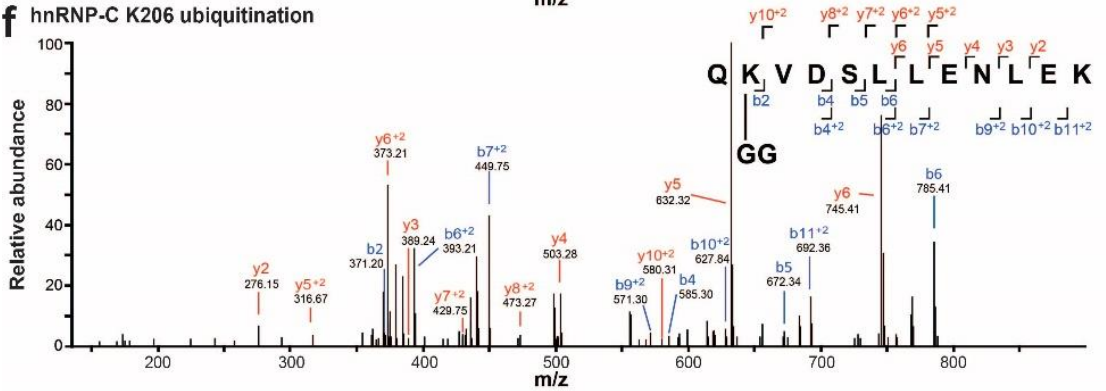

Supplementary Figure 5 | MS2 evidence for ubiquitination site localization in RALY (a) and hnRNP-C (b-f) peptides. Spectra were obtained from LC-MS/MS analyses using collision-induced dissociation (CID) at $35 \%$, and identified in MaxQuant 1.6.0.1. All modified residues can be confidently identified by confirming ions, except for hnRNP-C K198 (d), which lacks ions to distinguish between K197 and K198. Best evidence spectra were selected for annotation of b-ion (blue) and y-ion (red) series and their masses for singly- and doubly-charged fragments. 


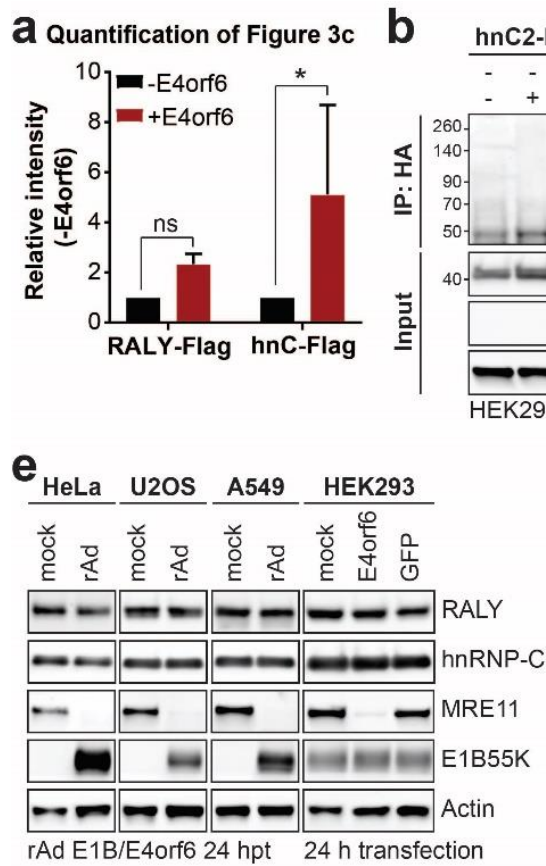

\section{C}

C Quantification of Figure 3d

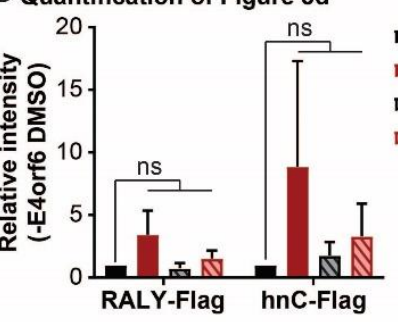

d

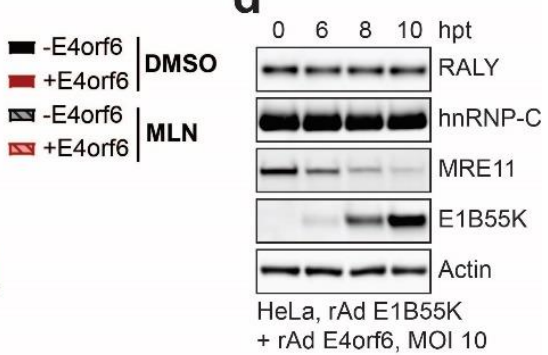

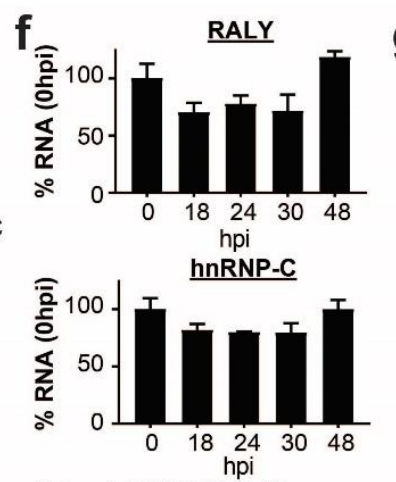

HeLa, Ad5 WT, MOI 10
Q Quantification of Figure 3i

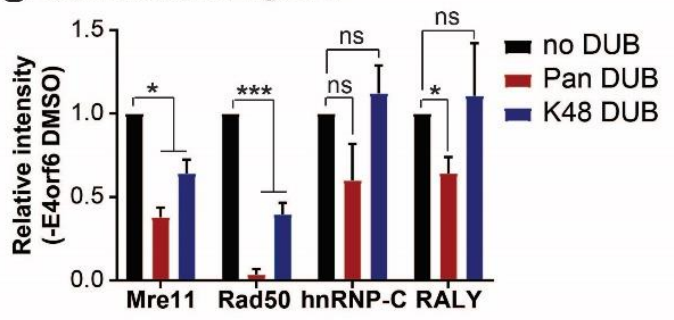

Supplementary Figure 6 | RALY and hnRNP-C are not decreased upon transduction in multiple cell lines. a, Quantification of immunoblot shown in Figure 3c in triplicate. b, HEK293 cells transfected with the indicated constructs for $24 \mathrm{~h}$ followed by denaturing IP with HA antibody and immunoblot analysis of hnRNP-C2-Flag. c, Quantification of immunoblot shown in Figure 3d in triplicate. d, Immunoblot analysis of protein levels in HeLa cells over a time course of transduction with recombinant Ad vectors expressing only E1B55K and E4orf6 (MOI=10). e, Immunoblot analysis of protein levels in HeLa, U2OS, A549 and HEK293 cells. HeLa, U2OS and A459 cells were transduced with recombinant Ad vectors expressing only E1B55K and E4orf6 for $24 \mathrm{~h}$. HEK293 cells, which contain an endogenous copy of E1B55K, were mock transfected or transfected with plasmids expressing E4orf6 or GFP. f, Bar graphs of RALY and hnRNP-C RNA levels over a time course of infection with Ad5 WT (MOI=10) relative to mock as determined by RT-qPCR, shown is mean+s.d, $n$ equals three biological replicates. g, Quantification of immunoblot shown in Figure $3 i$ in triplicate. All immunoblots are representative of at least three biological replicates. Statistical significance was calculated using a paired, two-tailed Student's t-test, ${ }^{*} p<0.05,{ }^{* *} p<0.01,{ }^{* * *} p<0.005$. 

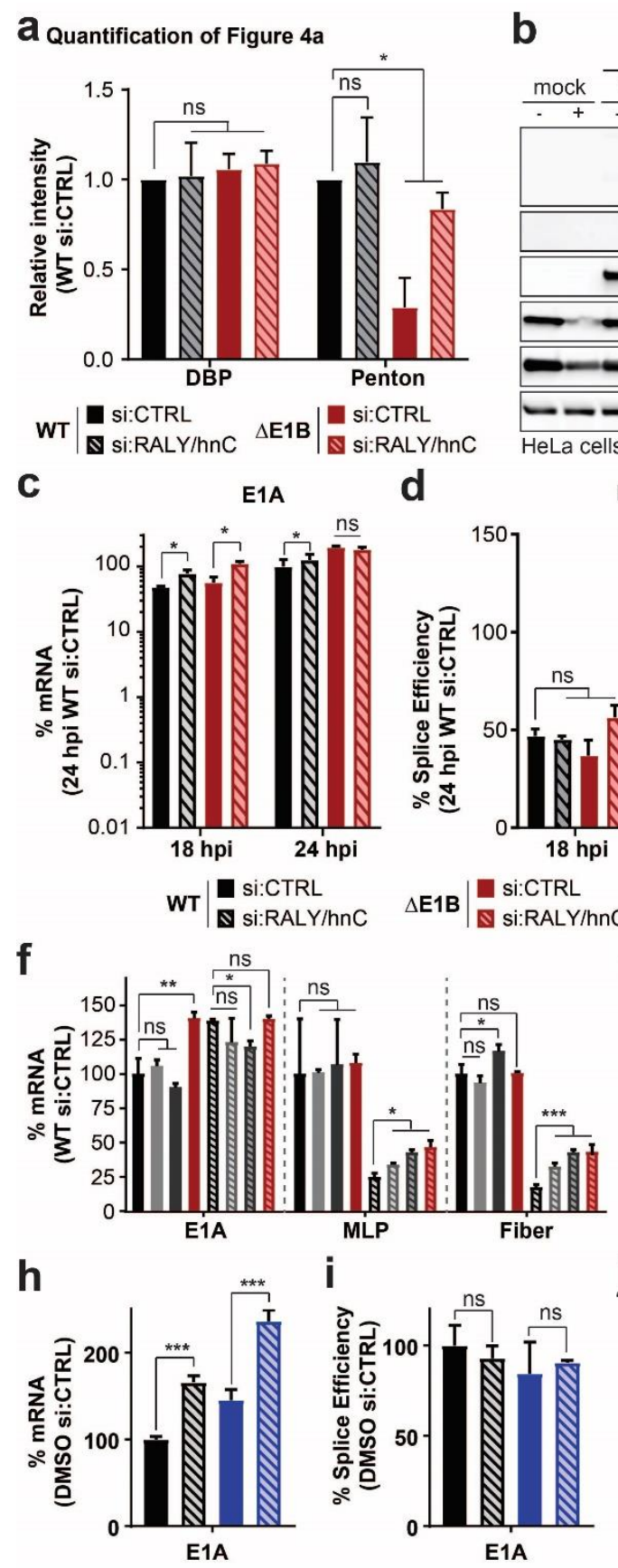

b

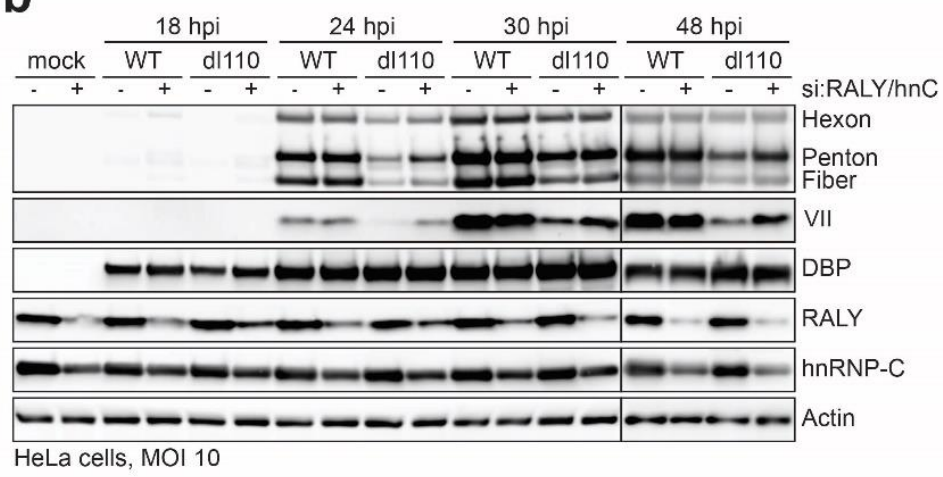

E1A

C RALY/hnRNP-C single knock-down
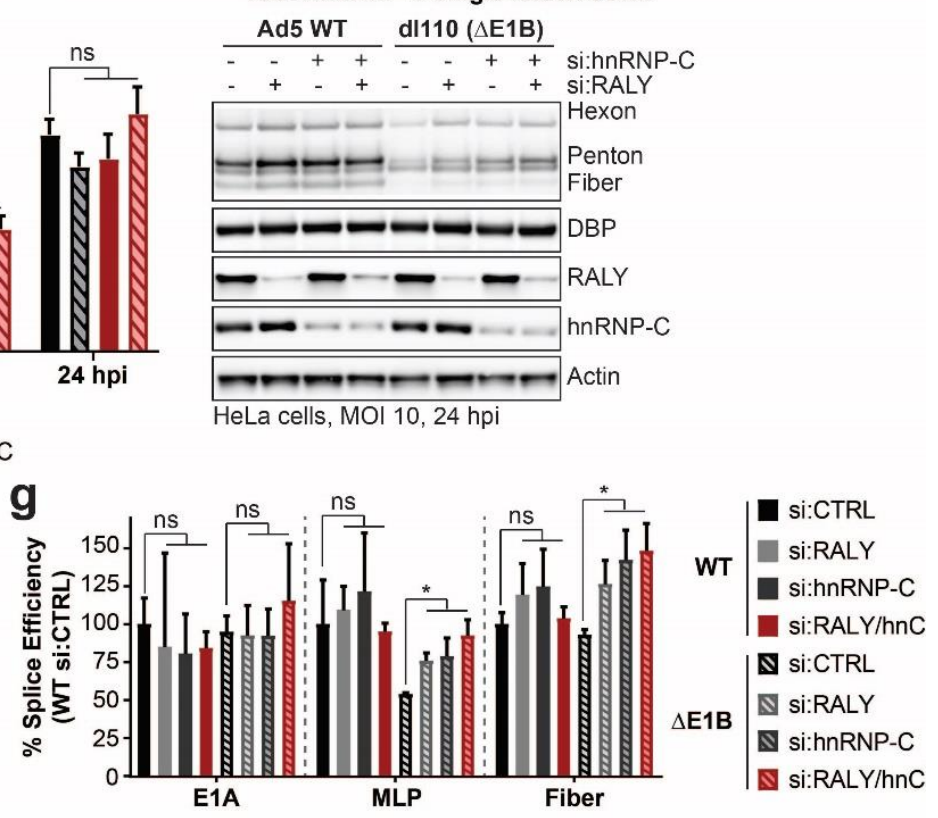

J Quantification of Figure 4i
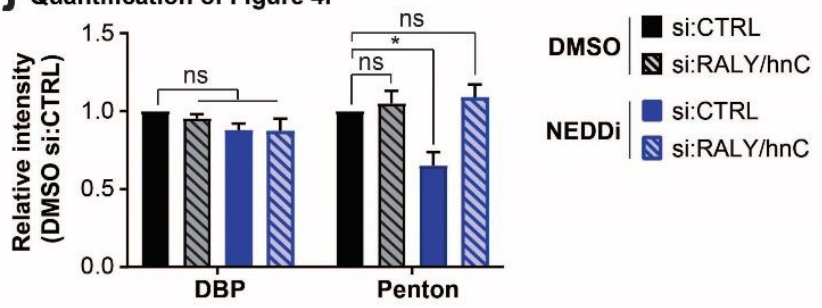

Supplementary Figure 7 | RALY and hnRNP-C single knockdown rescue late protein, RNA and splice efficiency during infection with Ad $\Delta$ E1B. a-d, HeLa cells transfected with control (siCTRL) or RALY and hnRNP-C (siRALY/hnC) siRNA $24 \mathrm{~h}$ prior to infection with Ad5 WT or $\triangle \mathrm{E} 1 \mathrm{~B}(\mathrm{MOI}=10)$, harvested at respective time points. a, Quantification of immunoblot shown in Figure $4 \mathbf{a}$ in triplicate. $\mathbf{b}$, Extended immunoblot analysis of viral and cellular protein levels. c, Bar graph representing spliced RNA levels of viral early transcript E1A measured by RT-qPCR. $\mathbf{d}$, Bar graph representing splicing efficiency as defined as the ratio of spliced to unspliced transcripts of E1A measured by RT-qPCR. e-g, HeLa cells transfected with control siRNA (siCTRL), siRNA for RALY (siRALY), siRNA for hnRNP-C (sihnRNP-C) or siRNA for both RALY and hnRNP-C (siRALY/hnC) $24 \mathrm{~h}$ prior to infection with Ad5 WT or $\triangle \mathrm{E} 1 \mathrm{~B}(\mathrm{MOI}=10)$ and harvested at $24 \mathrm{hpi}$. e, Immunoblot analysis of viral and cellular protein levels. f, Bar graph representing spliced RNA levels of E1A, MLP and fiber measured by RT-qPCR. $\mathbf{g}$, Bar graph representing splicing efficiency as defined as the ratio of spliced to unspliced transcripts of E1A, MLP and fiber measured by RT-qPCR. $\mathbf{h}$-j. HeLa cells transfected with control (siCTRL) or RALY and hnRNP-C (siRALY/hnC) siRNA $24 \mathrm{~h}$ prior to infection with Ad5 WT (MOI=10), treated with either DMSO or NEDDi at $8 \mathrm{hpi}$ and processed at $24 \mathrm{hpi}$. $\mathbf{h}$, Bar graph representing spliced RNA levels of E1A measured by RTQPCR. i, Bar graph representing splicing efficiency as defined as the ratio of spliced to unspliced transcripts of E1A measured by RT-qPCR. j, Quantification of immunoblot shown in Figure 4i in triplicate. All immunoblots are representative of at least three biological experiments. All graphs show the mean+s.d. with $n$ equals three biological replicates. Statistical significance was calculated using a paired (a and j) or unpaired (others), two-tailed Student's t-test, ${ }^{*} p<0.05,{ }^{* *} p<0.01,{ }^{* * *} p<0.005$. 


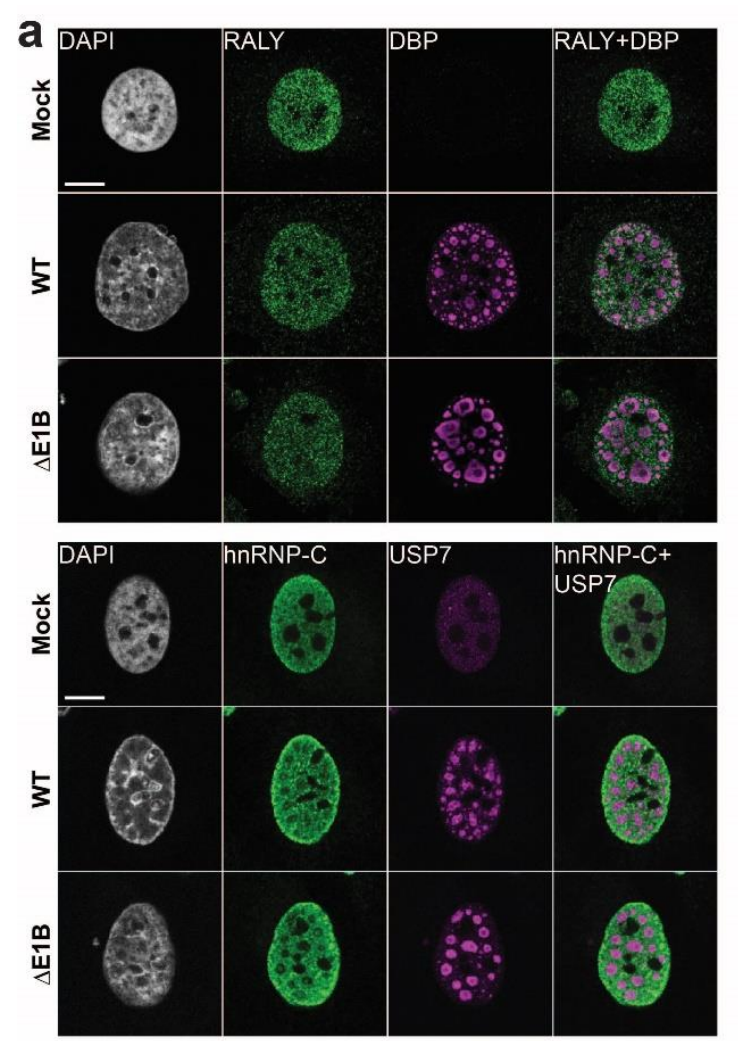

C

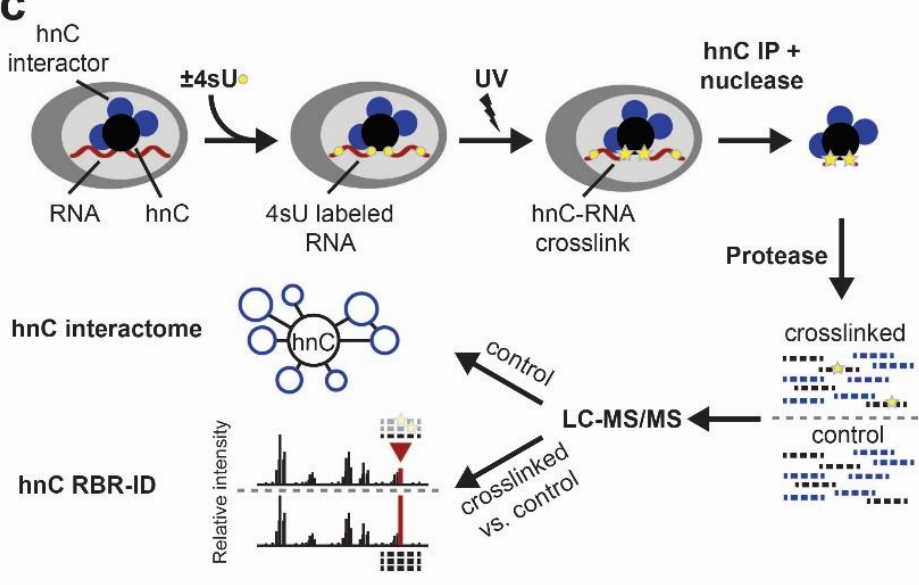

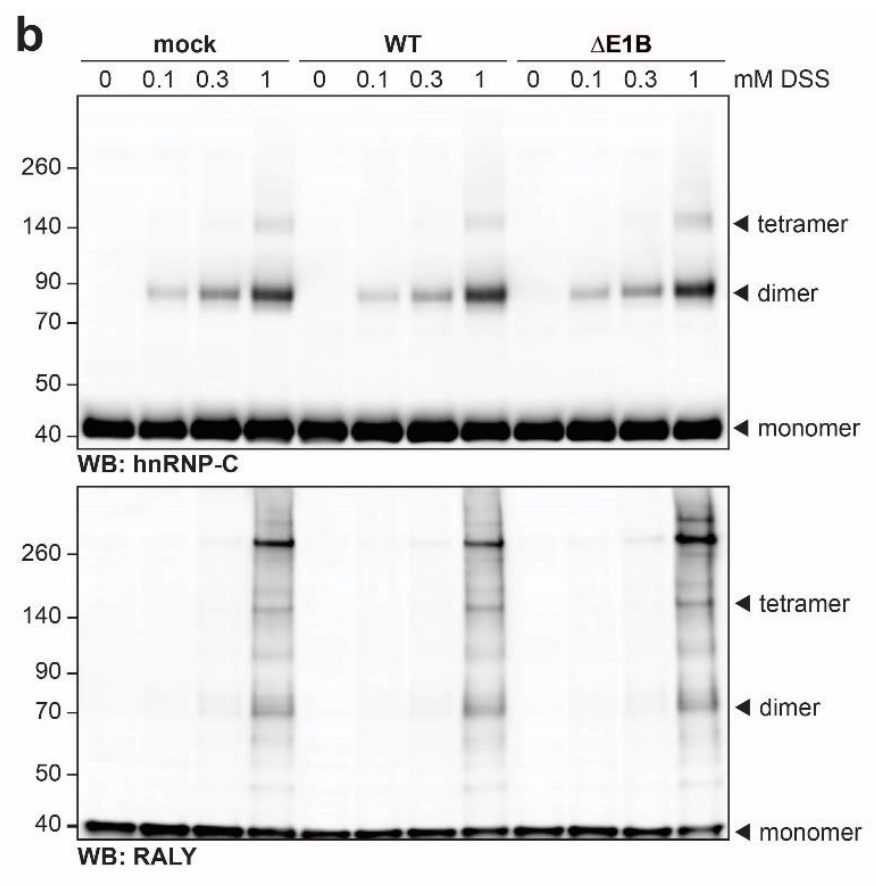
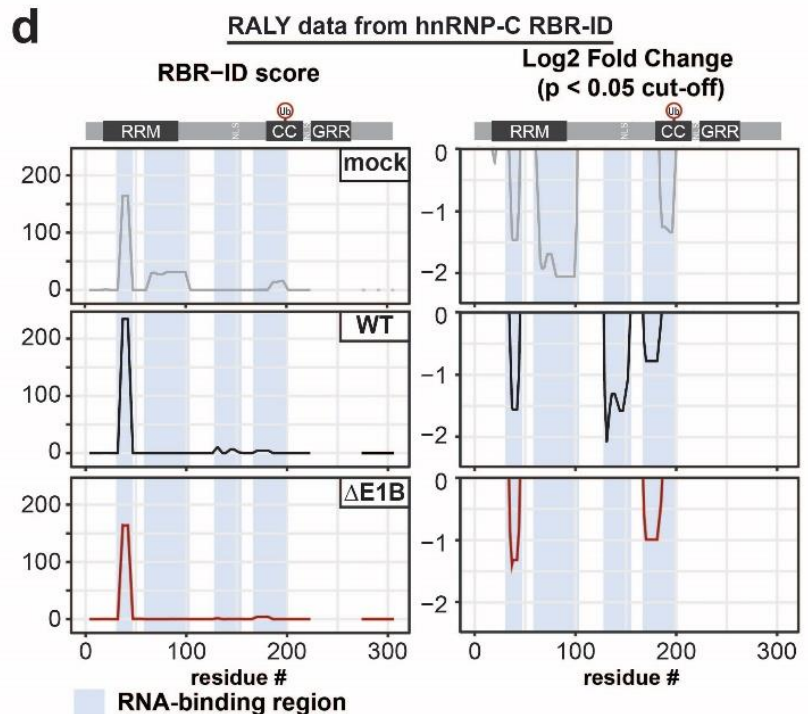

( $<<0.05$ cut-off)
C

$\begin{array}{lll}10 & \\ \text { RRM } & \text { CC GRR }\end{array}$

f Most highly abundant proteins identified in the hnRNP-C interactome

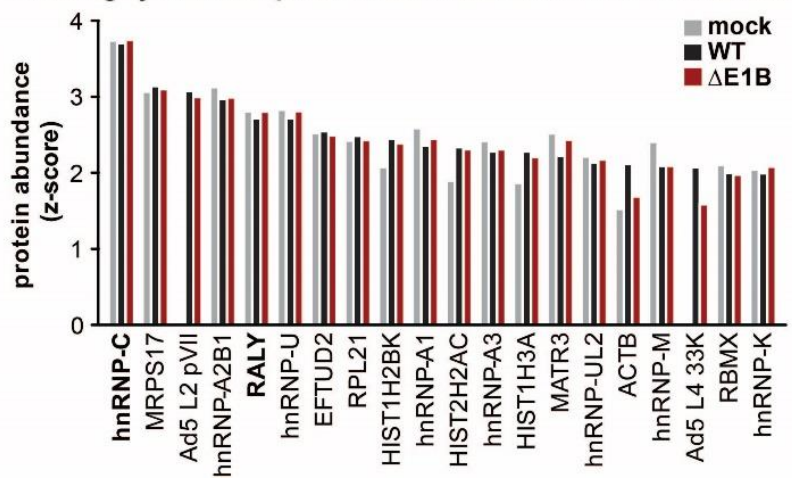

C Correlation matrix for hnRNP-C interactomes

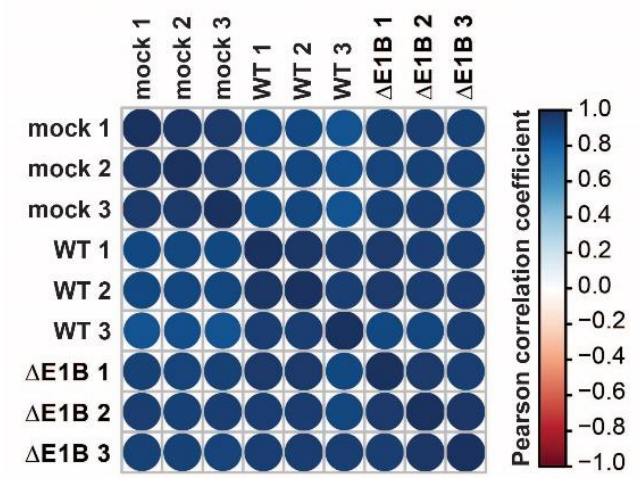

Supplementary Figure 8 | No dramatic difference in protein localization and protein-complex formation of RALY and hnRNP-C between Ad WT and $\triangle E 1 B$ infection. a, Representative images of immunofluorescence comparing the localization of 
bioRxiv preprint doi: https://doi.org/10.1101/2020.06.05.136671; this version posted June 5, 2020. The copyright holder for this preprint (which was not certified by peer review) is the author/funder. All rights reserved. No reuse allowed without permission.

RALY and hnRNP-C (both green) in mock, Ad WT and $\triangle E 1 B$ infection of HeLa cells (MOI=10, 24 hpi). Viral replication centers are stained by DBP or USP7 (both magenta) and nuclear DNA by DAPI (grey). Scale bar $10 \mu \mathrm{m}$. b, Immunoblot analysis of RALY and hnRNP-C protein complexes formed upon mock, Ad WT and $\triangle \mathrm{E} 1 \mathrm{~B}$ infection of HeLa cells $(\mathrm{MOI}=10)$ and treatment with indicated concentrations of disuccinimidyl suberate (DSS) for $30 \mathrm{~min}$ at $24 \mathrm{hpi}$. Representative of three biological replicates. c, Schematic for targeted hnRNP-C RNA-binding region identification (RBR-ID) and interactome. d, Data for RALY from hnRNP-C RBR-ID experiment comparing mock (grey), Ad5 WT (black), and $\triangle \mathrm{E} 1 \mathrm{~B}$ (red) at 24 hpi and MOI 10. Shown are smoothed residuelevel RBR-ID score plotted along the primary sequence (left) and smoothed residue-level fold-change between crosslinked and control conditions with a significance threshold of $p<0.05$ (right). RALY domain structure with ubiquitination site is shown above graphs. RNA-binding regions are highlighted in blue. e, Correlation matrix for hnRNP-C interactome between replicates of mock, Ad5 WT, and Ad5 $\triangle \mathrm{E} 1 \mathrm{~B}$. Color gradient is based on the Pearson correlation coefficient with correlation $(>0.0)$ in blue and anticorrelation $(<0.0)$ in red. f, Comparison of $z$-scores for top 20 proteins identified in hnRNP-C interactome during WT Ad5 infection (MOI 10, 24 hpi). Mock = grey, Ad5 WT = black, Ad5 $\Delta \mathrm{E} 1 \mathrm{~B}=$ red. 
a
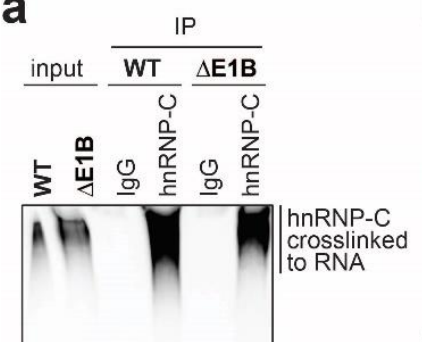

e

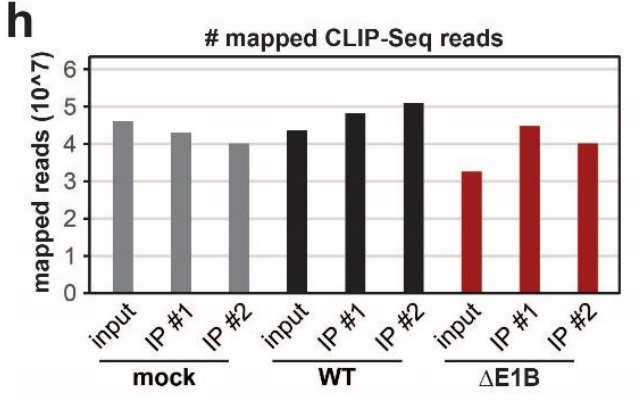

j
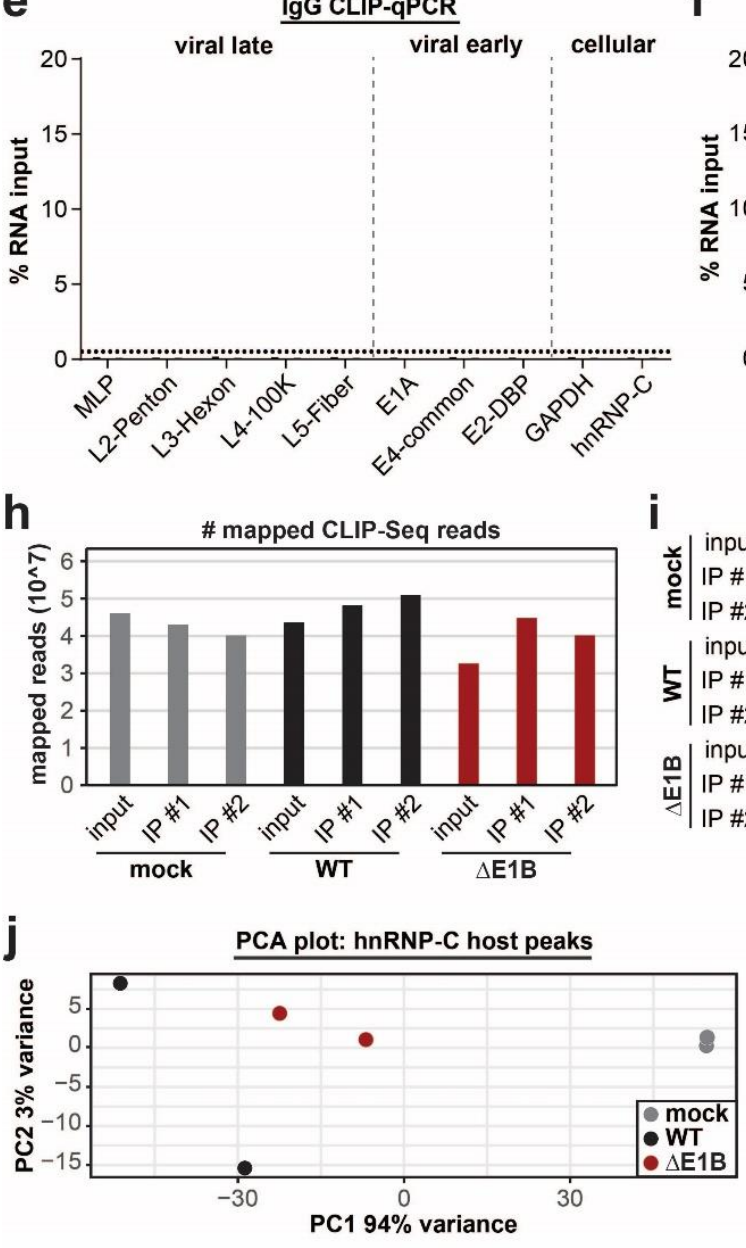

b

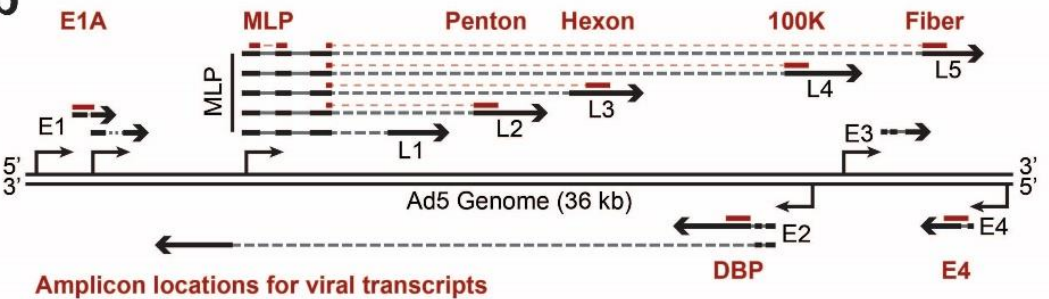

C hnRNP-C CLIP-qPCR $10 \%$ input

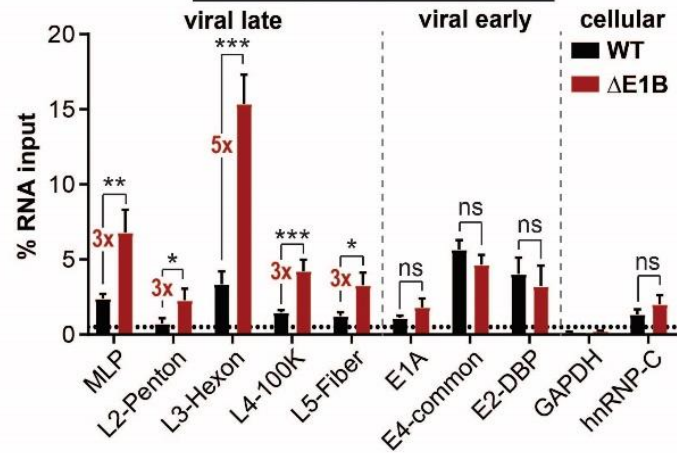

d

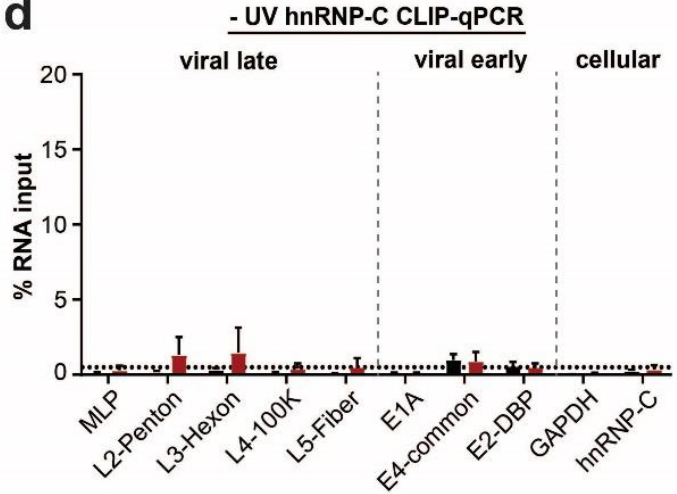

f

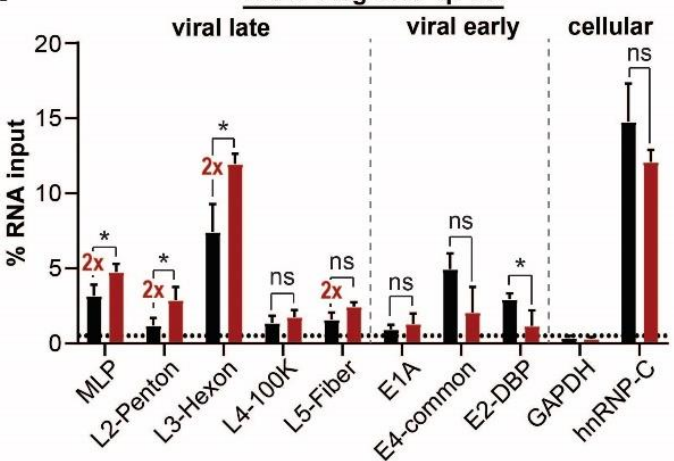

i

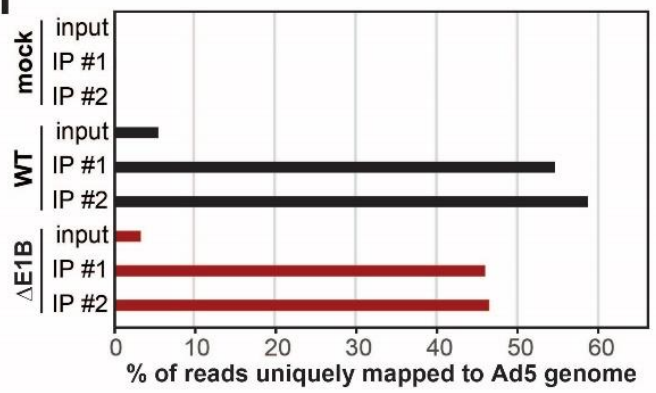

K hnRNP-C binding motifs host transcripts

\begin{tabular}{|c|c|c|c|}
\hline WT and $\triangle E 1 B$ & P-value & WT only & P-value \\
\hline 1 GCCATTTCCCAG & $1 e-34$ & CATGCCTTGAGC & 1e-14 \\
\hline$2 \longdiv { \text { CAGGTGGGAGTT } }$ & $1 e-27$ & & \\
\hline ATCCCAACTAG & $1 e-25$ & & \\
\hline 4 ATGATGAAAAGT & $1 \mathrm{e}-24$ & & \\
\hline 5 GCCCITTGCCT & $1 e-22$ & & \\
\hline 6 GTTGTCCTTAC & $1 \mathrm{e}-22$ & & \\
\hline
\end{tabular}

g
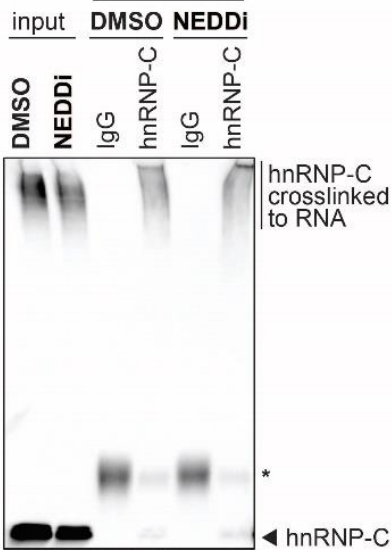

WB: hnRNP-C

Supplementary Figure 9 | hnRNP-C and RALY interact more with viral late RNA in the absence of E1B55K. a, Control immunoblot for hnRNP-C CLIP-qPCR shown in Figure $5 \mathrm{~b}$. Higher molecular weight complexes stained with hnRNP-C antibody represent hnRNP-C crosslinked to RNA. * marks the antibody heavy chain detected in the IP. Representative of at least three biological replicates for both CLIP-qPCR and immunoblot analysis thereof. $\mathbf{b}$, Schematic of the Ad5 genome and viral transcription units. Location of amplicons for viral early (E1A, DBP, E4) and viral late (MLP, Penton, Hexon, 100K, Fiber) are noted. c, HeLa 
bioRxiv preprint doi: https://doi.org/10.1101/2020.06.05.136671; this version posted June 5, 2020. The copyright holder for this preprint (which was not certified by peer review) is the author/funder. All rights reserved. No reuse allowed without permission.

cells infected with either WT Ad5 or $\triangle \mathrm{E} 1 \mathrm{~B}(\mathrm{MOI}=10)$, UV-crosslinked and harvested at 24 hpi, subjected to hnRNP-C CLIP with only $10 \%$ of input as compared to Figure $5 \mathrm{~b}$ and RT-qPCR for viral early and late transcripts. d, HeLa cells infected with either WT Ad5 or $\triangle \mathrm{E} 1 \mathrm{~B}(\mathrm{MOI}=10)$, without UV-crosslinking and harvested at $24 \mathrm{hpi}$, subjected to hnRNP-C CLIP and RT-qPCR for viral early and late transcripts. e, HeLa cells infected with either WT Ad5 or $\triangle \mathrm{E} 1 \mathrm{~B}(\mathrm{MOI}=10)$, UV-crosslinked and harvested at 24 hpi, subjected to IgG CLIP and RT-qPCR for viral early and late transcripts. f, HeLa cells induced for RALY-Flag expression with doxycycline for 3 days total, infected with either WT Ad5 or $\triangle \mathrm{E} 1 \mathrm{~B}(\mathrm{MOI}=10)$, UV-crosslinked and harvested at 24 hpi, subjected to Flag CLIP and RT-qPCR for viral early and late transcripts. For all CLIP-qPCR experiments GAPDH is a cellular negative control. hnRNP-C is a cellular positive control. g, Control immunoblot for hnRNP-C CLIP-qPCR shown in Figure 5c. Higher molecular weight complexes stained with hnRNP-C antibody represent hnRNP-C crosslinked to RNA. * marks the antibody heavy chain detected in the IP. Representative of three biological replicates for both CLIP-qPCR and immunoblot analysis thereof. $\mathbf{h}$, Number of mapped hnRNP-C eCLIP-Seq reads for the indicated conditions. i, Percentage of mapped reads that uniquely mapped to the Ad5 genome for the different hnRNP-C eCLIP-Seq conditions. j, PCA plot for hnRNP-C peaks mapped to host transcripts comparing mock (grey), Ad5 WT (black), and Ad5 $\triangle \mathrm{E} 1 \mathrm{~B}$ (red). k, Top 6 hnRNP-C binding motifs identified for binding sites in WT and $\triangle \mathrm{E} 1 \mathrm{~B}$ infection, WT infection only, and $\triangle \mathrm{E} 1 \mathrm{~B}$ infection only. 